\title{
Decision maker satisfaction in a web analytics context: The impact of analysts' skills
}

A thesis submitted in partial fulfillment of the requirements for the degree of Master's of Management Science at the Ted Rogers School of Information Technology Management, Ryerson University (Toronto, Ontario, Canada)

\section{Prepared by:}

Stephen Verspan

B.Comm., Concordia University (Montreal, Quebec, Canada)

\section{Supervisor:}

Dr. Ozgur Teretken

Professor, Ted Rogers School of Information Technology Management, Ryerson University (Toronto, Ontario, Canada)

Ted Rogers School of Information Technology Management

Ryerson University (Toronto, Ontario, Canada)

December 2012 


\section{Acknowledgement}

I would like to dedicate this thesis to my parents Mrs. Verdol and Mr. Verspan, and my sisters, who have always been present for me, and offered encouragement, especially throughout this journey. I thank my family, for the help and support, and more particularly my uncle Mr. Verdol for his precious advice on this thesis.

I would also like to thank my thesis supervisor, Dr. Ozgur Turetken, for always taking time out of his busy schedule to help me focus, and guide me through this journey. He always encouraged me to go the extra step and explore new things, and as a result, his support and assistance made the most valuable contribution to this thesis.

I am grateful to Dr. Ojelanki Ngwenyama for introducing me to research, providing me with much needed guidance, and helping me gain confidence from the very beginning of this endeavour. I am also grateful for the guidance provided by Dr. Rein Peterson, and his most appreciated input at the very beginning of this project. I also wish to acknowledge all my professors, Ted Rogers School of Business's administration personnel and its direction, as they all contributed to the knowledge I gained during the past two years. I would also like to acknowledge that this thesis was partially supported by a NSERC Discovery Grant.

Last but not least, I would like to thank my friends who stood by my side, supported me, and helped me achieve this unique milestone. 


\section{Table of contents}

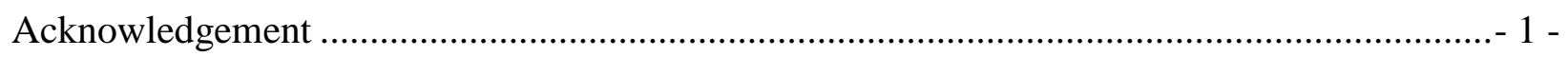

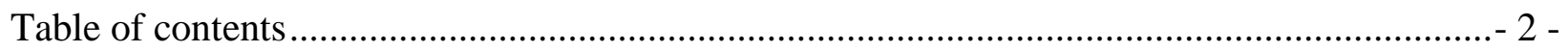

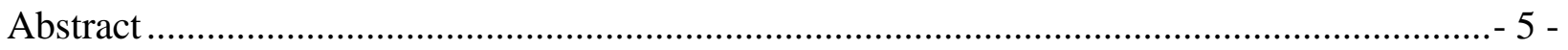

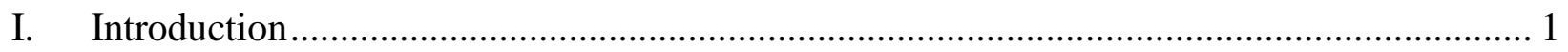

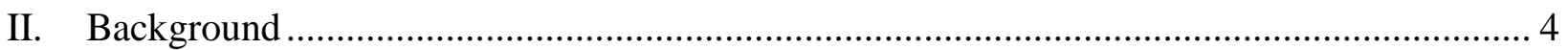

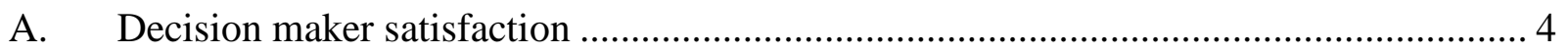

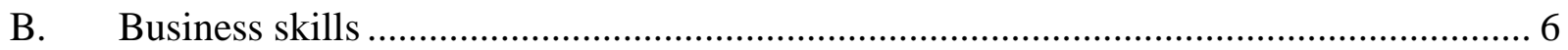

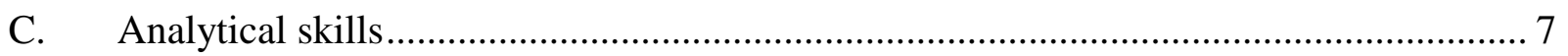

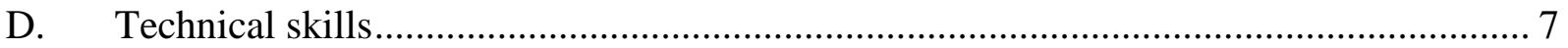

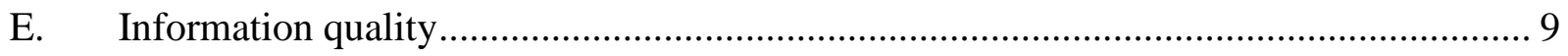

F. Relevant studies in the field of web analytics................................................................. 10

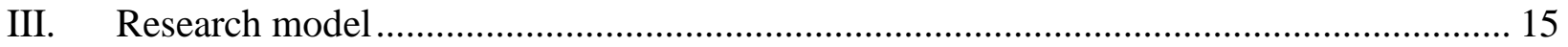

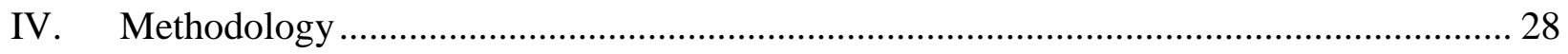

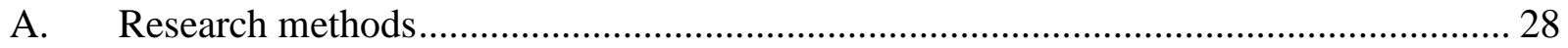

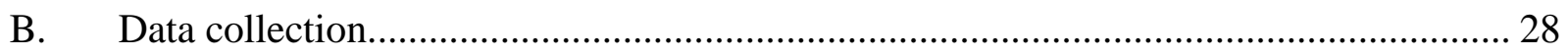

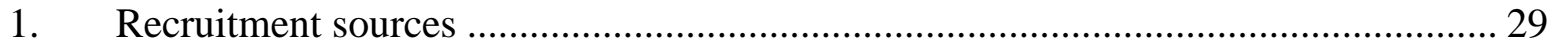

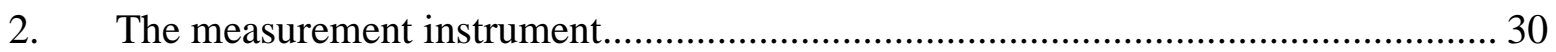

3. Incentives offered to participants ………………................................................... 35

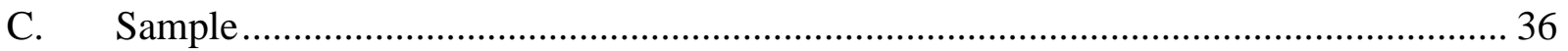

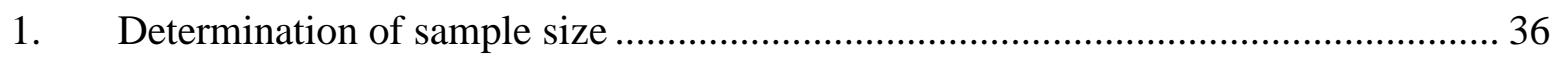

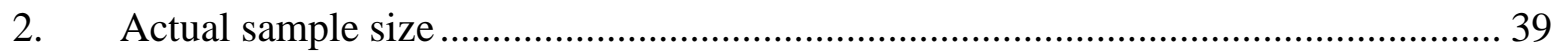




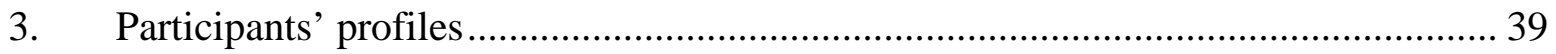

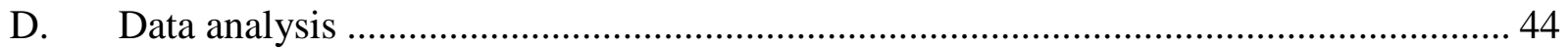

1. Method: Partial Least Squares .......................................................................... 44

2. Reliability: Internal consistency and unidimensionality .................................. 45

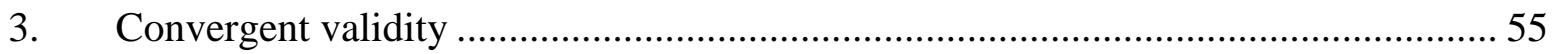

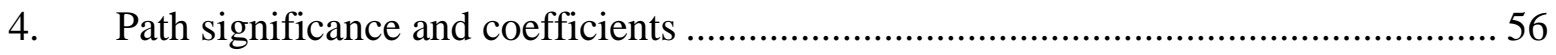

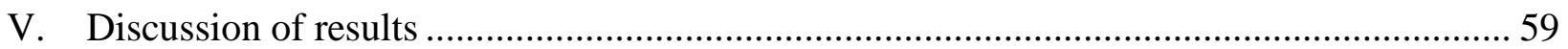

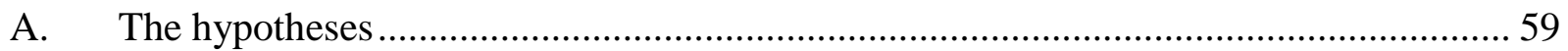

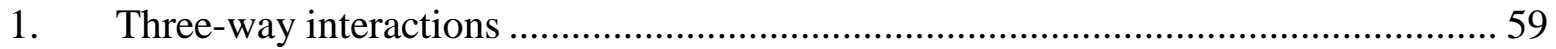

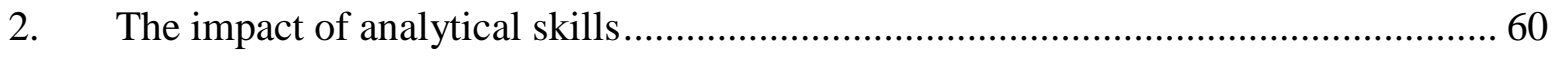

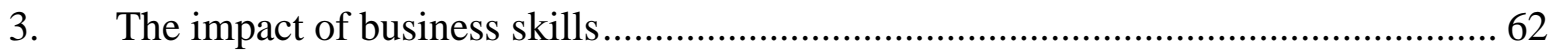

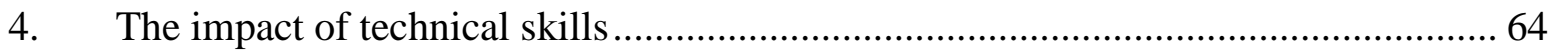

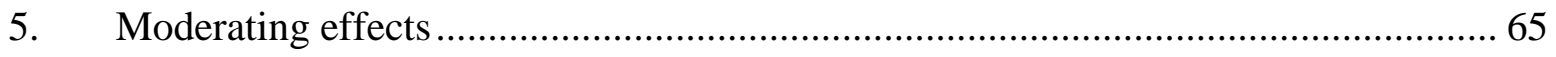

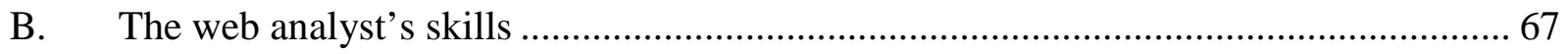

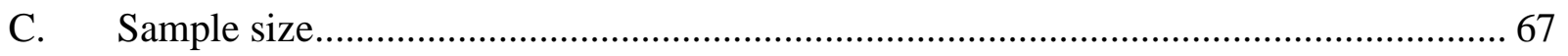

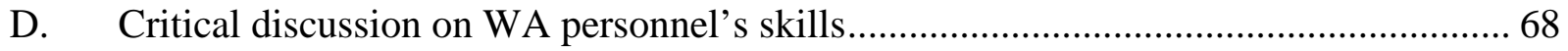

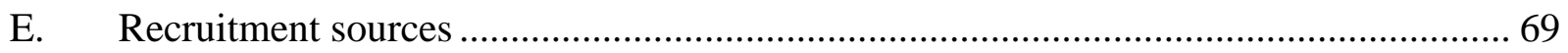

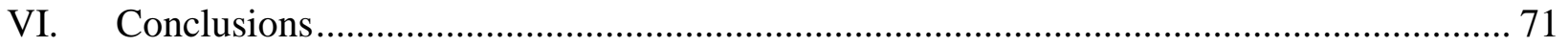

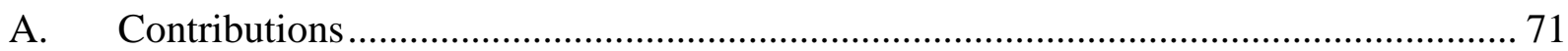

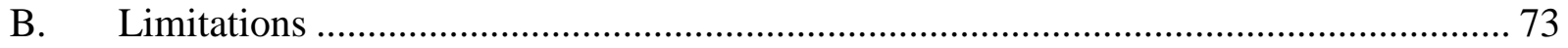

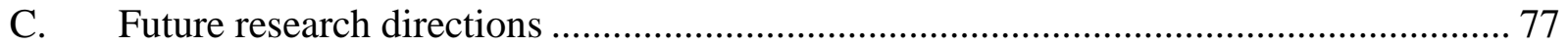

1. The definition of analytical skills and its moderating impact ............................... 77

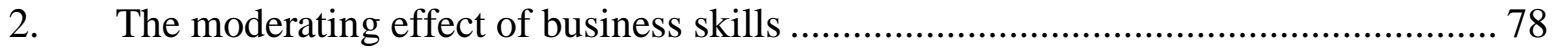


3. Understanding the "how" and the "why" .......................................................... 78

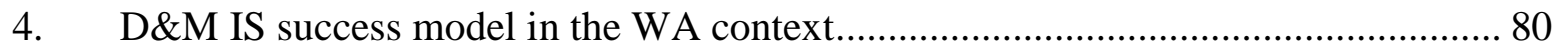

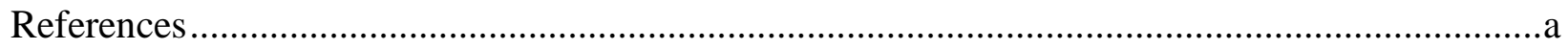

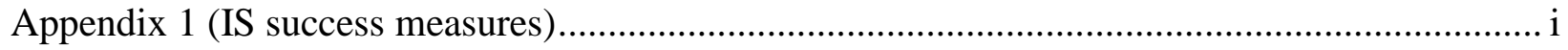

Appendix 2 (Questionnaire items) .............................................................................. ii

Appendix 3 (Original questionnaire items) ..................................................................... vi

Appendix 4 (Recruitment sources: LinkedIn groups)..................................................... ix

Appendix 5 (Introductory messages for the survey) .........................................................

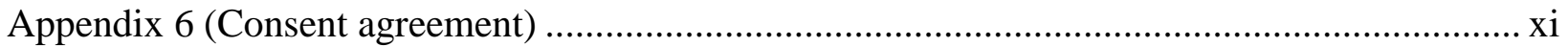

Appendix 7 (Thank you note and confirmation message) ................................................... xiii

Appendix 8 (Confirmation email to new iPads winners) .................................................... xiv

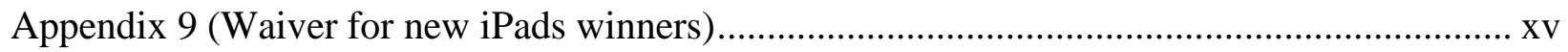

Appendix 10 (Confirmation email for soft copy of the paper) …......................................... xvi

Appendix 11 (Cross factor loadings) ............................................................................ xvii 


\section{Abstract}

This quantitative research targets decision makers, who rely on the analysis of web data (web analytics) in order to make strategic decisions. As identified in the literature, important factors in a web analytics context are information quality, human factors and the presence of actionable insights. Thus, the research had two objectives. The first objective was to provide a better understanding of the skill(s) that matter(s) the most when hiring, training, or working with a web analyst, with the objective of obtaining actionable insights from the reports the team of web analysts prepares. The second objective was to propose a model - based on the DeLone and McLean's (2002) Information Systems (IS) success model - that predicts web analytics success on the basis of decision maker satisfaction, which in turn depends on information quality, and business, analytical and technical skills of a team of web analysts. The results obtained from this study reveal that web data analysis expertise, and the ability to provide agreed upon practical insights are key skills that have a significant impact on decision maker satisfaction. These findings are beneficial to several stakeholders, such as academia, researchers, and the business community, as they provide empirical evidence that may help develop curriculums, provide directions for future research, and determine what profiles to target when hiring or training web analysts. Furthermore, these results provide evidence of the reliability of the proposed research model, and the applicability of the DeLone et al.'s (2002) IS success model to the WA context. 


\section{Introduction}

Web analytics (WA) is a "combination of people, process and technology" (Peterson, 2009, p. 215), used to "better understand the complex interactions between web site visitor actions and web site offers" (Phippen, Sheppard, and Furnell, p. 286). Increasingly, companies rely on web analytics tools and web mining practices to get a better understanding of the behaviour of customers who visit or generate business transactions on their websites. The use of these web analytics tools and web mining practices provides companies with information, based on which strategic decisions are developed for better servicing online customers and fulfilling companies' online business objectives.

According to DeLone and McLean (1992), an "information system creates information which is communicated to the recipient who is then influenced (or not!) by the information” (p. 61). As WA tools are software used to gather, analyze, and report on web data, the WA discipline can be considered a part of the larger Information Systems (IS) discipline. As such, past IS theory and empirical findings should help understand success in the WA context.

This study focuses on the impact that the WA personnel's skills have on the satisfaction of the decision maker who relies on the information (i.e.: actionable insights) provided by WA tools to make strategic decisions. Several studies in the Information Systems (IS) stream have supported the importance of the quality of the information provided by information systems, and decision-making satisfaction obtained from that information. For instance, Larcker and Lessig (1980) identified key factors (i.e.: perceived importance and usableness) and proposed a 
measurement tool to evaluate the perceived usefulness of information to decision makers. Sanders and Courtney’s (1985) study focused on identifying the key factors that impacted user satisfaction with and success of decision support systems. In the WA research stream, several studies mention the importance of information quality (Park, Kim, and Koh (2010)), personnel's skills (Attard (2004); Kaushik (2007); Peterson (2008); Sen, Dacin, and Patticis (2006); Waisberg and Kaushik (2009b)) and decision making satisfaction (Park et al. (2010)). As argued by Kaushik (2007) and Peterson (2009), engaging in WA requires a strategic investment in people, process, and technology. However, the majority of studies conducted in the WA context neither empirically test, nor provide the relative importance of information quality, and WA personnel's skills. In this study, I investigate the impact that the web analytics team's business, analytical and technical skills have on decision maker satisfaction. More precisely, the objectives of this study are:

- To develop a model based on DeLone et al.'s (2002) IS success model (i.e.: D\&W IS success model) to investigate the impact of the quality of the information obtained from WA tools, and web analytics team's business, analytical, and technical skills, on decision maker satisfaction;

- Determine the relative importance of the web analytics team's business, analytical, and technical skills in the WA context.

More precisely, this research intends to address the following research question: What WA personnel skills (i.e.: business, analytical or technical) impact decision maker satisfaction? 
The study is structured as follows:

Literature review: A relevant literature review of the IS and WA disciplines is proposed. Through the literature review, key success factors for the WA discipline are highlighted, and the gap in the literature is identified;

Research model: In this section, a new research model is proposed to study the impact of the identified key success factors in the WA context;

Methodology: This section provides details concerning the research method, data collection, sample size, and data analysis.

$>$ Results and implications: Results from this study and implications for the targeted audience, are discussed.

The study finally concludes with its unique contribution and limitations, which shall be considered and investigated by future research. 


\section{Background}

This study has two objectives. Firstly, it investigates the impact of the quality of the information obtained from WA tools, and web analytics team's business, analytical, and technical skills, on decision maker satisfaction. Secondly, it intends to determine the relative importance of the web analytics team's business, analytical, and technical skills in the WA context.

For the purpose of this study, a distinction is made between the web analytics team's business, analytical, and technical skills in order to better understand the role that each one of these components (along with information quality) plays, and their relative importance toward decision maker satisfaction.

\section{A. Decision maker satisfaction}

According to DeLone et al. (2002), "net benefits" is the ultimate success variable in the IS field that measures the net outcome in a specific context (for example, the context of the present study), and perspective (i.e.: the perspective of the user, organization, or society). Net benefits, or individual and organizational impacts (from the original D\&M IS success model), is a construct that was adapted from the decision-making satisfaction construct, which pertains to the Management Information Systems/Decision Support Systems (MIS/DSS) success theory. According to Sanders et al. (1985), DSS success is measured by two factors: overall satisfaction and decision-making satisfaction. The fact that both factors are part of the same construct indicates that a correlation exists between the two; the overall satisfaction with the DSS impacts the decision-making satisfaction obtained from the use of the DSS, and vice versa. Several 
studies in the IS success research stream have empirically supported the role of net benefits as the ultimate success variable (Bailey et al., 1983; Clemons et al., 1993; D’Ambra et al., 2001; DeLone et al., 2002; Doll et al., 1998; Gelderman et al., 1998; Grover et al., 1996; Guimaraes et al., 1997; Hitt et al., 1994).

In a WA context, I posit that the net benefit to a decision maker is the satisfaction obtained from the information provided by WA tools. In this context, I posit that satisfaction is influenced by the presence or absence of actionable insights in the information provided by WA tools and personnel, the ultimate goal for decision makers being leveraging those insights to make strategic business decisions. More precisely, decision maker satisfaction refers to the extent to which:

- The information provided by WA tools enables decision makers to gain practical insights that they can act on;

- Decision makers are able to set your priorities in decision making, as a result of the information provided by WA tools;

- Decision makers are able to present their arguments more convincingly, as a result of the information provided by WA tools;

- The information provided by WA tools helps improve the quality of the decisions that decision makers make;

- The speed at which decision makers gain insights, as a result of the information provided by WA tools;

- More relevant insights are available to decision makers for decision making, as a result of the information provided by WA tools; 
- The information provided by WA tools leads to a greater use of analytical aids in decision making.

\section{B. Business skills}

The importance of business skills has been highlighted in several research streams, such as IS success, Marketing, Resource-based view (RBV), Strategic Decision Making (SDM), and Strategic use of information systems (SUIS) (Goodhue, and Thompson, 1995; Heinrichs et al., 2003; Ravichandran et al., 2005; Teo, and King, 1997). In their study on IS success factors, Ravichandran et al. (2005) employed the Resource-Based View (RBV) and identified the IS personnel’s business skills, and knowledge of the firm, as key factors.

In a WA context, Heinrichs et al. (2003) posit that the performance of a firm depends on the knowledge workers' use of web analytics tools and understanding of their firm's business model. More information about Heinrichs et al.'s (2003) study is provided later on. In the WA context, business skills refer to:

- The understanding of business objectives and their importance to the organization;

- The consistent use of business terms to communicate effectively;

- The extent to which business problems are taken seriously;

- The extent to which a real interest in helping solve business problems is demonstrated;

- The response time to attend to request or business problems;

- The ability to communicate regular updates on a request. 


\section{Analytical skills}

The need for specialized human resources, who can perform information analysis, has been theoretically supported in several research streams, such as IS success, SDM, Web mining, and WA (Attard, 2004; Büchner, and Mulvenna, 1998; Goodhue et al., 1995; Heinrichs et al., 2003; Kaushik, 2007; Peterson, 2009; Sen, Dacin, and Patticis, 2006; Waisberg, and Kaushik, 2009b).

In a WA context, providing information analysis is a key factor (Büchner et al., 1998; Kaushik, 2007; Sen et al., 2006; Waisberg et al., 2009b). However, based on the literature review, no empirical study has evaluated the importance of analytical skills in a WA context. I conceptualize analytical skills as the skills related to the expertise in:

- Using data analysis techniques;

- Knowing and using statistics;

- Providing practical insights that decision makers can act on to support their decision making needs.

\section{Technical skills}

Several empirical studies in various research areas, such as IS success, RBV, SDM, and SUIS, and WA, have identified the importance of technical skills for the strategic use of IS (Attard, 2004; Cheney, and Lyons, 1980; Coff, 1997; Goodhue et al., 1995; Heinrichs et al., 2003; Johnston, and Carrico, 1988; King, Grover, and Hufnagel, 1989; King, and Teo, 1996;

Lee, Trauth, and Farewell, 1995; Mooney, Gurbaxani, and Kraemer, 1996; Pefanis Schlee, and 
Harich, 2010; Ravichandran, and Lertwongsatien, 2000a; Ravichandran et al., 2005). For instance, the results of the research conducted by Pefanis Schlee et al. (2010) on the skills that marketing students need to develop during their curriculum in order to be adequately equipped for today’s marketing positions, reveal that conceptual skills (i.e.: marketing theories, internet marketing, etc.) are as important as technical skills (i.e.: search engine optimisation, web analytics, etc.), throughout their career, and for all position levels (i.e.: from low level to senior level). In an IS context, it is worth noting that, from the results of their study on the key facilitators and inhibitors of the strategic use of IT and information, King et al. (1989) concluded that the technical abilities of a firm's IT personnel can help that firm obtain a competitive advantage over its competitors. Interestingly, when studying the strategic use of IS toward competitive advantage, Johnston et al. (1988) found that technical skills seem to be a concern only when companies did not have the support of strong administrative and decision-support systems.

In a WA context, to my knowledge, Attard (2004) is the only researcher who has conducted an empirical study, which highlights the lack of sophistication of WA tools used by organizations, and the need that those organizations have for advanced measurement techniques (e.g.: usability testing, measurement of visitors’ browsing history). Thus, Attard’s (2004) research puts the emphasis on the fact that technical skills are required to help compensate for the lack of features and reporting capabilities provided by WA tools. As inferred by Attard (2004), organizations need those technical skills in order to obtain a holistic view and understanding of the activity occurring on their websites. More information about Attard's (2004) study is provided later on. In the WA context, technical skills refer to skills related to: 
- Installing and configuring WA tools;

- The ability to quickly learn and work with new technologies as they become available;

- Programming skills.

\section{E. Information quality}

As per DeLone et al. (1992), the information quality construct and related success measures, have been used by some researchers to measure the quality of the information provided by an IS. The authors add that even though the measures pertaining to information quality are "shown here as separate entities, [they] are often included as part of the measurers of user satisfaction” (p. 66). Thus, information quality may be a determinant of satisfaction with the IS as well. Furthermore, the information quality construct provided in both the original and updated D\&L IS Success model is based on research conducted by Larcker et al. (1980) that provides an instrument to measure the perceived usefulness of the information provided by an IS. The instrument is composed of two constructs:

- perceived importance: "the quality that causes a particular information set to acquire relevance to the decision maker” (p. 123)

- perceived usableness: "the information quality that allows a decision maker to utilize the set as an input for problem solution” (p. 123)

This research relates to mine as it focuses on the perceived importance of the information provided by IS to decision makers, and the perceived usableness of that information. In a WA context, I intend to measure the perceived importance of the information provided by WA tools, 
and whether this information is useful as is, or needs to be transformed in order to trigger satisfaction from the decision maker. Thus, information quality refers to the extent to which:

- The information obtained from the WA tools is necessary to gain practical insights from web data;

- The information obtained from WA tools is partially or entirely sufficient to make a specific decision;

- Complex recalculations or adjustments are not necessary to use the information obtained from WA tools to make a specific decision;

- Additional analysis are not required to use the information obtained from your WA tools to make a specific decision;

- The information obtained from WA tools is provided in a format that allows decision makers to make a specific decision;

- The information obtained from WA tools is interpretable, without any recalculation or adjustment, or further analysis, to make a specific decision.

\section{F. Relevant studies in the field of web analytics}

Attard (2004) conducted a study, for the purpose of his dissertation, on the utilisation of web analytics toward the optimisation of return on investment (ROI). More precisely, the objective of his research was to determine whether a sample of Maltese firms utilize web analytics in order to optimize their ROI or not. From the results obtained, the author posits that the sampled firms do not take full advantage of the use of their web analytics tools, and that executives do not yet incorporate "web analytics into their strategic on-line decision making processes" (p. 135). The author mentions that the results also indicate that "[m]anagement is not 
investing enough time, money and human resources toward maximising Web analytics applications’ potential” (p. 135). In order to help executives and management make better decisions with web analytics, the author offers a guide that showcases solutions to commonly encountered challenges that are tied to online marketing strategies.

Attard's (2004) dissertation is interesting. The subject is very close to mine, especially since the author mentions the importance of the use of WA tools for strategic purposes, and human resources. However, the author does not elaborate on the distinction between the web analyst's business, analytical, and technical skills. He does have a question in his questionnaire that requires respondents to indicate the possible reasons why their use of web analytics is not optimized, and one of the answers (or factors) is the lack of specialised personnel. But as mentioned earlier, the author does not go further. It should be noted that I will be cautious about using the author's findings as he does not detail his methodology, especially the data analysis part. Attard (2004) only mentions the use of Excel spreadsheets, pivot tables, and filters. The author does not use any model, but uses constructs, about which the validity is unknown, as it is not provided. Likewise, the validity of the measures that he utilizes is unknown. He reports his results in terms of percentages, but does not provide any information about the reliability of his measures.

In the Strategic Decision Making (SDM) research stream, Heinrichs et al. (2003) posit that a competitive advantage could be reached via strategic performance capabilities. The authors argue that these capabilities are impacted by the knowledge workers' use of web analytics tools and understanding of their firms' business models. Their results show that the more 
knowledgeable the knowledge worker is about the firm's business model, the better he will be in utilising the web data obtained from the WA tool, and formulating better strategic recommendations. This study provides an interesting perspective, because it highlights the fact that knowing the business objectives of the firm is an important factor in the application of strategic decision making in a WA context.

In the SDM research stream, Weischedel, Matear, and Deans' (2005) study is also of interest. The objective of this inductive research is to study the use of web metrics for the purpose of strategic decision making. In order to determine if web businesses actually use web metrics to make strategic decisions, the authors employ a mixed methodology, which is composed of:

- Exploratory interviews: The authors interviewed representatives from eight different New Zealand companies about their use of web metrics. The results show that in most cases, web metrics are not used for strategic decision making;

- In-depth case study: Eight employees of a large U.S. company were interviewed. The results highlight the fact that web metrics are used for strategic decision making in that context, probably because of the amount of available resources (i.e.: employees, funds, etc.);

- $\quad$ Case studies: For the main data collection method, 18 case studies are used. All studied firms shared similarities in terms of size, business focus (i.e.: B2C), and the use of web 
metrics for strategic decision making. These case studies help provide information on "how SDM changes within the online environment, which tasks and stages web businesses face when making strategic decisions and which metrics can be used to inform the different stages of online SDM" (p. 69).

It should be noted that this paper was published before the full details about the research were available. It is worth mentioning also that the authors posited that "[w]eb metrics can create a distinct advantage and benefit when they are used for strategic decision-making in this environment” (p. 74).

This study highlights the use of web metrics (i.e.: information), and web analytics, for the purpose of strategic decision making, and provides valuable information for my research, even though I intend to investigate the importance of the web analyst's skills in this context, rather than focusing on web metrics.

Overall, the literature review of several IS-related research streams (Appendix 1 (IS success measures)) identifies the following variables: information quality, system quality, service quality, use, user satisfaction, and net benefits. The literature highlights the importance of key success factors and measures in the IS context, among which are information quality, specialised IS personnel and net benefits. Although the importance of information quality, web analytics team's business, analytical, and technical skills, and ability to obtain actionable insights have been identified, as depicted in Table 1, and to my knowledge, no empirical study in the WA research stream has tested the importance of business and analytical skills, and decision maker 
satisfaction with the information obtained from WA tools. As far as technical skills are concerned, Attard’s (2004) study seems to be the only one related to WA. To my knowledge, Park et al. (2010) are the only researchers who have empirically highlighted the importance of information quality in a WA context. Thus, as explained in this section, research on these four particular factors still suffers from a lack of clarification. Furthermore, the identification, comparison and ranking of required IS skills in an organization have been researched in the IS field. For instance, Benbasat, Dexter, and Mantha’s (1980) study highlighted the fact that both IS managers and systems analysts working for mature and less mature organizations agreed that the perceived value of generalist skills was superior to that of specialist skills. As indicated by the authors, generalist skills relate to managerial or organizational skills, whereas specialist skills refer to technical skills. Although these definitions leave room for interpretation, as managerial, organizational and technical skills are not clearly defined, this study is important as it suggests business, analytical and technical skills of WA personnel might have differing levels of impact on decision maker satisfaction. Based on the definitions that I propose for business, analytical, and technical skills, generalist skills would be related to the business and analytical skills, and specialist skills would relate to technical skills. To my knowledge, no research has been conducted on the relative importance of business, analytical and technical skills in the WA context. Through this study, I hope to make a unique contribution by not only highlighting the importance of information quality and WA personnel's skills, but also helping organizations determine what skills matter toward a decision maker's satisfaction, when hiring or training web analysts. 


\begin{tabular}{|l|l|l|l|}
\hline Success measure and factors & $\begin{array}{l}\text { Research } \\
\text { stream }\end{array}$ & $\begin{array}{l}\text { Empirical } \\
\text { studies }\end{array}$ & Theoretical studies \\
\hline Net benefits & WA & None & None \\
\hline Business skills & WA & None & None \\
\hline Analytical skills & WA & None & $\begin{array}{l}\text { Attard (2004); Kaushik (2007); } \\
\text { Peterson (2008); Sen et al. } \\
\text { (2006); Waisberg et al. (2009b) }\end{array}$ \\
\hline Technical skills & WA & Attard (2004) & Kaushik (2007); Peterson (2008) \\
\hline $\begin{array}{l}\text { Business vs. analytical vs. } \\
\text { technical skills }\end{array}$ & WA & None & None \\
\hline Information quality & WA & $\begin{array}{l}\text { Park et al. } \\
\text { (2010) }\end{array}$ & None \\
\hline
\end{tabular}

Table 1 - Success measure and factors for the research model

In the next section, I introduce my research model.

\section{Research model}

The available literature reveals that several empirical and theoretical studies have been concerned with identifying the indicators of information systems success. These studies pertain to various research streams, such as: Information Systems (IS) success (DeLone, and McLean, 2002), Decision Support Systems (DSS) (Sanders, and Courtney, 1985), Strategic Decision Making (SDM) (Heinrichs, and Lim, 2003), and Resource-based view (RBV) (Ravichandran, and Lertwongsatien, 2005).

As suggested above, several paradigms could have been chosen from for the purpose of conducting this research project. For instance, this research could have been conducted in the Decision Support Systems (DSS) paradigm, knowing that WA tools are utilised not only to capture and analyse web data, but also provide information upon which strategic decisions are 
made. As Keen (1980) reveals, DSS is a broad term that is used to define information systems, which are utilised to support decision makers in their decision making process. The author posits that DSS is actually composed of the following:

- Personal Support Systems (PSS), for use by individuals in tasks that do not involve interdependencies, so that the user can indeed make a decision;

- Group Support Systems (GSS), for tasks with "pooled" interdependencies, which thus require substantial face-to-face discussion and communication; and

- Organizational Support Systems (OSS), for tasks that involve "sequential" interdependencies. (p. 26)

Thus, in a WA context the above-mentioned categories, which are proposed by Keen (1980), would be related to the level of integration of the WA tool. As a matter of fact, a deeply integrated WA tool could communicate with databases pertaining to various departments within an organization, and provide reports that would tie web data coming from the company’s website, to revenues generated from off-line marketing campaigns, for instance. On the other hand, non-integrated WA tools would only provide web data coming from a company's website. Therefore, and for parsimony reasons, this research project will be conducted within the Information Systems (IS) success paradigm, because this paradigm allows for gaining an overall understanding of the main factors that affect the success of information systems, independently of their specific characteristics or utilization (e.g.: decision support systems, web analytics systems, data mining systems, etc.). 
The IS success paradigm was introduced by DeLone and McLean in 1992, with the first version of their D\&M IS success model, and based on research in the fields of communications, information influence theory, and management information systems (MIS) (DeLone et al., 2002). The result of this study was a proposal of a multidimensional framework, which consisted of "six interrelated dimensions of success: SYSTEM QUALITY, INFORMATION QUALITY, SYSTEM USE, USER SATISFACTION, INDIVIDUAL IMPACTS, and ORGANIZATIONAL IMPACTS” (p. 2). Through this framework, the authors posited that a firm could measure the success of its IS investments and initiatives based on the above-mentioned six dimensions. However, 10 years later, after reviewing over 150 articles that referred to their model, DeLone and McLean had to revisit their framework by:

- $\quad$ Adding Service quality as a new dimension: For many years, the area of information systems has been treated as a product-centric function, referring to success metrics such as the ones proposed in the original D\&M IS success model (e.g.: System quality, and Information quality). However, and as posited by Pitt and Watson (1995), “IS departments have always had a service role because they assist users in converting data into information” (p. 173). Thus, Pitt et al. (1995) conducted research that was based on the original D\&M IS success model, and in order to test their theory, they modified DeLone and McLean's model by adding a new construct: System quality. In order to measure this construct, the authors employed an analysis instrument called SERVQUAL. Based on the results of their study, the authors were able to empirically demonstrate that System quality was an often forgotten key dimension of the IS success that impacted both the Use and User satisfaction dimensions of the D\&M IS success model. Thus, DeLone 
and McLean agreed with the claim that the Service quality dimension of the IS success had to be part of their model (DeLone et al., 2002).

- $\quad$ Renaming the Use dimension Intention to use/Use: The renaming of the Use dimension was performed to address some of the concerns that arose from the ambiguity of the label Use. As DeLone et al. (2003) posit, “[g]iven the difficulties in interpreting the multidimensional aspects of 'use'-mandatory versus voluntary, informed versus uninformed, effective versus ineffective, and so on-we suggest 'intention to use' may be a worthwhile alternative measure in some contexts” (p. 23). The authors also stress the fact that Intention to use refers to an attitude, and as such can be very difficult to measure. DeLone et al. (2003) finally suggest that researchers "may choose to stay with ‘use,' but hopefully with a more informed understanding of it” (p. 23).

- Combining the Individual impacts and Organizational impacts dimensions into one dimension, Net benefits: This combination was performed for parsimony reasons. In fact, the impact of an information system can go beyond the borders of an individual user, or a specific organization, and for this reason a more inclusive construct needed to be proposed (DeLone et al., 2003). The rationale behind this decision being that the net benefits, or impacts, will be dictated by the specific objectives of the particular study (DeLone et al., 2003); these objectives could be set at the individual, organizational, or even societal level. Therefore, the authors leave it to the researchers to determine which net benefits would be appropriate for their own studies, and at what level of details. 
Thus, DeLone et al. (2002) introduced an updated model (Figure 1), which posits that System quality, Information quality, and Service quality independently and jointly impact the Use of, and User satisfaction with, information systems. It also posits that there is a causal relationship between Use, and User satisfaction, and that both of them independently and jointly affect the Net benefits obtained from information systems. Finally, and as a feedback loop, the Net benefits construct impacts both the Use, and User satisfaction constructs.

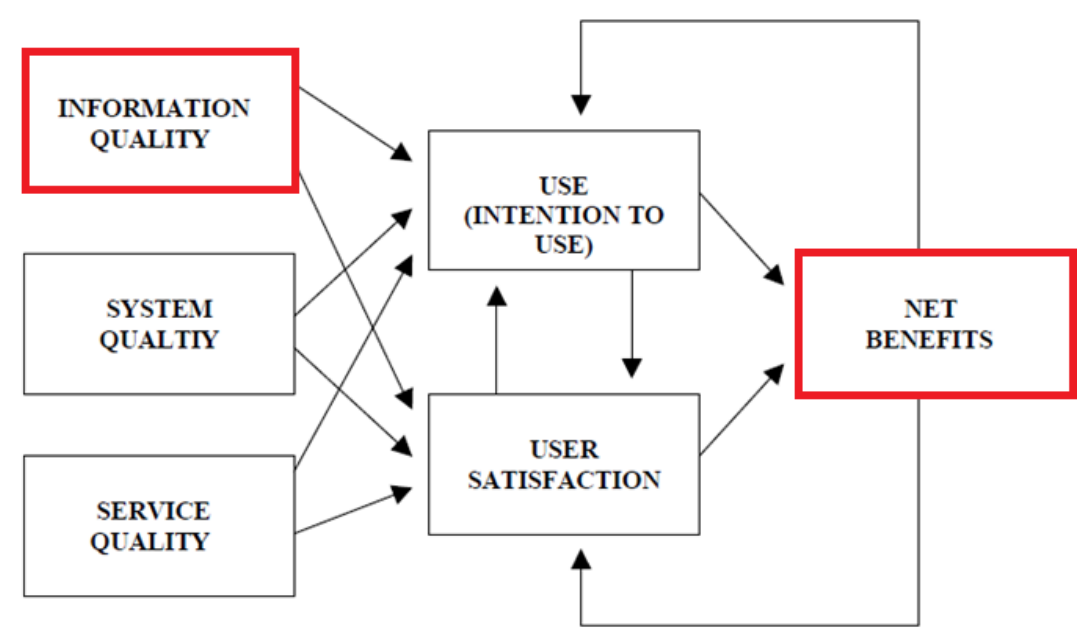

Figure 1 - The updated D\&M IS success model (DeLone et al., 2002)

Most researchers concerned with the study of IS success agree with the appropriateness of the updated D\&M IS success model. As cited by DeLone et al. (2003), and as depicted in Appendix 1 (IS success measures), several studies have empirically confirmed that System quality, Information quality, and Service quality are the antecedents of Use, and User satisfaction in an IS context (Agarwal, and Prasad, 1997; Brynjolfsson, 1996; Clemons, Reddi, and Row, 1993; DeLone et al., 1992; Hitt, and Brynjolfsson, 1994; Pitt et al., 1995). Also, DeLone et al. (2003) confirm that several researchers have empirically demonstrated that a causal relationship exists 
between Use, and User satisfaction (D'Ambra, and Rice, 2001; Gelderman, 1998; Guimaraes, and Igbaria, 1997), and that a relationship exists between Use and Net benefits (or Individual and Organizational impacts) (Bailey, and Pearson, 1983; Clemons et al., 1993; D’Ambra et al., 2001; Doll, and Torkzadeh, 1998; Gelderman, 1998; Grover, Jeong, and Segars, 1996; Guimaraes et al., 1997; Hitt et al., 1994).

In the MIS research stream, it is interesting to note the study conducted by Larcker et al. (1980). The objective of this research is to propose an instrument to measure the perceived usefulness of information for decision makers. Based on a literature review, the authors posit that perceived importance and perceived usableness seem to be two valid constructs for the purpose of designing an adequate measure instrument. To reiterate, the authors define:

- $\quad$ perceived importance as "the quality that causes a particular information set to acquire relevance to the decision maker” (p. 123)

- $\quad$ perceived usableness as "the information quality that allows a decision maker to utilize the set as an input for problem solution” (p. 123)

In order to identify the factors belonging to each construct, the authors interviewed graduate students and faculty members, and asked them to provide a list of attributes for each construct. As a result of the interviews and examinations of other faculty members and graduate students who were knowledgeable about the two constructs, a final list of six statements was proposed; three for each construct. The authors then conducted empirical tests with two pilot studies (one with senior executives, and another with expert judges), and a primary study with " 29 business 
school faculty and graduate students” (p. 126). Based on the results obtained, the authors ran validity and reliability analyses for the constructs and factors. Those analyses revealed that their proposed instrument was valid and reliable. This research is useful for my study, as it focuses on the perceived importance of the information provided by IS to decision makers, and the perceived usableness of that information. With the latter construct, the authors are interested in measuring "whether the present format of the information set can be used by decision makers or must be adjusted or transformed (if possible) to facilitate utilization” (p. 123). Knowing that the objective of my research is to understand how the web analyst's skills will help transform the information gathered from a WA tool into actionable insights, I believe that the use of Lacker et al.’s (1980) proposed instrument is justified.

To my knowledge, Park et al.’s (2010) study is the only one conducted in the WA context using the IS success theory. The objective of this research is to find the major factors that impact client firms’ continuous usage of Web Analytics Services (WAS) providers. In order to do so, the authors develop their own framework on the basis of the updated D\&L IS success model, and the exit/voice, and dependence models (Figure 2). 


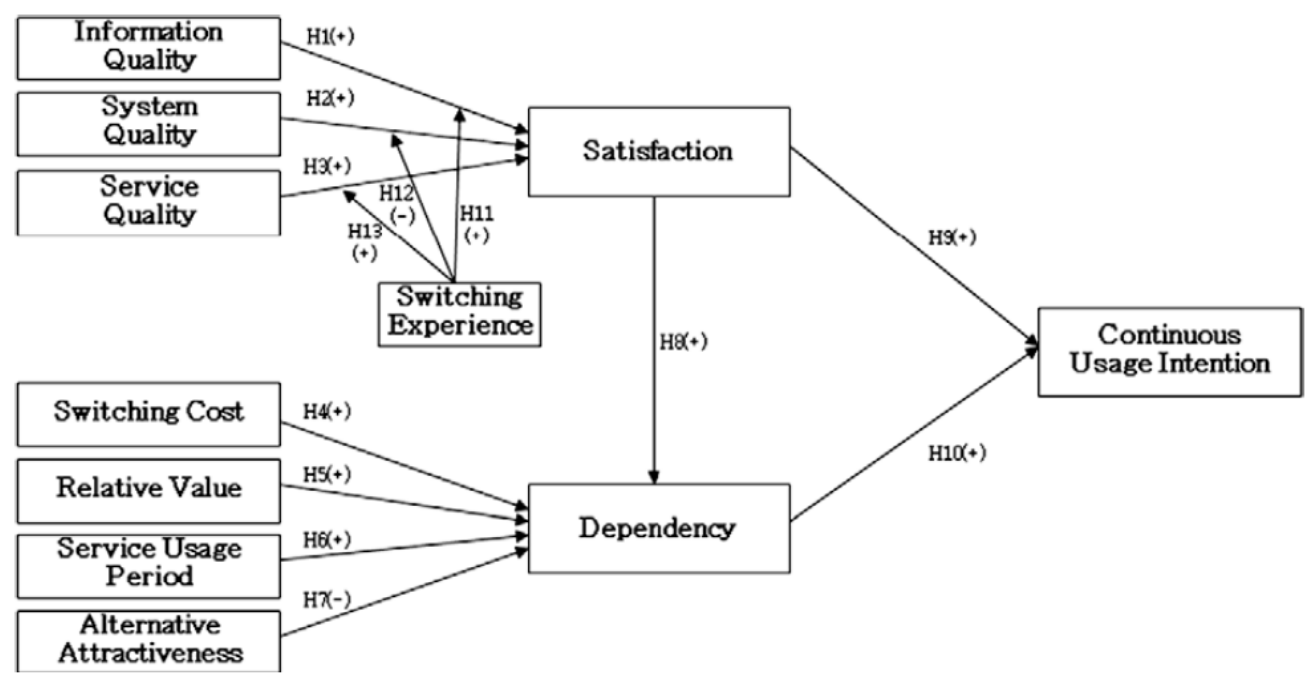

Figure 2 - Park et al.’s research model (Park et al., 2010)

From Figure 2, it appears that all constructs from the updated D\&M IS success model have been adapted, except for Use/Intention to Use. Net benefits, which DeLone et al. (2002) propose as the final success variable, which measures the net outcome, has been adapted by Park et al. (2010) as Continuous Usage Intention. Based on their findings, the authors identify that "satisfaction" and “dependence" play a major role in the decision that a firm makes toward whether maintaining the relationship with a WAS provider or not.

Park et al. (2010) provide an interesting approach to the study of the relationship between a firm and its WA service provider, and highlight the switching cost, which is associated to the migration from one WA tool to another. This is an important element that firms need to take into consideration, especially since all WA tools do not behave the same way, in the sense that they do not gather, compute, interpret, and render web data in the same fashion. Thus, switching from one tool to another is a sensitive process, as far as data consistency is concerned. However, my 
study focuses on a distinct area of the web analytics discipline, as I intend to study the impact of the web analyst's skills on the information provided by WA tools.

Based on the fact that the D\&M IS success model has been theoretically and empirically validated as being appropriate for the study of IS success, and its demonstrated appropriateness in the WA context, I believe that it provides an appropriate theoretical foundation and adequate framework for my study. For the purpose of this research, I propose a model, which excludes the following constructs from the updated D\&M IS success model: System quality, Service quality, Use/Intention to use and User satisfaction. The reasons for the removal of these constructs are as follows:

System quality, and service quality: I suggest the removal of the System quality, and Service quality constructs, because their roles as factors impacting both Use and User satisfaction have already been empirically supported. Furthermore, it is also implied that the user's skills (e.g.: business, analytical, or technical) will have an impact on the quality level of the WA tool, and service provided. Thus, on the basis of his skills, the user (i.e.: the web analyst) will be able to provide the WA vendor with feedback, which will help enhance the quality of the system, and service.

Use/Intention to use: I suggest the removal of the Use/Intention to use construct, because its causal relationship with User satisfaction, and impact on Net benefits (or Individual and Organizational impacts) have already been empirically supported. Since the utilisation of a WA tool is required in order to obtain web information, I assume that 
the web analyst has access to such tool, and that he uses it in order to produce the web analytics reports that decision makers require.

User satisfaction: I suggest the removal of the User satisfaction construct, because its causal relationship with Use/Intention to use, and impact on Net benefits (or Individual and Organizational impacts) have already been empirically supported. Furthermore, Delone et al. (1992) posit that

[some researchers] have chosen to study the information product for desired characteristics such as accuracy, meaningfulness, and timeliness (INFORMATION QUALITY). In the influence level, some researchers have analyzed the interaction of the information product with its recipients, the users and/or decision makers, by measuring USE or USER SATISFACTION. (p. 62)

Thus, Information quality would help measure the quality of the information provided by the IS, whereas Use or User satisfaction would be related to the measure of the relationship that exists between the user and IS. As my research focuses on the relationship that exists between the information provided by WA tools, and decision makers' satisfaction - and not on the relationship that exists between WA tools and the users who utilise them -, I believe that the analysis of the web analyst's satisfaction with the WA tool will not be related to the purpose of my research.

As previously mentioned, the literature identifies the key role that information quality and WA personnel's business, analytical and technical skills play in the WA context. However, current knowledge lacks a clear understanding of the direct and indirect impact of the identified key success factors. More precisely, organizations, business owners and academia (to name a 
few stakeholders), would greatly benefit from gaining a better understanding of how various WA-related skills can be singled out or combined to achieve better interpretation of web data, and support strategic business decisions. In an attempt to provide answers to questions that those stakeholders may have, and explain the role played by the identified key factors, I propose the following model:

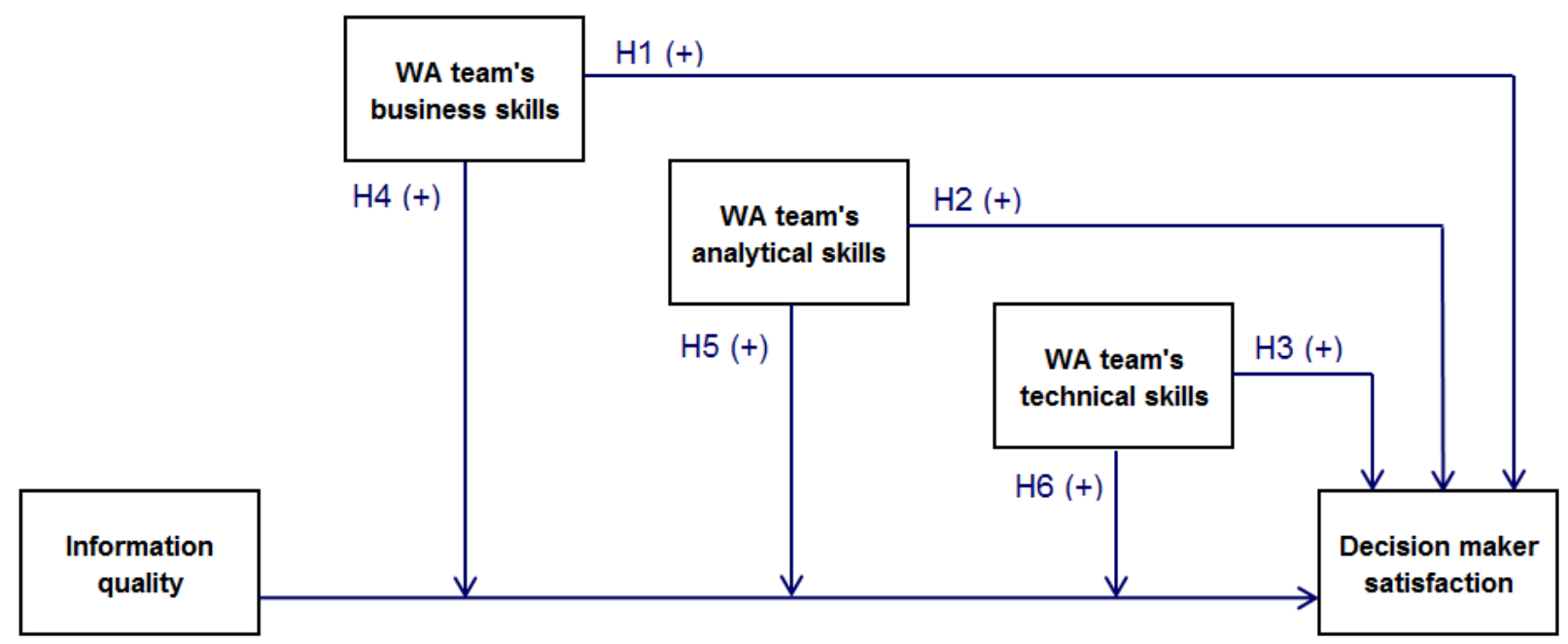

Figure 3 - Research model adapted from the updated D\&M IS success model (DeLone et al., 2002)

\section{Decision maker satisfaction:}

As revealed by Sanders et al. (1985) Overall satisfaction and Decision-making satisfaction are two key factors in the DSS success context. Thus, in a WA context, I posit that Decision maker satisfaction is the ultimate success variable that indicates satisfaction from the information provided by WA tools. As mentioned earlier, I posit that satisfaction is influenced by the presence or absence of actionable insights in the information provided by WA tools and personnel, the ultimate goal for decision makers being leveraging those insights to make strategic business decisions. 


\section{Web analytics team's business, analytical and technical skills:}

As revealed in the literature review, the web analytics team’s business, analytical and technical skills are important factors. In fact, the literature explicitly states that those are determinant factors for the gain of actionable insights from web data. Thus, I intend to empirically study the direct impact of these skills on decision maker satisfaction.

Thus, I propose the following hypotheses:

- H1: The web analytics team's business skills will have a positive impact on decision maker satisfaction.

- H2: The web analytics team's analytical skills will have a positive impact on decision maker satisfaction.

- H3: The web analytics team's technical skills will have a positive impact on decision maker satisfaction.

\section{Information quality:}

The importance of the quality of the information provided by an IS has been revealed in IS success research stream (Agarwal et al., 1997; Brynjolfsson, 1996; Clemons et al., 1993; DeLone et al., 1992; DeLone et al., 2002; Hitt et al., 1994; Larcker et al., 1980; Livari, 2005; Pitt et al., 1995; Waisberg et al., 2009a). In a WA context, I posit that information quality refers to the quality of the information obtained from WA tools, and its ability to provide actionable 
insights. I believe that the direct relationship that exists between information quality and decision maker satisfaction will most likely be confirmed by my findings. Thus, I also posit that the impact of information quality on decision maker satisfaction depends on the WA team's skill set, and intend to study the indirect, or moderating, impact of the WA team's skills on the relationship that exists between information quality and decision maker satisfaction. Therefore:

- H4: The business skills of the web analytics team will moderate the relationship between the information provided by the WA tool and decision maker satisfaction, such that the lack of business skills will decrease decision maker satisfaction with the provided information.

- H5: The analytical skills of the web analytics team will moderate the relationship between the information provided by the WA tool and decision maker satisfaction, such that the lack of analytical skills will decrease decision maker satisfaction with the provided information.

- H6: The technical skills of the web analytics team will moderate the relationship between the information provided by the WA tool and decision maker satisfaction, such that the lack of technical skills will decrease decision maker satisfaction with the provided information.

In the following section, the methodology used for this study is presented. 


\section{Methodology}

\section{A. Research methods}

For the purpose of this research, a quantitative research method applied in the positivism paradigm was appropriate. Furthermore, the literature review of the IS success, MIS/DSS, and Task-Technology fit theories revealed that the use of a questionnaire is a valid data collection method, for studies in an IS context.

\section{B. Data collection}

My investigation was based on the data gathered from an online questionnaire, which was addressed to decision makers who obtain web data analysis and insights from web analysts, and rely on those analysis and insights to make strategic decisions. The targeted decision makers were business owners, or managers and above, who would be in charge of online marketing, web analytics, or the IS department of their organizations. These individuals would work closely with web analysts, who would provide web analytics reports. As Ravichandran et al. (2005) posit, these higher-ranked employees would be "the most informed about the strategic issues [that their organizations face]” (p. 248). The scope of this study was geographically limited to Canada, and the United States of America (U.S.A.). The intent was to study and report on the key factors that impact both organizations and individuals in those countries. 


\section{Recruitment sources}

The above-mentioned professionals were contacted starting on April 15, 2012 through various channels. Below is the list of all channels used:

- LinkedIn Canada groups: 36 groups with a focus on online marketing, analytics, web analytics, online strategies and business intelligence were contacted. The assumption was that members of those groups would have an interest and professional expertise in the fields of interest to this research. Those groups were contacted between April 15, 2012 and June 17, 2012. The total number of members belonging to those groups was 764,901. Please refer to Appendix 4 (Recruitment sources: LinkedIn groups) for the complete list of LinkedIn groups that were contacted.

- Associations: The associations below were contacted between May 30, 2012 and June 17, 2012:

o American Marketing Association - Canadian chapters (American Marketing Association, n.d.)

o American Marketing Association - U.S.A. chapters (American Marketing Association, n.d.)

o International Institute of Business Analysis - Canadian chapters (International Institute of Business Analysis, n.d.)

o International Institute of Business Analysis - U.S.A. chapters (International Institute of Business Analysis, n.d.) 
o Information Resource Management Association of Canada (Information Resource Management Association of Canada, n.d.)

o Marketing Research and Intelligence Association (Marketing Research and Intelligence Association, n.d.)

o National Retail Federation (National Retail Federation, n.d.)

o Shop.org (Shop.org, n.d.)

o Toronto Area SAS Society (Toronto Area SAS Society, n.d.)

- Personal network: I contacted a total of 154 individuals in my personal network, through: email communications, and Facebook and LinkedIn private messages. Those individuals were contacted on the basis of their professional expertise in the field on interest.

\section{The measurement instrument}

The questionnaire was built using SurveyMonkey, and custom links to the questionnaire were created and then communicated through the above-mentioned channels. The questions are available in Appendix 2 (Questionnaire items). For a minimal monthly fee, I was able to build the questionnaire, create custom links to the survey, and export the results in Excel format. Zoomerang, another online questionnaire development vendor, which was bought by SurveyMonkey, provided similar services and features for an annual fee (i.e.: \$199). For cost and flexibility reasons, I decided to select SurveyMonkey’s services, as I did not anticipate data collection to last more than a few months. 
The questionnaire was submitted to a Master's student and an ethics committee for review purposes. Based on the feedback received, the following primary changes were made:

1. The length of the original online questionnaire was shortened by removing the introductory message, which provided background information about the survey and the research. Instead, the introductory message was added to the consent form (Appendix 6 (Consent agreement)), which was accessible through a link provided in the online questionnaire;

2. The exact date (i.e.: August 1, 2012) at which the draw for the two iPads was specified on the consent form. The original questionnaire contained an approximate date (i.e.: two to three weeks after the end of data collection);

3. The maximum number of participants (i.e.: 200) was originally not specified. I added this information to the consent form (Appendix 6 (Consent agreement));

4. Some of the terms used in the original questionnaire seemed to be unclear, and limit its accessibility to a larger audience. For instance, the use of “actionable insights” was deemed to be vague, and "information that can be acted upon” was preferred;

5. In order to ease the completion process, the background information section (i.e.: participants’ occupation, area of specialization, industry, and web analytics team and tools) was moved from the end of the questionnaire to the beginning. The intent of this 
change was to avoid discouraging participation by providing what seemed to be complicated questions to answer. The section containing questions about participants’ personal information (i.e.: education level, first and last names and email address) remained at the end of the questionnaire.

As specified by Lumsden and Morgan (2005), this use of an online questionnaire as a data collection method offers many advantages (over paper-based questionnaires), such as “cost, speed, appearance, flexibility, functionality, and usability” (p. 3). Other advantages are the elimination of mail processing, environmental friendliness, and ease of data collection (Attard, 2004). As well, because of the specific online aspect of the research study, and the occupations of the target audience, this medium was appropriate. I decided to adapt my questionnaire items from Larcker et al. (1980), Goodhue et al. (1995), Ravichandran et al. (2005), and Sanders et al. (1985):

- Larcker et al.'s (1980) research on the perceived usefulness of information provided empirical evidence of the validity and reliability of their questionnaire items. Thus, I adapted the questionnaire items of their study to the WA context. The questionnaire items for the Information quality construct are available in Appendix 2 (Questionnaire items).

- Goodhue et al.'s (1995) research on the relationship between Task-Technology Fit and individual performance provided empirical evidence of the validity and reliability of their questionnaire items. Thus, I adapted the section of their questionnaire about the IS personnel's business and technical skills, to my specific context; the questionnaire items 
for the WA team's business and technical skills constructs are available in Appendix 2 (Questionnaire items).

- Ravichandran et al.’s (2005) research on the impact of IS on a firm’s performance provided empirical evidence of the validity and reliability of their questionnaire items. Thus, I adapted the section of their questionnaire about the "IS Human Resource Skills and Specificity” (p. 269), to my specific context; the questionnaire items are available in Appendix 2 (Questionnaire items).

- Sanders et al.’s (1985) research on the MIS/DSS success measures provided empirical evidence of the validity and reliability of their questionnaire items. Thus, I adapted the sections of their questionnaire that pertain to decision-making satisfaction. The questionnaire items for the decision maker satisfaction construct are available in Appendix 2 (Questionnaire items).

The questionnaire contains a total of 40 items, including two preliminary questions. The preliminary questions are as follows:

a) For the purpose of this survey, "web analyst" refers to the individual, or the team of web analysts, who prepares the reports that help make strategic business decisions. Thus, "web analyst" could refer to a team or department, which would be composed of more than one web analyst. 
- I attest that I can express my views on the skills of the web analyst who prepares the web analytics reports that I need: Yes or No

b) The company that you work for, or own, is located in:

- United States of America

- Canada

- Other

Paragraph “a)” helped reinforce the fact that respondents needed to keep in mind that the survey questions focus on the skills of the web analyst as being an individual, or a team or department. Thus, respondents needed to be able to provide their views on the business, analytical, and technical skills of the individual, or department they obtain their reports from. The question was used for screening purposes. By replying “No”, the survey ended, and participants were redirected to a confirmation page (Appendix 7 (Thank you note and confirmation message)).

Question “b)” was also used for U.S.A. or Canada. By replying “Other”, the survey ended, and participants were redirected to a confirmation page (Appendix 7 (Thank you note and confirmation message)).

Appendix 2 (Questionnaire items) details the questionnaire items for each one of the research model's constructs. Each item was measured by the respondents with a Likert scale of seven responses (1 being Strongly disagree, and 7 being Strongly agree), as commonly found 
in the literature (Chin, Marcolin, and Newsted, 1996; Larcker et al., 1980; Park et al.; 2010; Pitt et al., 1995; Sethi et al., 1994). Items identified with a number sign (\#) were measured with a seven-point rating scale, which went from “None” (i.e.: 1) to “All” (i.e.: 7). Items with a "R” denoted negative statements or questions for which scale values needed to be reversed.

It should be noted that the questions marked with an asterisk (*), in the

\author{
INFORMATION QUALITY (IQ), WEB ANALYST'S ANALYTICAL SKILLS (WAAS), \\ and WEB ANALYST'S TECHNICAL SKILLS (WATS) portions of the questionnaire, \\ indicated questions that I added to the original sets, because of the specific character of my \\ study.
}

The original questionnaire items are available in Appendix 3 (Original questionnaire items), and the messages introducing the survey are available in Appendix 5 (Introductory messages for the survey).

\title{
3. Incentives offered to participants
}

To acknowledge the value of participants’ time and collaboration, each unique submission, which was completed by July 1, 2012, could be entered into a draw for a chance to win one (1) of two (2) new iPads. Participation in the draw was voluntary. Participants also had the option to request a copy of the research paper that will report on the findings of the research. In order to be entered in the draw, and/or receive a copy of the research paper, participants had to provide personal information (i.e.: first and last names, and email address), which were stored separately from their survey responses. It should be noted that the research paper will only be available upon completion of this present thesis. 
The draw occurred on October 19, 2012. Unique submissions were tracked by IP address. Out of the 156 participants, 23 did not check the option to be entered in the draw, and 47 did not check the option to receive a soft copy of the research paper. Each of the 133 participants, who indicated that they wanted to be added to the draw, was assigned a number from 1 to 133 . The “RANDBETWEEN” Excel formula was then used to randomly select the two winners of the two (2) new iPads. The winners were individually communicated with via email (Appendix 8 (Confirmation email to new iPads winners)) on October 19, 2012. The first iPad was delivered in person on October 20, 2012. The second iPad was delivered in person on October 22, 2012. Each winner was requested to fill out a waiver (Appendix 9 (Waiver for new iPads winners)) to acknowledge the receipt of the device.

The following section provides details about the sample size.

\section{Sample}

\section{Determination of sample size}

The adequate sample size was determined through a priori power analysis. As posited by Faul, Erdfelder, Lang, and Buchner (2007), “[a] priori analyses provide an efficient method of controlling statistical power before a study is actually conducted” (p. 176). As Faul et al. (2007) indicate, 
In a priori power analyses (Cohen, 1988), sample size $N$ is computed as a function of the required power level $(1-\beta)$, the prespecified significance level $\alpha$, and the population effect size to be detected with probability $1-\beta$. (p. 176)

Power level $(1-\beta)$ refers to the probability of rejecting the null hypothesis when it is actually false (Faul et al., 2007). "This is a Type II error, and for any given [population] ES, $\alpha$, and [sample size] $N$, its probability of occurring is $\beta$. Power is thus $1-\beta$, the probability of rejecting a false $H_{o}$.” (Cohen, 1992, p. 156). For general use, Cohen (1992) recommends a power level equals to 0.8 , which implies a $20 \%$ probability that a Type II error might occur.

Significance level $(\alpha)$ refers to the probability of rejecting the null hypothesis when it is actually true (i.e.: Type I error). Cohen (1992) posits that “[u]nless otherwise stated (and it rarely is), it is taken to equal .05” (p. 156).

The population effect size refers to "the degree to which the [null hypothesis] $H_{o}$, is believed to be false” (Cohen, 1992, p. 156). For multiple and multiple partial correlation, Cohen (1992) recommends three effect sizes (i.e.: 0.02, 0.15, and 0.35), which he respectively labels as small, medium, and large.

Based on the above, the power analysis program G*Power 3 was used to calculate the sample size. The specified parameters were as follows:

- $\quad$ Power level $(1-\beta)=0.8$ 
- Significance level $(\alpha)=0.05$

- $\quad$ Effect size $=0.15$ (i.e.: medium)

- Predictors $=4$

As indicated in Figure 4, the minimum sample size needed was 85 participants.

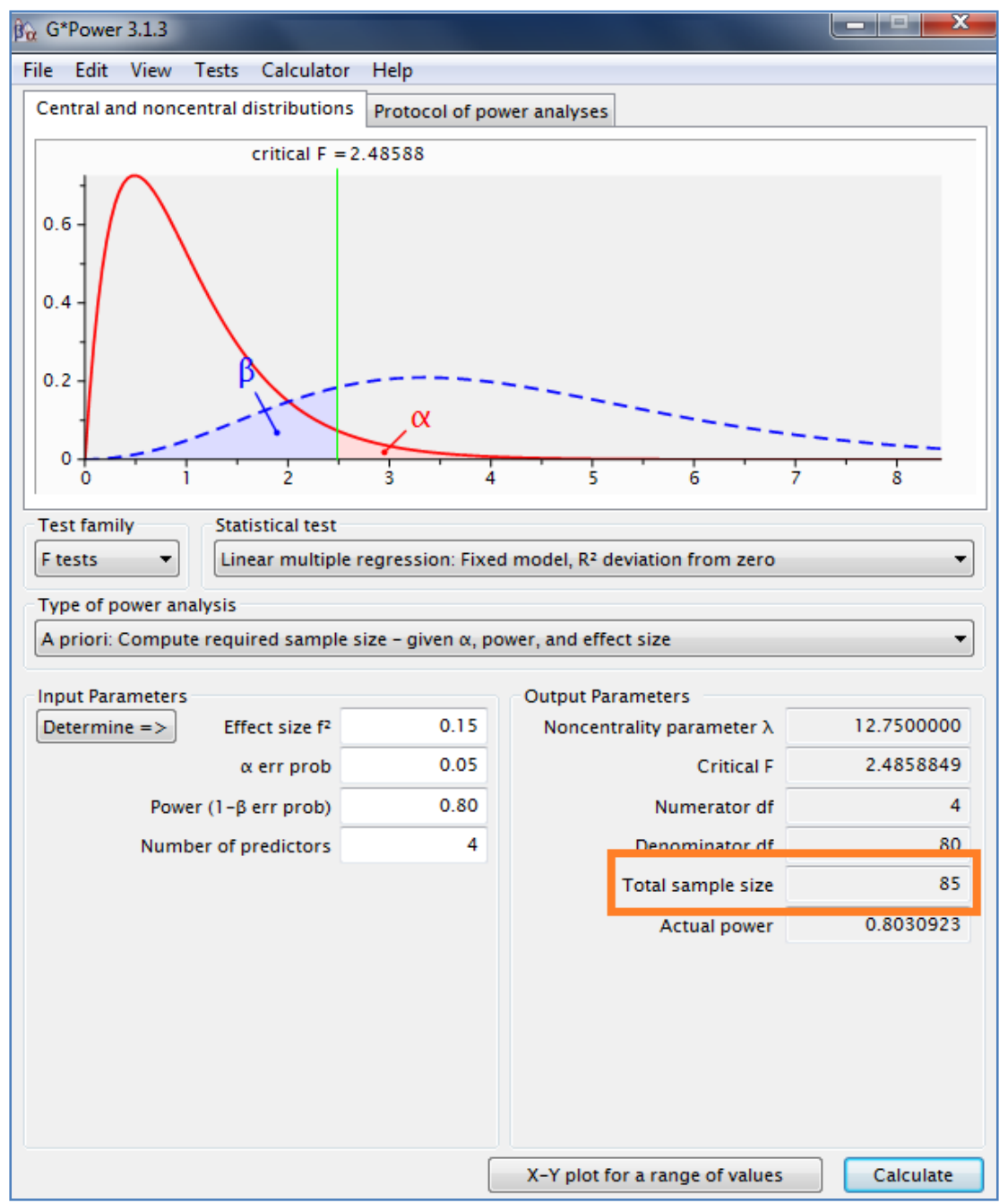

Figure 4 - Recommended minimum sample size 


\section{Actual sample size}

A total of 330 individuals participated in the survey. However, only 165 of them answered at least one question. This drop, or lack of actual participation, was likely due to the fact that none of the questions was mandatory (except for the personal questions required for participating in the draw and obtaining a soft copy of the research paper), and some participants tried to find an easy way to be added to the draw. After reviewing the data, I decided to only keep those participants who answered all questions. The final sample size was then 156 . This sample size represented 47 percent of the total number of participants, and was more than the minimum of 85 participants that was indicated by the results of the power analysis.

\section{Participants’ profiles}

Out of the 156 participants, 96 (i.e.: 61 percent) either worked for or owned a company located in Canada. The remaining participants either worked for or owned a company located in the U.S.A.

As depicted in Table 2, the top five occupations, which represented 77 percent of total participants’ occupations, were leadership roles. These are the roles that this study targeted. As previously mentioned, the individuals occupying

\begin{tabular}{|l|r|r|}
\hline Occupations & Total & $\%$ of total \\
\hline Manager & 50 & $32 \%$ \\
\hline Senior manager & 26 & $17 \%$ \\
\hline Director & 18 & $12 \%$ \\
\hline Specialist & 13 & $8 \%$ \\
\hline C-level executive & 13 & $8 \%$ \\
\hline Other & 36 & $23 \%$ \\
\hline Total & 156 & $100 \%$ \\
\hline \multicolumn{1}{|c|}{ Table 2 - Participants' occupations. }
\end{tabular}

these positions tend to possess not only a strategic understanding of the business issues and opportunities that the organizations they work for or own, but also adequate power to make strategic decisions and implement changes. The "Other" category was composed of: 
Six analysts

Five marketing specialists

Five owners

Five consultants

Five coordinators

Two senior consultants

One webmaster

One marketing (as entered by the participant)

Eighty-four percent of participants specialized in areas related to Marketing, Web analytics, IT/IS and SEO/SEM (Table 3).
$>$ One senior analyst

> One administrative assistant

$>$ One media specialist

One financial advisor

One teacher

One graphic designer

One account services personnel

$>$ One account manager

\begin{tabular}{|l|r|r|}
\hline Areas of specialization & Total & $\%$ of total \\
\hline Marketing & 69 & $44 \%$ \\
\hline Web analytics & 29 & $19 \%$ \\
\hline IT/IS & 26 & $17 \%$ \\
\hline SEO/SEM & 7 & $4 \%$ \\
\hline Other & 25 & $16 \%$ \\
\hline Total & 156 & $100 \%$ \\
\hline
\end{tabular}

Table 3 - Participants' areas of specialization.

It should be noted that for parsimony reasons areas of specialization specified by some participants were grouped into larger themes:

- Marketing includes:

o Search marketing

o Social Media Marketing

o Program marketing \& sponsorships

o $\quad$ B2B marketing o Online marketing

o Retail marketing

o Marketing/Business

Development 
o Marketing/Business

Analytics

o Marketing communications

o Marketing Strategy and implementation

o Marketing Analytics

o Marketing and Public relations o Marketing Management

o Marketing Research

o Event \& Eminence programs

o Event Marketing

o Direct Marketing

o B2B Marketing / ROI

o Sponsorships/marketing

o Customer service

- Communications includes: Communications and Content, and Communications and PR

- SEO/SEM includes: Search marketing, and Search Engine Optimization

- IT/IS includes:
o Web Services
o Emerging Analytics and
o Web production Digital Solutions Strategist
o Microsoft Suite
o Digital Product Development
o Google Analytics analysis,
o AB Testing
Web Support, Web
o Information technology
development

- Other includes:
o Unspecified
o Graphic design
o Communications
o Client recruitment
o Business development
o e-commerce 

o Research
o Consumer insights
o Sales
o Webcasts
o School
o Project Management
o Business Analysis
o Account Manager
o Television and Web Video
o Product management
o Bioinformatics tools, molecular genetics

Most participants belonged to the professional services industry (Table 4). Other indicated industries included Manufacturing, Education, Transportation, and Real estate, just to name a few. Thus, these results confirm

\begin{tabular}{|l|r|r|}
\hline Participants' industries & Total & \% of total \\
\hline Professional services & 67 & $43 \%$ \\
\hline Technology, media and & & \\
telecommunications & 37 & $24 \%$ \\
\hline Consumer business & 13 & $8 \%$ \\
\hline Financial services & 12 & $8 \%$ \\
\hline Public sector & 7 & $4 \%$ \\
\hline Other & 20 & $13 \%$ \\
\hline Total & $\mathbf{1 5 6}$ & $\mathbf{1 0 0 \%}$ \\
\hline \multicolumn{2}{|c|}{ Table 4 - Participants' industries. } \\
\hline
\end{tabular}

that the use of web data is common in many different industries.

The information provided on the participants' web analytics personnel was broken down as follows:

- 131 (i.e.: 84\%) indicated that the team of web analysts they interacted with consisted of one to three individuals;

- 14 (i.e.: 9\%) interacted with four to six web analysts;

- 10 (i.e.: 6\%) interacted with seven or more web analysts; 
- 1 (i.e.: 1\%) participant failed to provide this information.

The data summarized in Table 5

reveals that 50 percent of respondents used

either Google Analytics or Omniture

SiteCatalyst as their web analytics tool of

\begin{tabular}{|l|r|r|}
\hline Web analytics tools & Total & $\%$ of total \\
\hline Google Analytics & 62 & $40 \%$ \\
\hline Unknown & 33 & $21 \%$ \\
\hline Omniture & 16 & $10 \%$ \\
\hline Other & 45 & $29 \%$ \\
\hline Total & 156 & $100 \%$ \\
\hline \multicolumn{2}{|c|}{ Table 5 - Web analytics tools. }
\end{tabular}

choice. It should be noted that the "Other" category is composed of other web analytics tools used as unique solutions or in addition to others. In fact, several participants revealed that they used more than one web analytics tools:

- 81 percent (i.e.: 127) of them used only one web analytics tool;

- 7 percent (i.e.: 11) of them used two web analytics tools (e.g.: Google Analytics, Web Trends);

- 7 percent (i.e.: 12) of them used three web analytics tools (e.g.: Omniture, Webtrends, custom solutions);

- 3 percent (i.e.: 5) of them used four web analytics tools (e.g.: AT Internet, Google Analytics, IBM Coremetrics, Clicktracks);

- 1 participant used five web analytics tools;

- 1 participant failed to provide an answer.

All in all, the data obtained from participants were aligned with the objectives of this study. Decision makers in charge of key functions, such as Marketing, Web analytics, IT/IS and SEO/SEM participated in the survey. As revealed by the results, the use of web data, and 
certainly its analysis needs and integration to business strategies, matter to a wide range of industries.

Let us now review the details about data analysis.

\section{Data analysis}

\section{Method: Partial Least Squares}

The Partial Least Squares (PLS) was selected as an adequate data analysis method to ensure the validity and reliability of the model, and study the relationships between the constructs.

PLS has been the data analysis method of choice for several researchers in various research fields to identify key success factors (Henseler, Ringle, and Sinkovics, 2009). According to the authors, the popularity of PLS arose from four characteristics:

First, instead of solely drawing on the common reflective mode, the PLS path modeling algorithm allows the unrestricted computation of cause-effect relationship models that employ both reflective and formative measurement models (Diamantopoulos \& Winklhofer, 2001). Second, PLS can be used to estimate path models when sample sizes are small (Chin \& Newsted, 1999). Third, PLS path models can be very complex (i.e. consist of many latent and manifest variables) without leading to estimation problems (Wold, 1985). PLS path modeling is methodologically advantageous to CBSEM [Covariance-based Structural Equation Modeling] whenever improper or nonconvergent 
results are likely to occur (i.e. Heywood cases; see Krijnen, Dijkstra, \& Gill, 1998). Furthermore, with more complex models, the number of latent and manifest variables may be high in relation to the number of observations. Fourth, PLS path modeling can be used when distributions are highly skewed (Bagozzi, 1994), or the independence of observations is not assured, because, as Fornell (1982, p. 443) has argued, “there are no distributional requirements.” (p. 288)

According to Chin et al. (1996),

Partial Least Squares (PLS) can be a powerful method of analysis because of the minimal demands on measurement scales, sample size, and residual distributions. Although PLS can be used for theory confirmation, it can also be used to suggest where relationships might or might not exist and to suggest propositions for later testing. (p. 39)

Since the sample size was small (i.e.: 156 participants), and I intended to study the significance of the relationships between the constructs of my model, PLS was appropriate.

\section{Reliability: Internal consistency and unidimensionality}

The reliability of the measurement instrument was determined by measuring internal consistency and unidimensionality of the constructs. "Internal consistency refers to the interrelatedness of a set of items” (Schmitt, p. 350). Unidimensionality refers to how homogeneous a set of items belonging to a same construct are (Schmitt, 1996). As posited by Schmitt (1996), reliability relies on both internal consistency and unidimensionality. 


\section{a) Internal consistency}

As indicated by Schmitt (1996), Cronbach’s alpha $(\alpha)$ has been the coefficient of choice for internal consistency for several researchers. However, Chin et al. (1996) indicated that “[w]hile Cronbach’s alpha with its assumption of parallel measures represents a lower bound estimate of internal consistency, a better estimate can be gained using the composite reliability formula.” (p. 33) Furthermore, for the purpose of this study, IBM® SPSS ${ }^{\circledR}$ Statistics (SPSS) was used to perform certain data manipulations (details of which are provided later on), and SmartPLS was used to perform partial least squares analysis. SPSS is a powerful data analysis software that "features robust and sophisticated functionality and procedures that address the entire analysis lifecycle” (IBM SPSS Statistics, n.d.). SPSS was considered and used by several researchers (Marcoulides, Chin, and Saunders (2012); Lin, Wen, Marsh, and Lin (2010);

Benbasat et al. (1980)). SmartPLS is "a software application for the design of structural equation models (SEM) on a graphical user interface (GUI).” (Hansmann, and Ringle, p. 4) SmartPLS was considered and used by several researchers (Henseler, and Chin (2010); Goodhue, Lewis, and Thompson (2012); Hair, Ringle, and Sarstedt (2011)). As a measure of internal consistency, SPSS only reports on $\alpha$, whereas SmartPLS reports on both $\alpha$ and composite reliability. Thus, I decided to measure internal consistency with both $\alpha$ and composite reliability. The exact process that I followed was as follows:

1. Optimize $\alpha$ for each construct using SPSS

2. Create product items to be used as moderating or interaction effects using SPSS

3. Use bootstrapping technique using SmartPLS and obtain composite reliability of the constructs 
Below are the details for each one of the above steps.

\section{(1) $\quad$ Optimize $\alpha$ with SPSS}

After uploading the dataset to SPSS, and performing a reliability analysis, I noticed that the $\alpha$ of all my constructs could be optimized. Thus, I decided to tackle and optimize each construct separately, starting with Information quality (IQ). As depicted in Table 6, the $\alpha$ of the IQ construct was below the theoretically accepted 0.700 threshold (Park et al. 2010):

\section{Reliability Statistics}

\begin{tabular}{|r|r|r|}
\hline Cronbach's Alpha & $\begin{array}{c}\text { Cronbach's Alpha Based } \\
\text { on Standardized Items }\end{array}$ & N of Items \\
\hline .530 & .565 & 7 \\
\hline
\end{tabular}

Table 6 - Original reliability statistics for the IQ constructs obtained from SPSS software.

I then looked at the Item-Total Statistics report provided by SPSS to determine which indicators (i.e.: question items) could be eliminated in order to increase the internal consistency of the construct. As per Table 7, the removal of question item IQI_1_R would help bring the construct's $\alpha$ to 0.665 , from the original 0.530 .

Item-Total Statistics

\begin{tabular}{|l|r|r|r|r|r|}
\hline & $\begin{array}{c}\text { Scale Mean if } \\
\text { Item Deleted }\end{array}$ & $\begin{array}{c}\text { Scale Variance } \\
\text { if Item Deleted }\end{array}$ & $\begin{array}{c}\text { Corrected } \\
\text { Item-Total } \\
\text { Correlation }\end{array}$ & $\begin{array}{c}\text { Squared } \\
\text { Multiple } \\
\text { Correlation }\end{array}$ & $\begin{array}{c}\text { Cronbach's } \\
\text { Alpha if Item } \\
\text { Deleted }\end{array}$ \\
\hline IQI_2 & 23.3654 & 18.259 & .260 & .299 & .493 \\
IQI_3 & 23.1667 & 21.520 & .101 & .177 & .544 \\
IQU_3 & 23.4551 & 18.508 & .456 & .353 & .432 \\
IQU_4 & 23.6154 & 18.200 & .449 & .314 & .429 \\
IQI_1_R & 25.4487 & 23.230 & -.135 & .194 & .665 \\
IQU_1_R & 23.7179 & 15.920 & .439 & .313 & .404 \\
IQU_2_R & 25.0385 & 15.986 & .464 & .303 & .395 \\
\hline
\end{tabular}

Table 7 - Original Item-Total Statistics for the IQ construct obtained from SPSS software. 
I repeated the above steps, until the $\alpha$ could not be further optimized. As a result, indicators IQI_1_R and IQI_3 (Table 9) were eliminated, and the final $\alpha$ for the IQ construct was 0.679 (Table 8). The IQ construct was based on Larcker et al.’s (1980) questionnaire items, which were grouped into two distinct constructs (i.e.: perceived importance and perceived usableness). The fact that I combined Larcker et al.’s (1980) constructs into one (i.e.: IQ) was likely the reason why the $\alpha$ remained below the acceptable threshold.

\section{Reliability Statistics}

\begin{tabular}{|r|r|r|}
\hline \multicolumn{1}{|c|}{ Cronbach's Alpha } & $\begin{array}{c}\text { Cronbach's Alpha Based } \\
\text { on Standardized Items }\end{array}$ & N of Items \\
\hline .679 & .692 & 5 \\
\hline
\end{tabular}

Table 8 - Final reliability statistics for the IQ constructs obtained from SPSS software.

Item-Total Statistics

\begin{tabular}{|l|r|r|r|r|r|}
\hline & $\begin{array}{c}\text { Scale Mean if } \\
\text { Item Deleted }\end{array}$ & $\begin{array}{c}\text { Scale Variance } \\
\text { if Item Deleted }\end{array}$ & $\begin{array}{c}\text { Corrected } \\
\text { Item-Total } \\
\text { Correlation }\end{array}$ & $\begin{array}{c}\text { Squared } \\
\text { Multiple } \\
\text { Correlation }\end{array}$ & $\begin{array}{c}\text { Cronbach's } \\
\text { Alpha if Item } \\
\text { Deleted }\end{array}$ \\
\hline IQU_3 & 16.1346 & 15.020 & .482 & .324 & .618 \\
IQU_4 & 16.2949 & 14.996 & .439 & .300 & .630 \\
IQU_1_R & 16.3974 & 12.331 & .490 & .297 & .602 \\
IQU_2_R & 17.7179 & 12.952 & .455 & .288 & .619 \\
IQI_2 & 16.0449 & 14.004 & .348 & .148 & .670 \\
\hline
\end{tabular}

Table 9 - Final Item-Total Statistics for the IQ construct obtained from SPSS software.

The above steps were also applied to improve the $\alpha$ of the other contructs:

- As a result, indicators WABS_5_R, WABS_6, and WABS_7 were eliminated, and the final $\alpha$ for the WABS construct was 0.888 . The next step was to verify the internal 
consistency of the WABS construct with a composite reliability analysis with the SmartPLS software. More information on this analysis will be provided later on.

- $\quad$ The final $\alpha$ for the WAAS construct was 0.864 .

- As a result, indicators WATS_4, and WATS_5 were eliminated, and the final $\alpha$ for the WATS construct was 0.904 .

- $\quad$ The final $\alpha$ for the DMS construct was 0.953 .

The next step was to verify the internal consistency of each one of the above mentioned constructs with a composite reliability analysis, using the SmartPLS software. More information on this analysis will be provided later on.

\section{(2) $\quad$ Create moderating variables with SPSS}

In order to determine how various combinations of skills could impact decision maker satisfaction, new moderating variables had to be created.

The first step was to create new variables that would represent the following three-way interactions (i.e.: moderating effects):

- IQ x WABS x WAAS $\rightarrow$ DMS

- IQ x WABS x WATS $\rightarrow$ DMS
- IQ x WAAS x WATS $\rightarrow$ DMS

- WABS x WAAS x WATS $\rightarrow$ DMS 
It should be noted that the process of optimizing the $\alpha$ also allowed for the reduction of the number of question items, and subsequently permitted the calculation of the above three-way interactions. In fact, a minimum of 1,225 (i.e.: the product sum of the initial number of question items pertaining to each mediators) would have been required to calculate these three-way interactions.

In order to create the above new variables, the values of all indicators pertaining to each construct had to be standardized to a mean of zero and variance of one (Chin et al., 1996). According to (Chin et al., 1996), “[s]tandardizing or centering the indicators helps avoid computational errors by lowering the correlation between the product indicators and their individual components.” (p. 26). Further, “[t]his approach would be reasonable for ordinal to interval level items such as Likert scaled attitude items.” (Chin et al., 1996, p. 26) After standardizing all indicators, I used the Compute Variable function of SPSS to create the product items that would compose the above mentioned four moderating variables. For instance: WAAS_1x IQI_1x WABS_1.

It should be noted that the below two-way interactions were not created in SPSS, as SmartPLS does offer that functionality:

- $\mathrm{IQ}$ x WABS $\rightarrow$ DMS

- $\quad$ IQ x WAAS $\rightarrow$ DMS

- $\quad$ IQ x WATS $\rightarrow$ DMS
- WABS x WAAS $\rightarrow$ DMS

- WABS x WATS $\rightarrow$ DMS

- $\quad$ WAAS x WATS $\rightarrow$ DMS 
Furthermore, the sample size prevented me from computing the following four-way interaction: IQ x WABS x WAAS x WATS $\rightarrow$ DMS. In fact, and as indicated by an error message in SmartPLS, a sample size of at least 240 participants (i.e.: the product sum of the number of indicators contained in each construct; 5, 4, 4, and 3 respectively) was required for such calculation. This represents a limitation that should be addressed by future research.

(3) Bootstrapping and composite reliability with SmartPLS

Bootstrapping is a resampling method, which can be used with PLS software (e.g.: SmartPLS), to determine the significance of direct and moderating effects (Chin et al., 1996). Henseler, et al. (2009) posited that Bootstrapping treats the observed sample as if it represents the population. The procedure creates a large, pre-specified number of bootstrap samples (e.g., 5,000). Each bootstrap sample should have [at least] the same number of cases as the original sample. Bootstrap samples are created by randomly drawing cases with replacement from the original sample. (p. 305)

For the purpose of this study, the number of bootstrap samples used was 5,000, as recommended by Hair et al. (2011). After running the bootstrapping report in SmartPLS, the following results were obtained: 


\begin{tabular}{|c|c|c|c|c|}
\hline & AVE & $\begin{array}{l}\text { Composite } \\
\text { Reliability }\end{array}$ & R Square & Cronbach's Alpha \\
\hline DMS & 0.8116 & 0.9627 & 0.5502 & 0.9535 \\
\hline IQ & 0.4205 & 0.7805 & 0 & 0.6923 \\
\hline IQ x WAAS & 0.1296 & 0.4147 & 0 & 0.8617 \\
\hline IQ $\times$ WABS & 0.1747 & 0.1519 & 0 & 0.8858 \\
\hline IQ $x$ WATS & 0.1917 & 0.2211 & 0 & 0.8759 \\
\hline WAAS & 0.7114 & 0.9075 & 0 & 0.8641 \\
\hline WAAS $x$ WATS & 0.6504 & 0.957 & 0 & 0.9534 \\
\hline WABS & 0.7463 & 0.9216 & 0 & 0.8884 \\
\hline WABS $\times$ WAAS & 0.5531 & 0.9509 & 0 & 0.9476 \\
\hline WABS $\times$ WATS & 0.5276 & 0.928 & 0 & 0.9201 \\
\hline WATS & 0.8408 & 0.9406 & 0 & 0.9053 \\
\hline IQ x WAAS x WATS & 0.2144 & 0.9405 & 0 & 0.952 \\
\hline IQ $x$ WABS $x$ WAAS & 0.1527 & 0.8962 & 0 & 0.9552 \\
\hline IQ x WABS x WATS & 0.1337 & 0.0109 & 0 & 0.9355 \\
\hline WABS $x$ WAAS $x$ WATS & 0.6346 & 0.9873 & 0 & 0.9867 \\
\hline
\end{tabular}

Table 10 - Bootstrapping report obtained from SmartPLS software.

As indicated in Table 10, Cronbach's alpha provided coefficients that were above the 0.700 threshold for all constructs, except for IQ. On the other hand, composite reliability was high and acceptable for IQ, and low and unacceptable for several constructs, most of which happened to be moderators. Since those moderators were actually the combination of product items, the fact that some of them appeared to lack internal consistency was not surprising. Based on Chin et al.’s (1996) recommendation, which was previously mentioned, the composite reliability coefficients were utilized, instead of the alphas, as measures of internal consistency. Thus, internal consistency was demonstrated for all direct effects, as well as for six moderating effects out of 10 .

\section{b) Unidimensionality}

As previously mentioned, unidimensionality refers to the homogeneity of the constructs. In other words, the reliability of the measurement instrument depends on not only the internal 
consistency of its constructs, but also the fact that factor loadings are higher on the construct that those factors belong to.

As per Appendix 11 (Cross factor loadings), the loadings of the factors pertaining to the following constructs were higher on their respective constructs:

\begin{tabular}{|l|l|}
\hline Direct effects & Moderating effects \\
\hline DMS & WAAS x WATS \\
\hline IQ & WABS x WATS \\
WAAS & \\
WABS & \\
WATS & \\
\multicolumn{2}{r}{ Table 11 - Homogeneous constructs. }
\end{tabular}

Also based on the data provided in Appendix 11 (Cross factor loadings), unidimensionality failed for the following constructs:

\begin{tabular}{|c|c|}
\hline Moderating effects & Notes \\
\hline IQ x WAAS & $\begin{array}{l}8 \text { factors out of } 20 \text { (i.e. } 40 \% \text { ) load higher on this construct } \\
\text { than they do on other constructs. }\end{array}$ \\
\hline IQ $x$ WABS & $\begin{array}{l}12 \text { factors out of } 20 \text { (i.e.: } 60 \% \text { ) load higher on this } \\
\text { construct than they do on other constructs. }\end{array}$ \\
\hline IQ x WATS & $\begin{array}{l}9 \text { factors out of } 15 \text { (i.e.: } 60 \% \text { ) load higher on this } \\
\text { construct than they do on other constructs. }\end{array}$ \\
\hline WABS x WAAS & $\begin{array}{l}15 \text { factors out of } 16 \text { (i.e.: } 94 \% \text { ) load higher on this } \\
\text { construct than they do on other constructs. }\end{array}$ \\
\hline IQ $x$ WAAS x WATS & $\begin{array}{l}40 \text { factors out of } 60 \text { (i.e.: } 67 \% \text { ) load higher on this } \\
\text { construct than they do on other constructs. }\end{array}$ \\
\hline IQ $x$ WABS $x$ WATS & $\begin{array}{l}16 \text { factors out of } 60 \text { (i.e.: } 27 \% \text { ) load higher on this } \\
\text { construct than they do on other constructs. }\end{array}$ \\
\hline IQ $x$ WABS $x$ WAAS & $\begin{array}{l}29 \text { factors out of } 80 \text { (i.e.: } 36 \% \text { ) load higher on this } \\
\text { construct than they do on other constructs. }\end{array}$ \\
\hline WABS x WAAS x WATS & $\begin{array}{l}41 \text { factors out of } 48 \text { (i.e.: } 85 \% \text { ) load higher on this } \\
\text { construct than they do on other constructs. }\end{array}$ \\
\hline
\end{tabular}


Unsurprisingly, all constructs that trigger direct effects proved to be homogeneous. On the other hand, and as revealed in Table 11 and Table 12, only two out of the nine moderators proved to be nonhomogeneous. The fact that all moderating constructs are composed of product items, might explain the lack of homogeneity in most of them. It is interesting to note that moderators “WABS x WAAS” and “WABS x WAAS x WATS” were almost homogenous, with respectively $94 \%$ and $85 \%$ of their factors loading on them. Knowing that these two constructs achieved internal consistency (Table 10), they could be considered as being reliable for future research.

All in all, reliability, which is measured through internal consistency and unidimensionality, was supported for all constructs that trigger direct effects, as well as some of the moderators:

\begin{tabular}{|ll|}
\hline Direct effects & \multicolumn{1}{c|}{ Moderating effects } \\
\hline DMS & WAAS $\times$ WATS \\
\hline IQ & WABS $\times$ WATS \\
\hline WAAS & WABS $\times$ WAAS \\
\hline WABS & WABS $\times$ WAAS $\times$ WATS \\
\hline WATS & \\
\hline
\end{tabular}

Table 13 - List of reliable constructs.

As previously mentioned, since internal consistency was proven for moderators “WABS x WAAS” and "WABS x WAAS x WATS", and that more than $85 \%$ of their factors loaded on them, I believe that these constructs can also be considered reliable. 


\section{Convergent validity}

Batra and Ahtola (1990) posited that convergent validity refers to "high shared variance among multiple measures of each construct, relative to the amount of variance due to measurement error” (p. 160). The authors also mentioned that convergent validity can be “measured through the ‘average variance extracted' [AVE] statistic of Fornell and Larker 1981” (p. 160). Further, Batra et al. (1990) indicated that 0.50 is the threshold for acceptable convergent validity.

As depicted in Table 10, the AVE was above the 0.50 threshold for all constructs, except

for:

- IQ

- IQ x WAAS

- IQ x WABS
- IQ x WAAS x WATS

- IQ x WABS x WAAS

- IQ x WABS x WATS

- IQ x WATS

As previously mentioned, the IQ construct was a combination of what used to be two distinct constructs. Further, the above mentioned two- and three-way interactions were all composed of product items from various constructs. Thus, the fact that AVE was not above the 0.50 threshold was not surprising. Also, it should be noted that the IQ construct might have been the cause of low AVE, as it was a common factor to all variables that obtained low AVE. In fact, the other moderating variables, which did not include IQ, recorded acceptable AVE. 


\section{Path significance and coefficients}

As revealed by Henseler et al. (2009), path coefficients refer to "[t]he estimated values for path relationships in the structural model [, and] should be evaluated in terms of sign, magnitude, and significance” (p. 303). In other words, those coefficients provide an indication of the magnitude of the effect that one variable has on another. Henseler et al. (2009) further argued that those effects are considered small, medium or large for the following respective values: 0.02, 0.15 and 0.35 . In addition to effect sizes, the significance of those paths also needs to be considered. As indicated by Hair et al. (2011), path significance can be obtained by computing tvalues, and "[c]ritical $t$-values for a two-tailed test are 1.65 (significance level $=10$ percent), 1.96 (significance level = 5 percent), and 2.58 (significance level = 1 percent).” (p. 145)

Let us now review both path significance and coefficients obtained from SmartPLS:

\begin{tabular}{|c|c|c|}
\hline Relationships & $\begin{array}{l}\text { T Statistics } \\
(\mid 0 / \text { STERR|) }\end{array}$ & $\begin{array}{c}\text { Path } \\
\text { coefficients }\end{array}$ \\
\hline IQ -> DMS & 3.5962 & 0.3099 \\
\hline IQ $x$ WAAS -> DMS & 0.8137 & -0.1313 \\
\hline IQ x WABS -> DMS & 0.8531 & 0.2119 \\
\hline IQ $x$ WATS -> DMS & 0.2594 & 0.0317 \\
\hline WAAS -> DMS & 2.9627 & 0.3277 \\
\hline WAAS $x$ WATS $->$ DMS & 0.0468 & 0.0062 \\
\hline WABS -> DMS & 0.1723 & 0.0193 \\
\hline WABS $x$ WAAS $->$ DMS & 1.0767 & 0.1685 \\
\hline WABS $x$ WATS -> DMS & 0.9284 & -0.161 \\
\hline WATS -> DMS & 1.4814 & 0.1285 \\
\hline IQ $x$ WAAS x WATS -> DMS & 0.2654 & 0.0463 \\
\hline IQ $x$ WABS $x$ WAAS $->$ DMS & 0.2623 & -0.059 \\
\hline IQ $x$ WABS $x$ WATS -> DMS & 0.1838 & -0.0425 \\
\hline WABS $x$ WAAS $x$ WATS $->$ DMS & 0.8615 & 0.1607 \\
\hline
\end{tabular}

Table 14 - Path significance and coefficients obtained with SmartPLS. 
As revealed in Table 14, only two constructs have significant effects on DMS at the 5 percent significance level: “IQ” and "WAAS”. These constructs triggered close to large effects at 0.3099 and 0.3277 respectively. Thus, “Decision maker satisfaction” is impacted by “Information quality” and "Web analytics team’s analytical skills”. As a reminder, “Information quality” was used as a control variable, as its direct effect on "Decision maker satisfaction” was expected. All other relationships were non-significant.

The results obtained from this study provide evidence that hypotheses H1 (The web analytics team's business skills will have a positive impact on decision maker satisfaction) and H3 (The web analytics team's technical skills will have a positive impact on decision maker satisfaction) are not supported (Figure 5). In fact, technical and business skills do not individually have significant impacts in the proposed WA context. On the other hand, hypothesis H2 (The web analytics team's analytical skills will have a positive impact on decision maker satisfaction) is supported, and confirms that analytical skills represent a key factor in the proposed WA context.

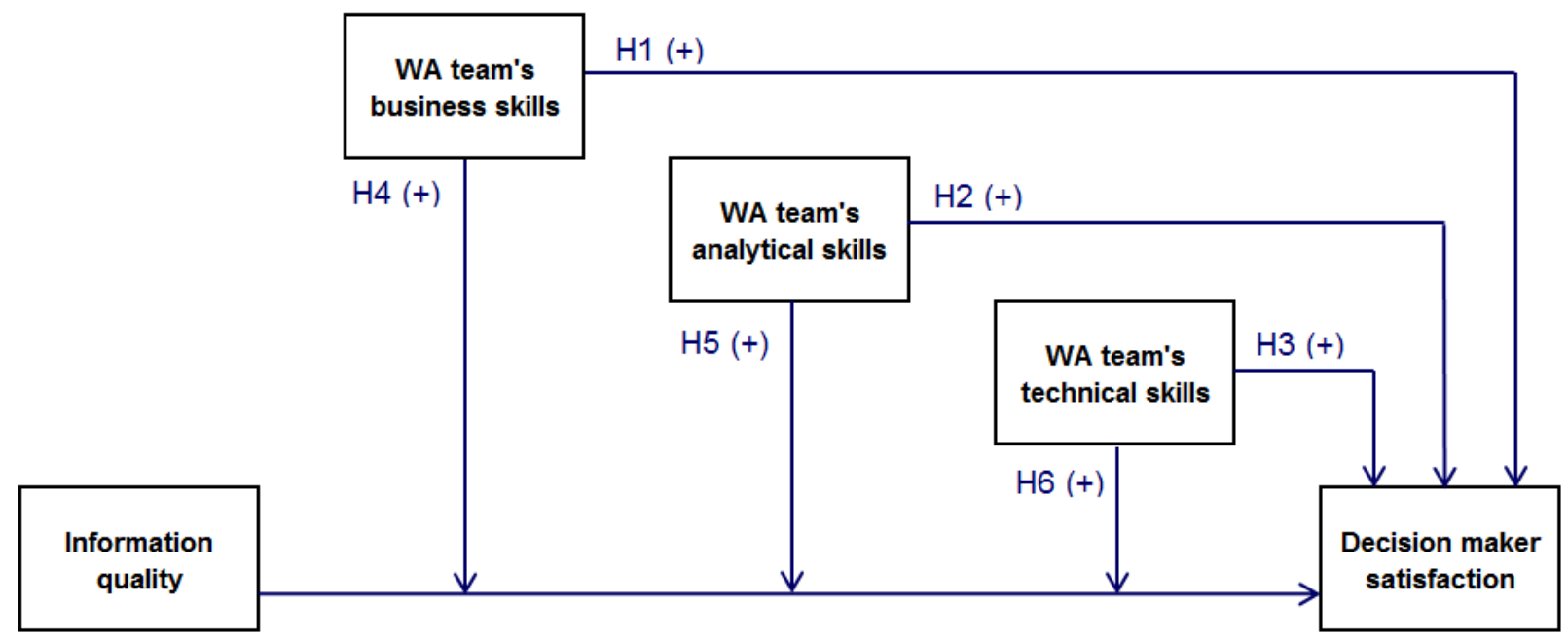

Figure 5 - Research model adapted from the updated D\&M IS success model (DeLone et al., 2002) 
This research project also focused on studying the impact that all possible combinations of the identified key WA team's skills might have in the proposed WA context. Thus, the results obtained did not provide any evidence that any combination of business, analytical and technical skills had a significant impact on either decision making satisfaction, or the relationship that exists between information quality and decision making satisfaction. Therefore, the remaining hypotheses are not supported:

- H4: The business skills of the web analytics team will moderate the relationship between the information provided by the WA tool and decision maker satisfaction, such that the lack of business skills will decrease decision maker satisfaction with the provided information.

- H5: The analytical skills of the web analytics team will moderate the relationship between the information provided by the WA tool and decision maker satisfaction, such that the lack of analytical skills will decrease decision maker satisfaction with the provided information.

- H6: The technical skills of the web analytics team will moderate the relationship between the information provided by the WA tool and decision maker satisfaction, such that the lack of technical skills will decrease decision maker satisfaction with the provided information. 


\section{Discussion of results}

\section{A. The hypotheses}

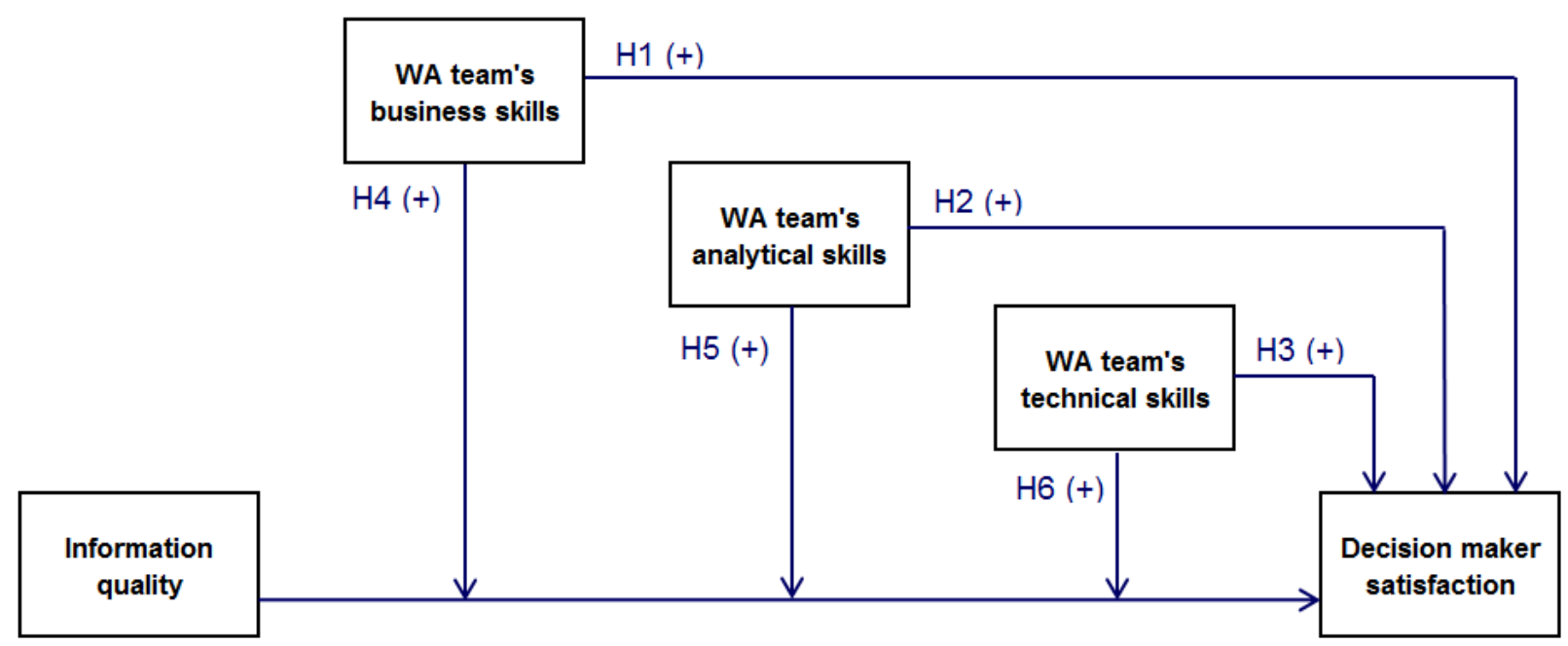

Figure 6 - Research model adapted from the updated D\&M IS success model (DeLone et al., 2002)

As indicated by the results, the hypothesis H2 (Figure 6) was the only one that was supported. Below we review the $\mathrm{H} 2$ hypothesis in greater detail, and look at the possible reasons why the other hypotheses were not supported.

\section{Three-way interactions}

As revealed by the data provided in Error! Reference source not found., all three-way interactions did not have a significant impact on decision maker satisfaction. Three-way interactions are challenging to interpret, because it is difficult to pinpoint the impact and contribution of each one of the variables that are part of the combination. Interestingly, the combination of all three personnel's skills does have a medium positive impact on decision 
maker satisfaction (i.e.: 0.1607). This indicates that the three skills are needed to a certain extent, even though their combined impact is deemed non-significant (i.e.: 0.8615).

\begin{tabular}{|crr|}
\hline Relationships & $\begin{array}{c}\text { T Statistics } \\
(\mid 0 / \text { STERR|) }\end{array}$ & $\begin{array}{c}\text { Path } \\
\text { coefficients }\end{array}$ \\
\hline IQ x WAAS x WATS -> DMS & 0.2654 & 0.0463 \\
\hline IQ x WABS x WAAS -> DMS & 0.2623 & -0.059 \\
\hline IQ x WABS x WATS -> DMS & 0.1838 & -0.0425 \\
\hline WABS x WAAS x WATS -> DMS & 0.8615 & 0.1607 \\
\hline
\end{tabular}

Table 15 - Path significance and coefficients for three-way interactions.

\section{The impact of analytical skills}

As previously mentioned, and for the purpose of this study, analytical skills were conceptualized as the skills related to the expertise in:

- Using data analysis techniques;

- Knowing and using statistics;

- Providing practical insights that decision makers can act on to support your decision making needs.

During data analysis, the following questionnaire item was dropped from the WAAS (i.e.: WA personnel's analytical skills) construct, because it negatively impacted the internal consistency of the construct: "WAAS_5* - The web analyst has very good statistical skills.” This was a question that I added to the set, as a means to evaluate whether statistical skills mattered to decision makers. However, and based on the data analysis, it seems that most participants did not consider that statistical skills pertained to analytical skills.

Let us now review the correlation between the construct and its indicators: 


\begin{tabular}{|lr|}
\hline WAAS & Outer loadings \\
\hline WAAS_1 & 0.7542 \\
\hline WAAS_2 & 0.8915 \\
\hline WAAS_3 & 0.8865 \\
\hline WAAS_4 & 0.8342 \\
\hline
\end{tabular}

Table 16 - Outer loadings for the WAAS construct provided by SmartPLS.

As a reminder, the question items listed in Table 16 were as follows:

1. WAAS_1 - Based on your previous experience, you would use the analytical skills of the web analyst in the future if you had a need.

2. WAAS_2 - You are satisfied with the level of web analysis expertise that you receive from the web analyst.

3. WAAS_3 - The web analyst delivers agreed-upon practical insights that you can act on to support your decision making needs.

4. WAAS_4* - The web analyst has very good analytical skills.

The data provided in Table 16 indicate that decision makers value:

1. The web data analysis expertise of their web data analysts;

2. The presence of agreed upon practical insights that allow them to make strategic decisions;

3. The analytical skills of their web data analysts;

4. The quality of the web data analysis provided by their web analysts.

Based on the above ranking, the web data analysis expertise is the indicator that impacts the latent variable the most. I leave it to future research studies to define web data analysis expertise, and determine its indicators. It would also be interesting to determine how decision maker would value the presence of unexpected, or not-agreed upon, practical insights in the reports that are provided to them. In fact, only reporting on agreed upon measures could prevent the discovery of critical factors that could help solve business issues. 


\section{The impact of business skills}

As previously mentioned, and for the purpose of this study, business skills were conceptualized as the skills related to:

- The understanding of business objectives and their importance to the organization;

- The consistent use of business terms to communicate effectively;

- The extent to which business problems are taken seriously;

- The extent to which a real interest in helping solve business problems is demonstrated;

- The response time to attend to request or business problems;

- The ability to communicate regular updates on a request.

During data analysis, the following questionnaire items were dropped from the WABS (i.e.: WA personnel's business skills) construct, because they negatively impacted the internal consistency of the construct:

- WABS_5_R - It often takes too long for the web analyst to communicate with you on your request.

- WABS_6 - The web analyst generally updates you on the status of your request for web analytics reports.

- WABS_7 - When you make a request for web analytics reports, the web analyst normally responds to your request in a timely manner.

The above questions focused on the ability to follow up in a timely manner on the requests placed by decision makers. 
Let us now review the correlation between the construct and its indicators:

\begin{tabular}{|lr|}
\hline WABS & Outer loadings \\
\hline WABS_1 & 0.8479 \\
\hline WABS_2 & 0.8889 \\
WABS_3 & 0.8437 \\
\hline WABS_4 & 0.8742 \\
\hline
\end{tabular}

Table 17 - Outer loadings for the WABS construct provided by SmartPLS.

As a reminder, the question items listed in Table 17 were as follows:

1. WABS_1 - The web analyst who you deal with understands your objectives and their importance to your organization.

2. WABS_2 - You feel that the web analyst can communicate with you in familiar business terms that are consistent.

3. WABS_3 - The web analyst takes your business problems seriously.

4. WABS_4 - The web analyst takes a real interest in helping you solve your business problems.

The data provided in Table 17 indicate that decision makers value:

1. The fact that the web data analyst understands and employs business terminologies;

2. The web data analyst's interest in helping solve business problems;

3. The understanding objectives and their importance;

4. The fact that the web data analyst takes business problems seriously.

Based on the above ranking, the ability to communicate by employing business terms, which decision makers are accustomed to, is key. Surprisingly, the results from this study show that business skills are not considered to have a significant impact, even though the construct has a close to low impact (i.e.: 0.0193 compared to the low-level threshold of 0.02) on decision maker 
satisfaction. These results are even more surprising when we consider the moderating impact of business skills in the proposed WA context.

\section{The impact of technical skills}

As previously mentioned, and for the purpose of this study, technical skills were conceptualized as the skills related to:

- Installing and configuring WA tools;

- The ability to quickly learn and work with new technologies as they become available;

- Programming skills.

During data analysis, the following questionnaire items were dropped from the WATS (i.e.: WA personnel's technical skills) construct, because they negatively impacted the internal consistency of the construct:

- WATS_4* - The web analyst has the ability to quickly learn and work with new technologies as they become available.

- WATS_5* - The web analyst has very good programming skills.

These were questions that I added to the set, as a means to evaluate whether programming skills, and the ability to keep up with advances in technology mattered to decision makers.

Let us now review the correlation between the construct and its indicators:

\begin{tabular}{|lr|}
\hline WAAS & Outer loadings \\
\hline WATS_1 & 0.9212 \\
\hline WATS_2 & 0.9359 \\
\hline WATS_3 & 0.8932 \\
\hline
\end{tabular}

Table 18 - Outer loadings for the WATS construct provided by SmartPLS. 
As a reminder, the question items listed in Table 18 were as follows:

- WATS_1 - When it comes to installing and configuring web analytics tools, you are confident in the technical skills of the web analyst.

- WATS_2 - The installation and configuration skills of the web analyst are adequate to your needs.

- WATS_3* - The web analyst has a very good technical knowledge.

The data provided in Table 18 indicate that decision makers primarily value installation and configuration skills, and then overall technical knowledge. However, the results from this study show that technical skills are not considered to have a significant impact (i.e.: 1.4814), even though the construct has a low to medium impact (i.e.: 0.1285) on decision maker satisfaction.

\section{Moderating effects}

When reviewing the results from this study, it is interesting to notice the following from the WA personnel's skills:

- Analytical skills:

o Have a low to medium negative effect (i.e.: -0.1313 ) on the relationship that exists between information quality and decision maker satisfaction. However, this effect is deemed non-significant (i.e.: 0.8137);

o Have a medium effect (i.e.: 0.1685 ) as moderators of the relationship that exists between business skills and decision maker satisfaction. However, this effect is deemed non-significant (i.e.: 1.0767). 
- Business skills:

o Have a strong effect (i.e.: 0.2119) on the relationship that exists between information quality and decision maker satisfaction. However, this effect is deemed non-significant (i.e.: 0.8531).

- Technical skills:

o Have a low effect (i.e.: 0.0317) on the relationship that exists between information quality and decision maker satisfaction. However, this effect is deemed non-significant (i.e.: 0.2594);

o Have a medium to high negative impact (i.e.: -0.161) on the relationship that exists between business skills and decision maker satisfaction. However, this effect is deemed non-significant (i.e.: 0.9284).

Let us review the correlations that exist between the latent variables of the proposed model:

\begin{tabular}{|lrrrrrr|}
\hline & DMS & \multicolumn{1}{c}{ IQ } & WAAS & WABS & WATS \\
\hline DMS & 1.0000 & 0 & 0 & 0 & 0 \\
\hline IQ & 0.5345 & 1.0000 & 0 & 0 & 0 \\
\hline WAAS & 0.5739 & 0.4174 & 1.0000 & 0 & 0 \\
\hline WABS & 0.3181 & 0.2934 & 0.6277 & 1.0000 & 0 \\
\hline WATS & 0.4461 & 0.2643 & 0.5063 & 0.3203 & 1.0000 \\
\hline
\end{tabular}

Table 19 - Variable correlations provided by SmartPLS

As revealed in X, the correlations among WAAS, WABS, WATS, and IQ range from medium to strong (i.e.: 0.2643 to 0.6277 ). These correlations could be the reasons why the above mentioned moderating effects have low to strong impacts, which are deemed non-significant. 


\section{B. The web analyst's skills}

All in all, the results obtained from this study support the evidence provided by Benbasat et al.'s (1980) research on the perceived and relative importance of generalist and specialist skills in the IS context. As previously mentioned, the authors identified generalist skills as being superior to specialist skills, and defined those generalist skills as managerial or organizational skills. On the other hand, specialist skills referred to technical skills. Thus, the fact that analytical skills are identified as the most important factor in the WA context, and technical skills are nonsignificant factors, partially corroborates Benbasat et al.’s (1980) findings, which applied to the larger IS context. However, my study provides evidence that business skills do not have a significant importance in the WA context. I believe that these findings encourage the following two courses of action:

1. There is a need to further define generalist skills, as it incorporates more than just managerial and organizational skills, especially in the WA context;

2. Analytical skills should be considered as generalist skills, as they are tied to business skills. In fact, analysis in the WA context is performed on the basis of business requirements, and therefore will only matter if they help address business issues.

\section{Sample size}

For the purpose of this study, a sample size of 85 participants was recommended, as indicated by the results of the a priori power analysis. With a power level set at $95 \%$ instead of $80 \%$ (as it was the case for my study), and a significance level set at 0.02 instead of 0.05 , a sample size of 153 participants would be required, all other parameters being equal (i.e.: effect 
size $=0.15$; predictors $=4$ ). Thus, based on my actual sample size was 156 and the characteristics of my model, I am confident that the probabilities of rejecting type I and II errors were at least 98\% and 95\% respectively. However, using a low population effect size (i.e.: 0.02) might have helped better evaluate the role of business skills in the WA context (as explained in the above section). Thus, with a low effect size, and other parameters equal to the ones used for my study (i.e.: power level $=0.8$; significance level $=0.05$ ), a sample size of 602 participants would have been required.

\section{Critical discussion on WA personnel's skills}

The main objective of this study was to provide an answer to the following question: What WA personnel skills (i.e.: business, analytical or technical) impact decision maker satisfaction? Based on the results obtained, we now know that decision makers' satisfaction is impacted the most by analytical skills. In fact, decision makers indicated that web data analysis expertise and the ability to provide agreed upon practical insights were the most valuable analytical skills. Thus, this study identifies the most important skills that WA personnel need to possess, when compared to business and technical skills. However, the results provided by this study do not intend to posit that only analytical skills are needed in the WA context. In fact, and as revealed in the literature, business, analytical and technical skills are critical factors in the WA context. As a matter of fact, web data analysis is guided by business requirements and needs, and therefore web data analysis expertise and business skills are both tied together. Furthermore, WA personnel need to know how to use WA tools in order to obtain the data required for their reports. Thus, technical skills are needed to navigate through the interface of WA tools; technical skills are therefore key factors that matter in the WA context. 
It would be safe to believe that all WA personnel possess business, analytical and technical skills. The contribution of this study arises in a situation where, for instance, a decision maker needs to know how to bring his web analytics reports to the next level. The answer to this business issue is a stronger focus on analytical skills, and more precisely on web data analysis expertise, and ability to provide agreed upon practical insights. This answer provides guidelines for various stakeholders involved in the WA field.

\section{E. Recruitment sources}

As mentioned in the data collection section, the following recruitment sources were leveraged: LinkedIn Canada groups, professional associations, and my personal network. Out of the 156 participants that were selected to be part of the final sample, only 50 of them came from LinkedIn. As a reminder, a unique message was posted on each one of the 36 selected groups, which had a total number of 764,901 members. Thus, each posted message brought an average of 1.4 participants. However, those 50 participants represented only $0.00654 \%$ of the total number of members of those groups. Therefore, even though the large pool of potential participants offered by those LinkedIn groups seemed very attractive, the actual conversation rate of those members into participants was very low. On the other hand, 76 out of the 156 participants came from my personal network, and were contacted through emails and Facebook messages. I sent a total of 117 emails and Facebook messages, and thus obtained a 65\% conversion rate. The remaining 30 participants came from professional associations, which webmasters or members in charge of marketing/communication took care of circulating the information concerning my survey. Individual emails (i.e.: approximately 200) were sent to each one of the U.S. and Canadian chapters of identified five associations. Although the total number of members 
belonging to those associations was not shared with me, participation from those associations was very low.

My recommendation as far as recruitment sources are concerned is to try to leverage established connections and contacts as much as possible. If social networks (e.g.: LinkedIn) are considered, then researchers must not forget that relationship nurturing is critical in that context. Thus, I might have been able to achieve a better participation rate from LinkedIn, by engaging with the selected groups beforehand. Concerning professional associations, it should be noted that most of them do not allow non-members to communicate directly with their members, and that the end of the summer is usually the time when members are surveyed, or hiatus are in place. I contacted most associations in August, and several of them did not want to overwhelm their members with too many surveys (i.e.: in addition to their own), or could not circulate my survey because they were on hiatus. I hope that this information will help other researchers. 


\section{Conclusions}

\section{A. Contributions}

As indicated by the list of industries that participants in the study belonged to, this research has wide applicability. Thus, various stakeholders are concerned with this study, as it provides them with the necessary tools and knowledge to help assess the importance of, and the skills that matter in the WA context.

Furthermore, this study aims to contribute to the IS success theoretical paradigm, by confirming its applicability to the web analytics discipline. One of the objectives of this research was to compare business, analytical and technical skills to determine to determine which one(s) prevails in the WA context. Based on the results obtained, this study shows that web data analysis expertise is critical in the WA context. Therefore, the unique contribution of the study resides in the fact that it demonstrates that among all WA key success factors identified in the literature, analytical skills are the most important skills to have.

All in all, the findings offered by this study indicate the direction that decision makers and academia, among other stakeholders, should follow when hiring or training web analytics personnel. In fact, the web data analysis expertise is a key determinant in the gain of actionable insights, and of decision making satisfaction.

As demonstrated, the strategic use of web data spans across industries, and represents an actual business challenge for organizations, business owners and other decision makers 
interested in obtaining relevant insights for the purpose of making strategic business decisions. Determining what to do with data in general is a current business concern that belongs to "big data” discussions; hence the relevance of the topic and purpose of this study.

Therefore, academia needs to ensure that students interested in careers in web analytics are adequately educated, so that their skills fit with actual business needs. Understanding the current state of web analytics learning and education, and its relevance toward the current job market, is beyond the scope of this study. However, the results from this research provide a strong indication of the importance of building a strong expertise in web data analysis, with a focus on the ability to provide agreed upon practical insights, to business decision makers. Furthermore, organizations, business owners, and decision makers at large need to ensure that their web data analysts possess the right skillset, for them to be able to gain the insights required for strategic decision making. The results from this study imply that processes related to hiring and training have to be adequately formatted and target the right audience. Determining the exact set of analytical skills and tools must vary from one business environment to another, as business objectives, resources, and needs differ from one organization to another. However, this determination falls beyond the scope of my research, and ought to be furthered by future research.

In the following section, I provide details about the limitations of my study. 


\section{B. Limitations}

Several limitations apply to this study. In fact, I decided not to focus on certain tangible and intangible factors, which might have directly or indirectly impacted my research model. The main factors that I recognised were as follows: the web analyst's background, decision maker's background, web analytics tools, and training and support provided by web analytics vendors.

\section{Web analyst's background:}

The objective of this research project was to understand how the current business, analytical, and technical skills impact the satisfaction of decision makers who rely on web data to make strategic decisions. Thus, this study did not focus on how those skills were obtained or developed, or can be furthered. For instance, the educational or professional background, or even personal interests of the web analyst could help frame how and why the web analyst obtained the current skills, which are used on the job. I acknowledge that it would be interesting to analyze these factors in order to determine which ones influence a web analyst's career path the most, and get a better understanding of the profile required for a specific aspect of a web analyst's job. However, I believe that the analysis of those factors would produce results that are distinct from the ones that I intended to obtain, and could be considered for a separate study.

\section{Decision maker's background:}

Once the web analytics reports are completed, they are provided to a decision maker who examines the report, searching for insights that will help formulate strategic business decisions. 
Thus, in addition to the web analyst's business, analytical, and technical skills, one might argue that it would also be important to consider the decision maker's communication skills,

knowledge of the web, WA tools, objectives of the business unit, and so on and so forth. This would be a valid point, as it would be primordial that the decision maker can clearly communicate what the needs are, understand the technology used and its limitations, knows how to leverage the provided insights in order to develop strategies, etc. I acknowledge that this would have been a valuable component to study, but it would have led me away from my main focus, which was the web analyst and the skills that are needed to satisfy decision makers.

\section{Web analytics tools:}

Each WA tool provides a unique user experience. Some require the user to have more technical knowledge than others do. The way the web data is gathered, computed, interpreted, and rendered varies from one tool to another. Thus, one might argue that the breadth of knowledge of various WA tools is an important factor, which might impact or influence the web analyst's skills and performance. Although I agree that a web analyst needs to possess at least an understanding of the main WA tools that are available on the market, I would argue that this focus differs from the one that I intended to apply for my study. Since I am interested in understanding how the web analyst's current skills allow for decision makers' satisfaction (and gain of actionable insights), I believe that it is safe to assume that the web analyst in question has a fairly good knowledge of the WA tool(s) that need to be used for the duty. In fact, considering the web analyst's knowledge of various WA tools would be useful if the objective of the research 
was to study how that knowledge could help the web analyst adjust to a switch from one WA tool to another. However, this was not the objective of my research.

\section{Training and support provided by web analytics vendors:}

One might argue that the training and support provided by WA vendors could affect the web analyst’s performance, and directly shape or impact skills. This would be a valid point, as the web analyst's current skills could be closely related to the level of service provided by WA vendors. However, I would argue that, even though training and support could benefit the web analyst technically-wise (i.e.: the utilization of the tool), the impact on business skills for instance would be fairly limited. In fact, I believe that the knowledge of the firm, and its internal structure and mechanisms, would be complicated to acquire from a third party. As far as data analysis goes, I believe that it would be the responsibility of the web analyst to perform adequate analyses, using data provided by both WA tools and other systems; this task would go beyond WA vendors' mandate, which is to help clients utilize their WA tools as effectively as possible. Thus, I leave it to future research projects to determine the impact of the training and support provided by WA vendors on the web analyst's skills.

Additional limitations apply to the data collection method. In fact, my questionnaire was directed at decision makers. Those decision makers are tasked with reporting on what they perceive the web analyst's business, analytical and technical skills to be. As mentioned by Ravichandran et al. (2005), I acknowledge that "[i]t is possible that the self-reported quality performance measures could be biased” (p. 405); thus, measuring a set of factors through the 
self-reported perception of a third party could result in biased results. However, I believe that the self-reported perception of those decision makers is reliable, because this perception will be based on the quality of the web analytics reports and actionable insights that are provided to them, as well as the interaction with the web analyst. Furthermore, being the recipients of the web analytics reports and actionable insights, they possess the authority necessary to influence how the web data is reported to them, and what is needed to gain the required actionable insights.

However, alternative data collection methods, which would allow researchers to directly measure the factors of interest, could be considered. One of them could be a questionnaire targeted at web analysts. This questionnaire could be developed in order to directly test and measure the web analysts' knowledge of the business they are involved in, as well as their analytical and technical skills. While this alternate data collection could generate unbiased results, it does have limitations. Firstly, a separate questionnaire would have to be created for decision makers. Secondly, researchers would have to find a way to correlate the results obtained from both questionnaires, in order to derive usable findings. This alternate method should however be considered for future research.

Finally, this study failed to analyze four-way interactions that were part of the proposed research model. As revealed in the literature, such analysis is quite rare, because of the complex calculations, and the sample size that it would require.

As revealed through the above-mentioned limitations, there are several angles and factors, which could have been considered for this study. However, and as explained above, I 
believe that the study of those factors, and alternate data collection and analysis methods, would be better suited to future research.

Let us now review future research directions.

\section{Future research directions}

\section{The definition of analytical skills and its moderating impact}

Participants completed the survey without being offered the exact definitions of the investigated factors (i.e.: business, analytical and technical skills) from the messages used to communicate with them (i.e.: emails, LinkedIn posts, etc.). Thus, some ambiguity might have impacted the results of this survey, as participants were left to define business, analytical and technical skills as they wished.

Furthermore, and based on the results obtained from this study, web data analysis expertise and the ability to provide agreed upon actionable insights, were key web data analysis skills that decision makers indicated as being the most valuable. Here as well, future research studies need to provide clear definitions for both, in order to help stakeholders pinpoint exactly what is takes to obtain or further web data analysis expertise, and the ability to provide agreed upon actionable insights. 


\section{The moderating effect of business skills}

Web data analysis is performed to provide answers to predefined business issues or questions. Thus, there is a link between business skills and analytical skills. Knowing how analytical skills are tied to the understanding of business requirements, it would be worth investigating why the combination of analytical and business skills (i.e.: WABS x WAAS) was found to be non-significant in this study.

For future research, the use of a larger sample size, or the removal of the product items that affected the internal reliability of the "IQ x WABS" and "WABS x WAAS" constructs, could be considered to help determine if these constructs are key factors impacting decision maker satisfaction.

\section{Understanding the "how" and the "why"}

The results provided in this study provide a solid basis for future research related to the management and training of WA personnel. As indicated above, several stakeholders and industries are concerned with the findings that I share. However, the main objective of this study was to provide answers to the "what": what skills matter in the WA context to satisfy decision makers. Thus, I believe that future research that would aim at providing answers to "how" and "why" questions would bring a valuable contribution to the WA field. Now that we know that the web analyst's analysis skills are key determinant of the decision maker's satisfaction, we need to understand not only how those skills can be acquired, furthered, or even identified, but also why business skills do not play a larger role in this context. 
In fact, certain key questions ought to be the concern of academia, research community, and the business world. For instance, students interested in careers in the WA field need to have access to adequate training that will prepare them for the "real world”. Knowing that web data analysis are performed to provide answers to business issues, the research community would be interested in determining why business skills do not play a larger role in the WA context. Furthermore, employees willing to either enter the WA field, or further their web data analysis skills need to have access to adequate training programs and resources. Here are several questions, which I believe will help guide future research:

How can web data analysis skills be acquired or furthered?

- How can current curriculums offered to students, or training programs offered to employees, be adapted to the needs of the job market?

- How can critical thinking, or any other areas that aim at fostering innovation, be used to complement training on data analysis techniques?

How can web data analysis skills be identified in students or employees?

- How to determine if one is meant for the web analyst role?

- How to properly train career advisors and human resources managers?

Why business skills do not play a larger role in the WA context?

- Why an understanding of the business is not a major factor in the WA context?

- Why business skills are not main skills that web analysts need to possess? 
I believe that the above questions would help complement the findings of my study, by providing an understanding of the necessary factors that may help analysis skills arise in the WA context.

\section{D\&M IS success model in the WA context}

For the purpose of this study, and for parsimony reasons, only two constructs from the original D\&M IS success model were kept (i.e.: Information quality, and Net benefits). I believe that the use of the entire IS success model, applied to the WA context (i.e.: inclusion of WA personnel's skills) would lead to interesting results. In fact, it would interesting to study how System quality, Service quality, Use, and User satisfaction impact decision maker satisfaction in the WA context, and what their relative importance is in that context. Furthermore, WA personnel's skills could be considered to be part of the Service quality construct, since these skills impact, and could help define, the quality of the service provided by WA personnel. I leave it to future research to provide empirical evidence. 


\section{References}

Agarwal, R., \& Prasad, J. (1997). The role of innovation characteristics and perceived voluntariness in the acceptance of information technologies. Decision Sciences, 28(3), 557-580.

American Marketing Association. (n.d.). Find a Professional Chapter. Retrieved June 17, 2012, from http://www.marketingpower.com/Community/_layouts/FindaChapter.aspx

Armstrong, C.P., \& Sambamurthy, V. (1999). Information technology assimilation in firms: The influence of senior leadership and it infrastructures. Information Systems Research, 10(4), 304-327.

Attard, R. M. (2004). IMPLEMENTING SUCCESSFUL E-BUSINESS INITIATIVES VIA ON-LINE CUSTOMER-RELATED WEB METRICS. Doctoral Dissertation, University of Malta.

Bagozzi, R. P. (1994). In: Principles of marketing research (pp. 317-385). Oxford: Blackwell.

Bailey, J. E., \& Pearson, S. W. (1983). Development of a tool for measuring and analyzing computer user satisfaction. Management Science, 29(5), 530-545.

Batra, R., \& Ahtola, O. (1991). Measuring the Hedonic and Utilitarian Sources of Consumer Attitudes. Marketing Letters, 2(2), 159-170.

Benbasat, I., Dexter, A. S., \& Mantha, R. W. (1980). Impact of organizational maturity on information system skill needs. MIS Quarterly, 4(1), 21-34.

Boynton, A. C., Zmud, R. W., \& Jacobs, G. C. (1994). The influence of IT management practice on IT use in large organizations. MIS Quarterly, 18(3), 299-318.

Brynjolfsson, E. (1996). The contribution of information technology to consumer welfare. 
Information System Research. 7 (3), 281-300.

Büchner, A. G., \& Mulvenna, M. D. (1998). Discovering internet marketing intelligence through online analytical web usage mining. ACM - ACM SIGMOD Record, 27(4).

Burrell, G., \& Morgan, G. (1979). Sociological paradigms and organisational analysis. Sage Publications London, 1-37.

Capon, N., Farley, J., Hoening, S., \& Lehmann, D. (1992). Profiles of product innovations among large U.S. manufacturers. Management Science, 38(2), 157-169.

Cheney, P. H., \& Lyons, N. R. (1980). Information systems skill requirements: A survey. MIS Quarterly, 4(1), 35-43.

Chin, W. W., Marcolin, B. L., \& Newsted, P. R. (1996). A PARTIAL LEAST SQUARES LATENT VARIABLE MODELING APPROACH FOR MEASURING INTERACTION EFFECTS: RESULTS FROM A MONTE CARLO SIMULATION STUDY AND VOICE MAIL EMOTION/ADOPTION STUDY. Paper presented at the PROCEEDINGS OF THE SEVENTEENTH INTERNATIONAL CONFERENCE ON INFORMATION SYSTEMS, Cleveland, Ohio.

Chin, W. W., \& Newsted, P. R. (1999). Structural equation modeling analysis with small samples using partial least squares. In: R. H. Hoyle (Ed.), Statistical strategies for small sample research (pp. 307-342). Thousand Oaks, CA: Sage.

Clemons. E. K., Reddi. S. P, \& Row, M. C. (1993). The impact of information technology on the organization of economic activity: The "move to the middle" hypothesis. Journal of Management Information Systems, 10(2), 9-35.

Cohen, J. (1988). Statistical power analysis for the behavioral sciences (2nd ed.). Hillsdale, NJ: Erlbaum. 
Cohen, J (1992). "A power primer". Psychological Bulletin, 112 (1), 155-159.

Coff, R. W. (1997). Human assets and management dilemmas: Coping with hazards on the road to resource-based theory. Academy of Management Review, 22(2), 374-402.

D'Ambra, J., \& Rice R. E. (2001). Emerging factors in user evaluation of the Worldwide Web. Information \& Management, 38(6), 373-384.

DeLone, W. H., \& McLean, E. R. (1992). Information systems success: The quest for the dependent variable. Information Systems Research, 3(1), 60-95.

DeLone, W. H., \& McLean, E. R. (2002). Information systems success revisited. Hawaii International Conference on System Sciences, Proceedings of the 35th

DeLone, W. H., \& McLean, E. R. (2003). The DeLone and McLean model of information systems success: A ten-year update. Journal of Management Information Systems, 19(4), 9-30.

Diamantopoulos, A., \& Winklhofer, H. (2001). Index construction with formative indicators: An alternative to scale development. Journal of Marketing Research. 38(2), 269-277.

Doll, W. J., \& Torkzadeh, G. (1998). Developing a multidimensional measure of systems use in an organizational context. Information \& Management. 33(4), 171-185.

Duncan, N. B. (1995). Capturing flexibility of information technology infrastructure: A study of resource characteristics and their measure. Journal of Management Information Technology, 12(2), 37-57.

Elezadi-Amoli, J., \& Earhoomand, A. E. (1996). A structural model of end user computing satisfaction and user performance. Information \& Management, 30(2), 65-73.

Faul, F., Erdfelder, E., Lang, A.-G., \& Buchner, A. (2007). G*Power 3: A flexible statistical power analysis for the social, behavioral, and biomedical sciences. Behavior Research 
Methods, 39, 175-191.

Feeny, D.F., Earl, M., \& Edwards, B. (1996). Organizational arrangements for IS: Roles of users and specialists. In M.J. Earl (ed.). Information Management: The Organizational Dimension. Oxford: Oxford University Press, 1996, pp. 231-246.

Firestone, W. A. (1987). Meaning in method: The rhetoric of quantitative and qualitative research. Educational Researcher, 16, 7, 16-21. Retrieved December 21, 2010, from http://www.elps.vt.edu/janosik/Firestone.pdf

Fornell, C. (1982). A second generation of multivariate analysis: An overview. In: C. Fornell (Ed.), A second generation of multivariate analysis (Vol. 1, pp. 1-21). New York, NY: Praeger.

Gelderman, M. (1998). The relation between user satisfaction, usage of information systems, and performance. Information \& Management, 34(1), 11-18.

Ginzberg, M. J. (1981). Early Diagnosis of MIS Implementation Failure: Promising Results and Unanswered Questions. Management Science, 27(4), 459-478.

Goodhue, D., Lewis, W., \& Thompson, R. (2012). Comparing PLS to Regression and LISREL: A Response to Marcoulides, Chin, and Saunders. MIS Quarterly, 36(3), 703-716.

Goodhue, D. L., \& Thompson, R. L. (1995). Task-technology fit and individual performance. MIS Quarterly, 19(2), 213-236.

Grover, G., Jeong, S. R., \& Segars, A. H. (1996). Information systems effectiveness: The construct space and patterns of application. Information \& Management. 31(4), 177-191.

Guimaraes, T, \& Igbaria, M. (1997). Client/server system success: Exploring the human side. Decision Sciences. 28(4), 851-875.

Hair, J. F., Ringle, C., \& Sarstedt, M. (2011). PLS-SEM: Indeed A Silver Bullet. Journal of 
Marketing Theory and Practice, 19(2), 139.

Hansmann, K. W., \& Ringle, C. M. (2004). SmartPLS Manual. Retrieved August 15, 2012, from

http://dychen1981.cai.swufe.edu.cn/software/Data\%20Analysis/smartPLS2/manual.pdf

Heinrichs, J. H., \& Lim, J. (2003). Integrating web-based data mining tools with business models for knowledge management. Decision Support Systems, 35(1), 103-112.

Henderson, J. C. (1990). Plugging into strategic partnerships: The critical is connection. Sloan Management Review, 31(3), 7-18.

Henseler, J., \& Chin, W. W. (2010). A Comparison of Approaches for the Analysis of Interaction Effects Between Latent Variables Using Partial Least Squares Path Modeling. Structural Equation Modeling, 82, 82-109.

Henseler, J., Ringle, C. M., \& Sinkovics, R. R. (2009). The use of partial least squares path modeling in international marketing, in Rudolf R. Sinkovics, Pervez N. Ghauri (ed.) New Challenges to International Marketing (Advances in International Marketing, Volume 20), Emerald Group Publishing Limited, pp.277-319

Hitt, L., \& Brynjolfsson, E. (1994). The three faces of IT value: Theory and evidence. In J.I. DeGross, S.L. Huff, and M.C. Munro (eds.). Proceedings of the International Conference on Information Systems. Atlanta, GA. Association for Information Systems, 263-278.

Hansmann, K. W., \& Ringle, C. M. (2004). SmartPLS Manual. Retrieved August 15, 2012, from http://dychen1981.cai.swufe.edu.cn/software/Data\%20Analysis/smartPLS2/manual.pdf IBM SPSS Statistics. (n.d.). IBM SPSS Statistics Editions. Retrieved November 14, 2012, from 
http://www-01.ibm.com/software/analytics/spss/products/statistics/

Igbaria, M., \& Tan, M. (1997). The consequences of the information technology acceptance on subsequent individual performance. Information \& Management, 32(3), 113-121.

Information Resource Management Association of Canada. (n.d.). Contact Names \& Addresses (Year 2012 - 2013). Retrieved May 31, 2012, from http://www.irmac.ca/php/board/contact.php

International Institute of Business Analysis. (n.d.). IIBA Chapters. Retrieved May 30, 2012, from http://www.iiba.org/IIBA/Chapters/IIBA_Website/Chapters_Pages/Chapters.aspx?hkey =1a14eec7-27c7-48fd-beea-91ba5764f286

Ishman, M. (1998). Measuring information system success at the individual level in crosscultural environments. In E.J. Garrity and G.L. Sanders (eds.). Information Systems Success Measurement. Hershey. PA: Idea Group, pp. 60-78.

Jiang. J. J., Klein. G., \& Carr, C. L. (2002). Measuring information systems service quality: SERVQUAL from the other side. MIS Quarterly, 26(2), 145-166.

Johnston, H. R., \& Carrico, S. R. (1988). Developing capabilities to use information strategically. MIS Quarterly, 12(1), 37-48.

Kaushik, A. (2007). Web Analytics: An Hour a Day. Indianapolis, IN: Wiley Publishing, Inc. Keen, P.G.W. (1980). Decision Support Systems: A Research Perspective. Center for Information System Research, 54. Retrieved November 5, 2011, from http://www.iiasa.ac.at/Publications/Documents/XB-80-512.pdf\#page=33

King, W. R., Grover, V., \& Hufnagel, E. H. (1989). Using information and information technology for sustainable competitive advantage: Some empirical evidence. 
Information and Management, 17(2), 87-93.

King, W. R., \& Teo, T. S. H. (1996). Key dimensions of facilitators and inhibitors for the strategic use of information technology. Journal of Management Information Systems, 12(4), 35-53.

Krijnen, W. P., Dijkstra, T. K., \& Gill, R. D. (1998). Conditions for factor (in) determinacy in factor analysis. Psychometrika, 63(4), 359-367.

Larcker, D. F., \& Lessig, V. P. (1980). Perceived usefulness of information: A psychometric examination. Decision Sciences, 11(1), 121-121. Retrieved from http://ezproxy.lib.ryerson.ca/login?url=http://search.proquest.com/docview/198163840? accountid=13631

Lee, D. M. S., Trauth, E. M., \& Farewell, D. (1995). Critical skills and knowledge requirements of IS professionals: A joint academic/industry investigation. MIS Quarterly, 19(3), 313340.

Lin, G. C., Wen, Z., Marsh, H. W., and Lin, H. S. (2010). Structural Equation Models of Latent Interactions: Clarification of Orthogonalizing and Double-Mean-Centering Strategies. Structural Equation Modeling, 17, 374-391.

LinkedIn. (n.d.). Online Marketing, Web Analytics, and E-commerce Group -WebAnalysts.Info. Retrieved March 26, 2011, from http://www.LinkedIn.com/groups?about=\&gid=2967\&trk=anet_ug_grppro

LinkedIn. (n.d.). SEO SEM Social Media (Search Engine Optimization \& Internet Marketing. Retrieved March 26, 2011, from http://www.LinkedIn.com/groups?about=\&gid=71207\&trk=anet_ug_grppro LinkedIn. (n.d.). Toronto Digital Marketing Professionals. Retrieved March 26, 2011, from 
http://www.LinkedIn.com/groups?about=\&gid=62937\&trk=anet_ug_grppro

Livari, J. (2005). An Empirical Test of the DeLone-McLean Model of Information Systems Success. Database for Advances in Information Systems, 36(2).

Lumsden, J. and Morgan, W. (2005). Online-Questionnaire Design: Establishing Guidelines and Evaluating Existing Support, in Proceedings of the 16th Annual International Conference of the Information Resources Management Association (IRMA'2005), San Diego, California, USA, 15-18 May, pp. 407 - 410

Mahmood, M. A., \& Soon, S. K. (1991). A comprehensive model for measuring the potential impact of information technology on organizational strategic variables. Decision Sciences, 22(4), 869-897.

Marcoulides, G. A., Chin, W. W., \& Saunders, C. (2012). WHEN IMPRECISE STATISTICAL STATEMENTS BECOME PROBLEMATIC: A RESPONSE TO GOODHUE, LEWIS, AND THOMPSON1. MIS Quarterly, 36(3), 717-728.

Marketing Research and Intelligence Association. (n.d.). Contact us - Board of directors. Retrieved May 31, 2012, from http://www.mria-arim.ca/CONTACT/Directors.asp Mooney, J. G., Gurbaxani, V., \& Kraemer, K. L. (1996). A process oriented framework for assessing the business value of information technology. DATA BASE for Advances in Information Systems, 27(2), 68-81.

National Retail Federation. (n.d.). Shop.org Staff and Contact information. Retrieved June 17, 2012, from http://www.nrf.com/modules.php?name=Pages\&sp_id=145\&pmenu_id=1\&mn_type=1

Nelson, K. M., \& Cooprider, J. G. (1996). The contribution of shared knowledge to is group performance. MIS Quarterly, 20(4), 409-432. 
Nidumolu, S. R., \& Knotts, G. W. (1998). The effects of customizability and reusability on perceived process and competitive performance of software firms. MIS Quarterly, 22(2), 105-137.

Park, J., Kim, J., \& Koh, J. (2010). Determinants of continuous usage intention in web analytics services. Electronic Commerce Research and Applications, 9(1), 61-72.

Pefanis Schlee, R., \& Harich, K. (2010). Knowledge and skill requirements for marketing jobs in the 21st century. Journal of Marketing Education, 32(3), 341-352.

Peterson, T. E. (2009). Competing on web analytics. Journal of Direct, Data and Digital Marketing Practice, 10(3), 214.

Phippen, A., Sheppard, L., \& Furnell, S. (2004). A practical evaluation of web analytics. Internet Research, 14(4), 284-293.

Pitt. L. F., Watson, R. T., \& Kavan. C. B. (1995). Service Quality: A Measure of Information Systems Effectiveness. MIS Quarterly, 19(2), 173-188.

Powell, T. C., \& Dent-Micallef, A. (1997). Information technology as competitive advantage: The role of human, business, and technology resources. Strategic Management Journal, 18(5), 375-405.

Premkumar, G., \& King W. R. (1994). The evaluation of strategic information system planning. Information \& Management, 26(6), 327-340.

Ravichandran, T, \& Lertwongsatien, C. (2000a). Strategic implications of information systems resources and capabilities: A competence-based model. In M. Goul, P. Gray, and H.M. Chung (eds.). Proceedings of the 2000 Americas Conference on Information Systems. Atlanta: Association for Information Systems, pp. 536-538.

Ravichandran, T, \& Rai, A. (2000b). Quality management in systems development: An 
organizational system perspective. MIS Quarterly, 24(3), 381-416.

Ravichandran, T., \& Lertwongsatien, C. (2005). Effect of information systems resources and capabilities on firm performance: A resource-based perspective. Journal of Management Information Systems, 21(4), 237.

Rockart, J. R, \& Short, J. (1989). IT in the 1990s: Managing organizational interdependence. Sloan Management Review, 30(2), 7-17.

Sabherwal, R. (1999). The relationship between information systems planning sophistication and information system success: An empirical assessment. Decision Sciences, 30(1), 137-167.

Sabherwal, R., \& King, W. R. (1992). Decision Processes for Developing Strategic Applications of Information Systems: A Contingency Approach. Decision Sciences, 23(4), 917-943.

Sabherwal, R., Jeyaraj, A., \& Chowa, C. (2006). Information system success: Individual and organizational determinants. Management Science, 52(12), 1849.

Sanders, G. L., \& Courtney, J. F. (1985). A field study of organizational influencing DSS success. MIS Quarterly, 9(1), 77-93.

Schultz, R.L. \& Slevin, D.P. (1975). Implementation and Organizational Validity: An Empirical Investigation. In Implementing Operations Research/Management Science, Schultz, R. L., \& Slevin, D. P. (eds.), American Elsevier, New York, New York, 1975, pp. 153-182

Segars, A. H., \& Grover, V. (1998). Strategic information systems planning success: An investigation of the construct and its measurement. MIS Quarterly, 22(2), 139-163.

Segars, A. H., Grover, V., \& Teng, J. T. C. (1998). Strategic information systems planning: Planning system dimensions, internal coalignment, and implications for planning 
effectiveness. Decision Sciences, 29(2), 303-345.

Sen, A., Dacin, P. A., \& Patticis, C. (2006). Current trends in web data analysis. Communications of the ACM, 49(11), 85-91.

Sethi, V., \& King, W. R. (1994). Development of measures to assess the extent to which an information technology application provides competitive advantage. Management Science, 40(12), 1601.

Shop.org. (n.d.). Shop.org Staff and Contact information. Retrieved June 17, 2012, from http://www.shop.org/web/guest/about/stafflist

Schmitt, N. (1996). Uses and Abuses of Coefficient Alpha. Psychological Assessment, 8(4), 350-353.

SurveyMonkey. (n.d.). Homepage. Retrieved March 26, 2011, from http://www.surveymonkey.com/

SurveyMonkey. (n.d.). Ready to Create Surveys Like a Pro?. Retrieved March 26, 2011, from http://www.surveymonkey.com/Home_Pricing2.aspx

Teo, T. S. H., \& King, W. R. (1997). Integration between business planning and information systems planning: An evolutionary-contingency perspective. Journal of Management Information Systems, 14(1), 185-214.

Toronto Area SAS Society. (n.d.). Contact Us. Retrieved May 15, 2012, from http://www.torsas.ca/page11.php

Turetken, O., Jain, A., Quesenberry, B., \& Ngwenyama, O. (2011). An empirical investigation of the impact of individual and work characteristics on telecommuting success. Professional Communication, IEEE Transactions on, 54(1), 56-67.

Venkatraman, N. (1994). IT-Enabled business transformation: From automation to business 
scope redefinition. Sloan Management Review, 35(2), 73-87.

Waisberg, D., \& Kaushik, A. (2009a). Web analytics 2.0: Empowering customer centricity. SEMJ.Org, 2(1).

Waisberg, D., \& Kaushik, A. (2009b). Web analytics 2.0: Empowering customer CentricityPart II. SEMJ.Org, 2(2).

Web Analytics Association. (n.d.). Homepage. Retrieved March 26, 2011, from http://www.webanalyticsassociation.org/

Web Analytics Association. (n.d.). Your Membership in the WAA. Retrieved March 26, 2011, from http://www.webanalyticsassociation.org/?page=membership

Welsch, G .M. (1981a). A Multidimensional Measure of Perceived Decision Support System Implementation Success. DSS-81 Transactions, Atlanta, Georgia.

Wold, H. O. (1985). Partial least squares. In: S. Kotz \& N. L. Johnson (Eds), Encyclopedia of statistical sciences (Vol. 6, pp. 581-591). New York, NY: Wiley.

Zoomerang. (n.d.). Sign up for Zoomerang today!. Retrieved March 26, 2011, from http://www.zoomerang.com/signup/

Weischedel, B., Matear, S., \& Deans, K. R. (2005). A qualitative approach to investigating online strategic decision making. Qualitative Market Research: An International Journal, 8(1), 61-76. 


\section{Appendix 1 (IS success measures)}

\begin{tabular}{|c|c|c|c|}
\hline $\begin{array}{l}\text { Factors and } \\
\text { success measure }\end{array}$ & $\begin{array}{l}\text { Research } \\
\text { streams }\end{array}$ & Empirical studies & Theoretical studies \\
\hline \multirow[t]{2}{*}{ Information quality } & IS success & $\begin{array}{l}\text { Agarwal et al.(1997); Brynjolfsson } \\
\text { (1996); Clemons et al. (1993); Hitt et } \\
\text { al. (1994); Livari (2005); Pitt et al. } \\
\text { (1995) }\end{array}$ & $\begin{array}{l}\text { DeLone et al. } \\
\text { (1992); DeLone et } \\
\text { al. (2002); Waisberg } \\
\text { et al. (2009a) }\end{array}$ \\
\hline & WA & Park et al. (2010) & None \\
\hline \multirow[t]{2}{*}{ System quality } & IS success & $\begin{array}{l}\text { Agarwal et al.(1997); Brynjolfsson } \\
\text { (1996); Clemons et al. (1993); } \\
\text { Goodhue et al. (1995); Hitt et al. } \\
\text { (1994); Livari (2005); Pitt et al. } \\
\text { (1995) }\end{array}$ & $\begin{array}{l}\text { DeLone et al. } \\
\text { (1992); DeLone et } \\
\text { al. (2002); } \\
\text { Sabherwal et al. } \\
(2006)\end{array}$ \\
\hline & WA & None & Peterson (2008) \\
\hline \multirow{3}{*}{ Service quality } & IS success & $\begin{array}{l}\text { Agarwal et al.(1997); Brynjolfsson } \\
\text { (1996); Clemons et al. (1993); } \\
\text { Grover et al. (1996); Hitt et al. } \\
\text { (1994); Livari (2005); Pitt et al. } \\
\text { (1995) }\end{array}$ & DeLone et al. (2002) \\
\hline & RBV & $\begin{array}{l}\text { Feeny et al. (1996); Henderson } \\
\text { (1990); Lee et al. (1995); Nelson et } \\
\text { al. (1996); Ravichandran et al. } \\
\text { (2000a); Ravichandran et al. } \\
\text { (2000b); Ravichandran et al. (2005) }\end{array}$ & \\
\hline & WA & Park et al. (2010) & None \\
\hline \multirow[t]{2}{*}{ Use } & IS success & $\begin{array}{l}\text { Agarwal et al.(1997); Bailey et. al } \\
\text { (1983); Brynjolfsson (1996); } \\
\text { Clemons et al. (1993); D'Ambra et al. } \\
\text { (2001); Doll et al. (1998); Etezadi- } \\
\text { Amoli et al. (1996); Gelderman et al. } \\
\text { (1998); Goodhue et al. (1995); } \\
\text { Grover et al. (1996); Guimaraes et } \\
\text { al. (1997); Hitt et al. (1994); Igbaria } \\
\text { et al. (1997); Ishman et al. (1998); } \\
\text { Jiang et al. (1999); Livari (2005); } \\
\text { Park et al. (2010); Pitt et al. (1995) }\end{array}$ & $\begin{array}{l}\text { DeLone et al. } \\
\text { (1992); DeLone et } \\
\text { al. (2002) }\end{array}$ \\
\hline & WA & Park et al. (2010) & None \\
\hline \multirow[t]{3}{*}{ User satisfaction } & IS success & $\begin{array}{l}\text { Agarwal et al.(1997); Brynjolfsson } \\
\text { (1996); Clemons et al. (1993); } \\
\text { D'Ambra et al. (2001); Gelderman et } \\
\text { al. (1998); Ginzberg (1981); } \\
\text { Guimaraes et al. (1997); Hitt et al. } \\
\text { (1994); Jiang et al. (1999); Livari } \\
\text { (2005); Pitt et al. (1995) }\end{array}$ & $\begin{array}{l}\text { DeLone et al. } \\
\text { (1992); DeLone et } \\
\text { al. (2002) }\end{array}$ \\
\hline & DSS & $\begin{array}{l}\text { Ginzberg (1981); Sanders (1985); } \\
\text { Schultz et al. (1975); Welsh (1981a) }\end{array}$ & None \\
\hline & WA & Park et al. (2010) & None \\
\hline Net benefits & IS success & $\begin{array}{l}\text { Bailey et al. (1983); Clemons et al. } \\
\text { (1993); D'Ambra et al. (2001); Doll et } \\
\text { al. (1998); Gelderman et al. (1998); } \\
\text { Grover et al. (1996); Guimaraes et } \\
\text { al. (1997); Hitt et al. (1994) }\end{array}$ & DeLone et al. (2002) \\
\hline
\end{tabular}

Table 20 - IS success measure and factors as per the D\&M IS success model (DeLone et al., 2002) 
Appendix 2 (Questionnaire items)

\section{Notes:}

- Items identified with a number sign (\#) were measured with a seven-point Likert scale, which went from "None" (i.e.: 1) to "All” (i.e.: 7). Items with a "R" denoted negative statements or questions, which scale needed to be reversed.

- It should be noted that the questions marked with an asterisk (*), in the INFORMATION QUALITY (IQ), WEB ANALYST'S ANALYTICAL SKILLS (WAAS), and WEB ANALYST'S TECHNICAL SKILLS (WATS) portions of the questionnaire, indicated questions that I added to the original sets, because of the specific character of my study.

\section{BACKGROUND INFORMATION}

1. Your occupation:

[Please select one answer from the choices below]

- Owner

- C-level executive

- Director

- Senior manager

- Manager

- Other: please specify

2. What area(s) do you specialise in?

[Please choose all that apply]

- Information security

- Information systems

- Information Technology

- Online marketing

- Search Engine Optimisation

- Search Marketing

- Web analytics

- Other: please specify

3. Your industry:

[Please select one answer from the choices below]

- Accounting

- Consumer business

- Finance

- Financial Services

- Media

- Professional services 
- Public sector

- Technology

- Telecommunications

- Other: please specify

4. Number of web analysts from whom you receive reports: [Please select one answer from the choices below]

- $1-3$

- $4-6$

- $7-9$

- More than 10

5. What web analytics tool(s) is/are currently utilised at your company? [Please choose all answers that apply]

- AT Internet

- IBM Coremetrics

- Google Analytics

- Omniture

- IBM Unica

- WebTrends

- Yahoo! Web Analytics

- Other: please specify

\section{INFORMATION QUALITY (IQ)}

6. IQI_1_R - It would be extremely difficult to gain practical insights that you can act on without at least the information obtained from your organization's web analytics tool.

7. IQI_2 - The information obtained from your organization's web analytics tool is sufficient to make a specific decision.

8. IQI_3\# - What portion of the information presented is essential for or instrumental in making a specific decision?

9. IQU_1_R - In order to use the information obtained from your organization's web analytics tool to make a specific decision, extremely complex recalculations or adjustments are necessary.

10. IQU_2_R* - Additional analysis must be performed in order to use the information obtained from your organization's web analytics tool to make a specific decision.

11. IQU_3\# - What portion of the information obtained from your organization's web analytics tool is in a format that allows you to make a specific decision?

12. IQU_4\# - What portion of the information obtained from your organization's web analytics tool is interpretable, without any recalculation or adjustment, or further analysis, to make a specific decision? 


\section{WEB ANALYST'S BUSINESS SKILLS (WABS)}

13. WABS_1 - The web analyst who you deal with understands your objectives and their importance to your organization.

14. WABS_2 - You feel that the web analyst can communicate with you in familiar business terms that are consistent.

15. WABS_3 - The web analyst takes your business problems seriously.

16. WABS_4 - The web analyst takes a real interest in helping you solve your business problems.

17. WABS_5_R - It often takes too long for the web analyst to communicate with you on your request.

18. WABS_6 - The web analyst generally updates you on the status of your request for web analytics reports.

19. WABS_7 - When you make a request for web analytics reports, the web analyst normally responds to your request in a timely manner.

\section{WEB ANALYST'S ANALYTICAL SKILLS (WAAS)}

20. WAAS_1 - Based on your previous experience, you would use the analytical skills of the web analyst in the future if you had a need.

21. WAAS_2 - You are satisfied with the level of web analysis expertise that you receive from the web analyst.

22. WAAS_3 - The web analyst delivers agreed-upon practical insights that you can act on to support your decision making needs.

23. WAAS_4* - The web analyst has very good analytical skills.

24. WAAS_5* - The web analyst has very good statistical skills.

\section{WEB ANALYST'S TECHNICAL SKILLS (WATS)}

25. WATS_1 - When it comes to installing and configuring web analytics tools, you are confident in the technical skills of the web analyst.

26. WATS_2 - The installation and configuration skills of the web analyst are adequate to your needs.

27. WATS_3* - The web analyst has a very good technical knowledge.

28. WATS_4* - The web analyst has the ability to quickly learn and work with new technologies as they become available.

29. WATS_5* - The web analyst has very good programming skills. 


\section{DECISION MAKER SATISTACTION (DMS)}

30. DMS_1 - The information provided by your organization's web analytics tool has enabled you to gain practical insights that you can act on.

31. DMS_2 - As a result of the information provided by your organization's web analytics tool, you are better able to set your priorities in decision making.

32. DMS_3 - The use of information provided by your organization's web analytics tool has enabled you to present your arguments more convincingly.

33. DMS_4 - The information provided by your organization's web analytics tool has improved the quality of the decisions you make in this organization.

34. DMS_5 - As a result of the information provided by your organization's web analytics tool, the speed at which you gain insights has increased.

35. DMS_6 - As a result of the information provided by your organization's web analytics tool, more relevant insights has been available to you for decision making.

36. DMS_7 - The information provided by your organization's web analytics tool has led you to greater use of analytical aids in your decision making.

\section{Information about you:}

37. Highest degree, or diploma, that you earned:

[Please specify the area of concentration]

- PhD.: please specify the area of concentration

- Master's: please specify the area of concentration

- Bachelor's: please specify the area of concentration

- College diploma: please specify the area of concentration

38. I wish to be entered in the draw, and/or receive a soft copy of the academic paper that reports on the results of this research: Yes or No

Please note that if you have answered "Yes" to question 38, question 39 is mandatory.

\section{Personal information:}

- First name:

- Last name:

- Email address:

40. I wish to: [Please select all answers that apply]

- Be entered in the draw for a chance to win one (1) of two (2) new iPads

- Receive a soft copy of the academic paper that reports on the results of this research 


\section{Appendix 3 (Original questionnaire items)}

Sanders et al.’s (1985) DSS success factors:

\section{Overall Satisfaction*}

- I have become dependent on DSS.

- As a result of DSS, I am seen as more valuable in this organization.

- I personally benefitted from the existence of DSS in this organization.

- I have come to rely on DSS in performing my job.

- All in all I think that DSS is an important system for this organization.

- DSS is extremely useful.

\section{Decision-Making Satisfaction}

- Utilization of DSS has enabled me to make better decisions.

- As a result of DSS, I am better able to set my priorities in decision making.

- Use of data generated by DSS has enabled me to present my arguments more convincingly.

- DSS has improved the quality of decisions I make in this organization.

- As a result of DSS, the speed at which I analyze decisions has increased.

- As a result of DSS, more relevant information has been available to me for decision making.

- DSS has led me to greater use of analytical aids in my decision making.

Figure 7 - DSS success factors for Overall Satisfaction and Decision-Making Satisfaction (Sanders et al., 1985) 


\section{Goodhue et al.’s (1995) Technology-to-Performance Chain factors for relationship with}

\section{users measures:}

Relationship with Users

IS UNDERSTANDING OF BUSINESS: (How well does IS understand my unit's business mission and its relation to corporate objectives?)

UNBS1 - The IS people we deal with understand the day-to-day objectives of my work group and its mission within our company.

UNBS2 - My work group feels that IS personnel can communicate with us in familiar business terms that are consistent.

IS INTEREST AND DEDICATION: (to supporting customer business needs.)

INDN1 - IS takes my business group's business problems seriously.

INDN2 - IS takes a real interest in helping me solve my business problems.

RESPONSIVENESS: (Turnaround time for a request submitted for IS service.)

RESP1 - It often takes too long for IS to communicate with me on my requests.

RESP2 - I generally know what happens to my request for IS services or assistance or whether it is being acted upon.

RESP3 - When I make a request for service or assistance, IS normally responds to my request in a timely manner.

CONSULTING: (Availability and quality of technical and business planning assistance for systems)

CONS1 - Based on my previous experience I would use IS technical and business planning consulting services in the future if I had a need.

CONS2 - I am satisfied with the level of technical and business planning consulting expertise I receive from IS

IS PERFORMANCE: (How well does IS keep its agreements?)

PERF2 - IS delivers agreed-upon solutions to support my business needs

Figure 8 - Technology-to-Performance Chain factors for relationship with users measures (Goodhue et al., 1995)

Ravichandran et al.'s (2005) IS success measures:

Table A1. Factor Analysis of IS Human Resource Skills and Specificity

\begin{tabular}{|c|c|c|}
\hline Items & $\begin{array}{l}\text { IS human } \\
\text { resource } \\
\text { specificity }\end{array}$ & $\begin{array}{l}\text { IS personnel } \\
\text { skill }\end{array}$ \\
\hline $\begin{array}{l}\text { Our IS staff has very good technical knowledge; they are one of the best technical groups an IS } \\
\text { department could have. }\end{array}$ & 0.074 & 0.830 \\
\hline Our IS staff has the ability to quickly learn and apply new technologies as they become available. & 0.155 & 0.863 \\
\hline Our IS staff has the skills and knowledge to manage IT projects in the current business environment. & 0.418 & 0.605 \\
\hline $\begin{array}{l}\text { Our IS staff has the ability to work closely with customers and maintain productive user or client } \\
\text { relationships. }\end{array}$ & 0.389 & 0.620 \\
\hline $\begin{array}{l}\text { Our IS staff has excellent business knowledge; they have a deep understanding of the business priorities } \\
\text { and goals of our organization. }\end{array}$ & 0.719 & 0.253 \\
\hline Our IS staff understands our firm's technologies and business processes very well. & 0.713 & 0.311 \\
\hline Our IS staff understands our firm's procedures and policies very well. & 0.779 & 0.200 \\
\hline Our IS staft is aware of the core beliefs and values of our organization. & 0.612 & 0.159 \\
\hline Our iS staff often does not know who are responsible for important tasks in this organization. (R) & 0.659 & 0.034 \\
\hline Our IS staff is conversant with the routines and methods used in the IS department. & 0.553 & 0.359 \\
\hline
\end{tabular}

Notes: $(\mathrm{R})$ is reverse-coded. Item loadings greater than 0.50 are indicated in boldface.

Figure 9 - IS success measures (Ravichandran et al., 2005) 
Larcker et al.’s (1980) Information usefulness measures:

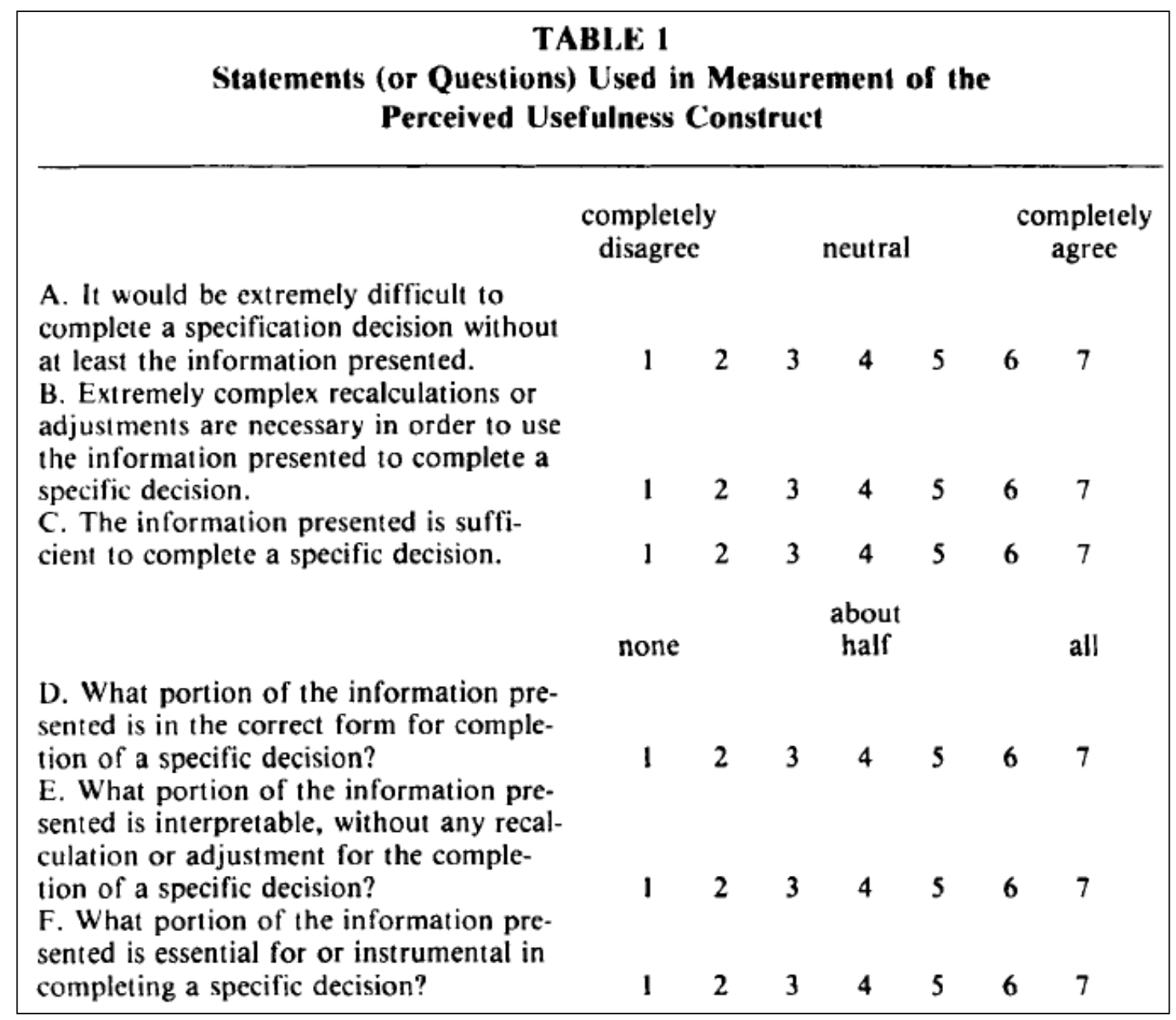

Figure 10 - Information usefulness measures (Larcker et al., 1980) 


\section{Appendix 4 (Recruitment sources: LinkedIn groups)}

\begin{tabular}{|c|c|c|}
\hline Name & Contacted on & $\begin{array}{l}\text { Number of } \\
\text { members on } \\
\text { contacted date }\end{array}$ \\
\hline A/B Testing and Multivariate Testing & 15-Apr-12 & 1,296 \\
\hline Advanced Web Metrics with Google Analytics by Brian Clifton & 2-May-12 & 2,073 \\
\hline analytics alliance- the unassociation & 15-Apr-12 & 142 \\
\hline Analytics Community & 15-Apr-12 & 417 \\
\hline AT Internet - web analytics and online intelligence community & 10-May-12 & 266 \\
\hline AWA - Advanced Web Analytics & 15-Apr-12 & 1,798 \\
\hline Business Analytics & 15-May-12 & 28532 \\
\hline Business Intelligence Group & 15-May-12 & 46,390 \\
\hline Community Managers (Social Media Managers) & 15-Apr-12 & 2,441 \\
\hline Data Mining, Statistics, and Data Visualization & 15-May-12 & 10291 \\
\hline Digital Analytics Association & 15-Apr-12 & 11,425 \\
\hline Digital Analytics Canada - Québec & 5-Jun-12 & 470 \\
\hline Digital and Customer Analytics Group - IQ Workforce & 15-Apr-12 & 2,402 \\
\hline Digital Marketing & 15-Apr-12 & 172,860 \\
\hline $\mathrm{eM}+\mathrm{C}$ & 15-Apr-12 & 732 \\
\hline eMetrics Marketing Optimization Summit & 15-Apr-12 & 841 \\
\hline Excellent Analytics & 30-Apr-12 & 359 \\
\hline Global Analytics Network (+5K analytic professionals) & 15-Apr-12 & 15,207 \\
\hline Google Analytics & 15-Apr-12 & 11,535 \\
\hline Interactive Analytics & 15-Apr-12 & 1,627 \\
\hline International Web Analytics Circle & 7-May-12 & 242 \\
\hline Mobile Analytics & 15-Apr-12 & 3,312 \\
\hline Numeric - Web Analytics & 15-Apr-12 & 586 \\
\hline Omniture Users Group & 7-May-12 & 3,940 \\
\hline Online and Web Analytics Worldwide & 17-Jun-12 & 583 \\
\hline Online marketing & 15-Apr-12 & 13,706 \\
\hline Online Marketing, Web Analytics, and E-commerce Group --... & 15-Apr-12 & 41,443 \\
\hline Real Analytics: Talk about today's business analytics & 15-Apr-12 & 3,701 \\
\hline Research \& Analytics (a subgroup of Social Media Marketing) & 15-May-12 & 509 \\
\hline $\begin{array}{l}\text { Search Engine and Social Media Optimisation - Online } \\
\text { Marketing }\end{array}$ & 15-Apr-12 & 713 \\
\hline Social Media Analytics & 15-Apr-12 & 1,807 \\
\hline Social Media Marketing & 15-May-12 & 358,091 \\
\hline Toronto Area SAS Society & 15-May-12 & 421 \\
\hline Toronto Digital Marketing Professionals & 15-Apr-12 & 8,117 \\
\hline Web Analytics Demystified & 15-Apr-12 & 5,243 \\
\hline \multirow[t]{2}{*}{ Web Analytics Professionals } & 15-Apr-12 & 11,383 \\
\hline & Total & 764,901 \\
\hline
\end{tabular}

Table 21 - List of contacted LinkedIn groups. 


\section{Appendix 5 (Introductory messages for the survey)}

\section{Introductory message for LinkedIn groups and email campaign}

Hi all,

I am a graduate student at Ryerson University in Toronto, Ontario, Canada. I am kindly requesting your participation in the survey that I conduct to obtain my Master's in the Management of Technology and Innovations.

My research project targets decision makers who rely on web analytics reports to make strategic decisions. More precisely, I am interested in studying the skills that web analysts must possess, in order to produce reports that contain practical insights that decision makers can act on.

As members of this LinkedIn group, I assume that you make a strategic use of web analytics, and that this research is of interest to you.

To acknowledge the value of your participation, each unique submission, which will be completed by June 1, 2012, could be entered into a draw for a chance to win one (1) of two (2) new iPads. The total number of participants in this study is set to 200.

Please find the link to the survey as an attachment.

I thank you in advance for your participation.

Stephen.

\section{Introductory message on SurveyMonkey}

The consent form will be used as the introductory message to the survey (Appendix 6 (Consent agreement)). 


\section{Appendix 6 (Consent agreement)}

The following signifies your agreement to participate in the research study being conducted. Before you give your consent, it is important that you read the following information. Please contact me at sverspan@rverson.ca to ask any questions you may have.

\section{Investigator}

Stephen Verspan

Graduate student, Master's of Management Science, Ryerson

University (Toronto, Ontario, Canada)

sverspan@ryerson.ca

\section{Co-Investigator}

Ozgur Turetken

Associate Professor, Associate Director, External Relations, Research and Graduate Programs, Ted Rogers School of Information Technology Management, Ryerson University (Toronto, Ontario, Canada)

Office: (416) 9795000 x2481

turetken@ryerson.ca

\section{Description \& Purpose}

This research project is conducted for obtaining my thesis in the Management of Technology and Innovations.

My research project targets decision makers who rely on web analytics reports to make strategic decisions. More precisely, I am interested in studying the skills that web analysts must possess, in order to produce reports that contain practical insights that decision makers can act on. From the results of this study, I hope that decision makers will be able to better assess their web

\section{RYERSONUNIVERSITY}

analytics needs in terms of their specific business objectives, and the particular skill set of their current or potential employees.

\section{Risks or Discomforts}

The study will pose no risk or discomfort to the participants.

\section{Benefits of the Study}

I hope that this research will provide decision makers with actionable findings about the characteristics that they should look for in web analysts, in terms of business, analytical, and technical skills. Thus, my research aims at contributing to various research and professional streams, as it targets any decision maker who relies on web analytics reports to make strategic decisions. Please note that there is no guaranteed direct benefit to individual participants.

\section{Confidentiality}

All information gathered, including participants' contact information and data gathered from the survey, will be kept confidential. Please note that names and emails will be securely stored on a password-protected server, separately from data and only for the purposes of the draw and to provide reports. All data will be stored until March 1, 2013, and will then be destroyed. Only aggregate data will be used in any publications resulting from the study, making it impossible to identify individual responses. The data will be accessible to Stephen Verspan and Ozgur Turetken only. 
Please note that if you do not wish to take part in the draw, or receive a copy of the results, then you do not have to provide your name or email address at any point in the survey.

\section{Costs and/or Compensation for Participation}

This survey, which is composed of 43 questions, should take you approximately 15 minutes to complete.

To acknowledge the value of your participation, each unique submission, which will be completed by July 1, 2012, could be entered into a draw for a chance to win one (1) of two (2) new iPads. The total number of participants is set to 200. There will be two (2) winners, and the draw will occur on August 1, 2012.

Following the draw, the two (2) winners will be contacted via the personal email addresses that they will provide in the survey.

If you decide to participate in the draw, and/or are willing to receive a soft copy of the academic paper that reports on the results of this research, please note that you will have to provide your first name, last name, and email address.

Participation in the draw is optional. Participants can choose not to receive a soft copy of the academic paper that reports on the results of this research.

\section{Voluntary Nature of Participation}

This study is voluntary in nature. Participants may opt-out at any point during the study. Those who do not wish to participate in the study, or opt-out during the study, will not receive any compensation.

\section{Questions about the Study}

If you have any questions about the research, please contact me at sverspan@ryerson.ca.

If you have questions regarding your rights as a participant in this study, you may contact the Ryerson University Research Ethics Board for information.

\section{Research Ethics Board}

c/o Office of the Vice President, Research and

\section{Innovation}

Ryerson University

350 Victoria Street

Toronto, ON M5B 2K3

416-979-5042 


\section{Appendix 7 (Thank you note and confirmation message)}

The following message was displayed after completion of the survey:

The survey is now completed! Thank you for your time.

If you have agreed to participate in the draw, and are the lucky winner of one (1) of the two (2) new iPads, you will be contacted via the email address that you have provided. Clear instructions on how to claim your prize will be provided by email.

If you have indicated that you wish to receive a soft copy of the academic paper that reports on the results of this research, I will email you the paper, once it is completed. The email address that you have provided will be used to communicate with you.

For any questions, please contact me at sverspan@ryerson.ca.

Again, thank you!

Stephen Verspan.

The following message was displayed when participants replied "No" to preliminary question "a)" (i.e.: I attest that I can express my views on the skills of the web analyst who prepares the web analytics reports that I need), or "Other" to preliminary question "b)" (i.e.: The company that you work for, or own, is located in):

Thank you for your time.

Unfortunately, you need to be able to express your views on the skills of the web analyst who prepares your web analytics reports, in order to participate in this study.

You also need to either work for, or own, a company that is located in the United States of America or Canada, in order to be able to participate in this study.

Please feel free to forward the [link to this survey] to anybody you know you may be able to participate.

Thank you,

Stephen Verspan. 


\section{Appendix 8 (Confirmation email to new iPads winners)}

Individual emails were sent to each winner on October 19, 2012. Both winners were located in Toronto; thus, the devices were delivered in person:

Sender's name: Stephen Verspan

Sender's email address: sverspan@ryerson.ca

Subject line: New iPad winner - Ryerson Master’s thesis

Dear [first name],

First of all, I would like to thank you once again for participating in my survey. The draw for the two (2) new iPads occurred on October 19, 2012, and I am very glad to announce you that you are one of the two lucky winners!

Please indicate a day and time at which you would like to have your device delivered. I will deliver it myself, for a chance to congratulate you in person.

Regards,

Stephen Verspan. 


\section{Appendix 9 (Waiver for new iPads winners)}

\section{RYERSONUNIVERSITY}

October 19, 2012

\section{Main investigator}

Stephen Verspan

Graduate student, Master's of Management Science, Ryerson University (Toronto, On., Canada) sverspan@ryerson.ca

Dear participant,

I would like to thank you once again for participating in my survey - Decision maker satisfaction in a web analytics context: The impact of analysts' skills.

The draw for the two (2) new iPads occurred on October 19, 2012, and I am very glad to announce that you are one of the two lucky winners!

Please print your name and sign the below waiver to acknowledge that you have received your new iPad.

I, , hereby confirm

that:

- I was assigned one of the two (2) winning numbers for the above mentioned study, which was conducted by Stephen Verspan and Dr. Ozgur Turetken;

- I have collected my new iPad on

Please sign below: 


\section{Appendix 10 (Confirmation email for soft copy of the paper)}

I intend to send one email to all participants who would have indicated that they wished to obtain a soft copy of the academic paper that reports on the results of this research; all email addresses will be added to the Bcc field:

Sender's name: Stephen Verspan

Sender's email address: sverspan@ryerson.ca

Subject line: Web analytics academic paper - Ryerson Master’s thesis

Dear [first name],

I would like to thank you once again for participating in my survey - Gain of actionable insights in a web analytics context: toward a new model -, which was conducted between April 15, 2012 and July 1, 2012.

You indicated that you wished to receive a soft copy of the academic paper that reports on the results of my research, and this is the reason why I am contacting you today.

Please find enclosed a soft copy of the paper. If you have any questions, feel free to contact me directly at this present email address.

Regards,

Stephen Verspan. 


\section{Appendix 11 (Cross factor loadings)}

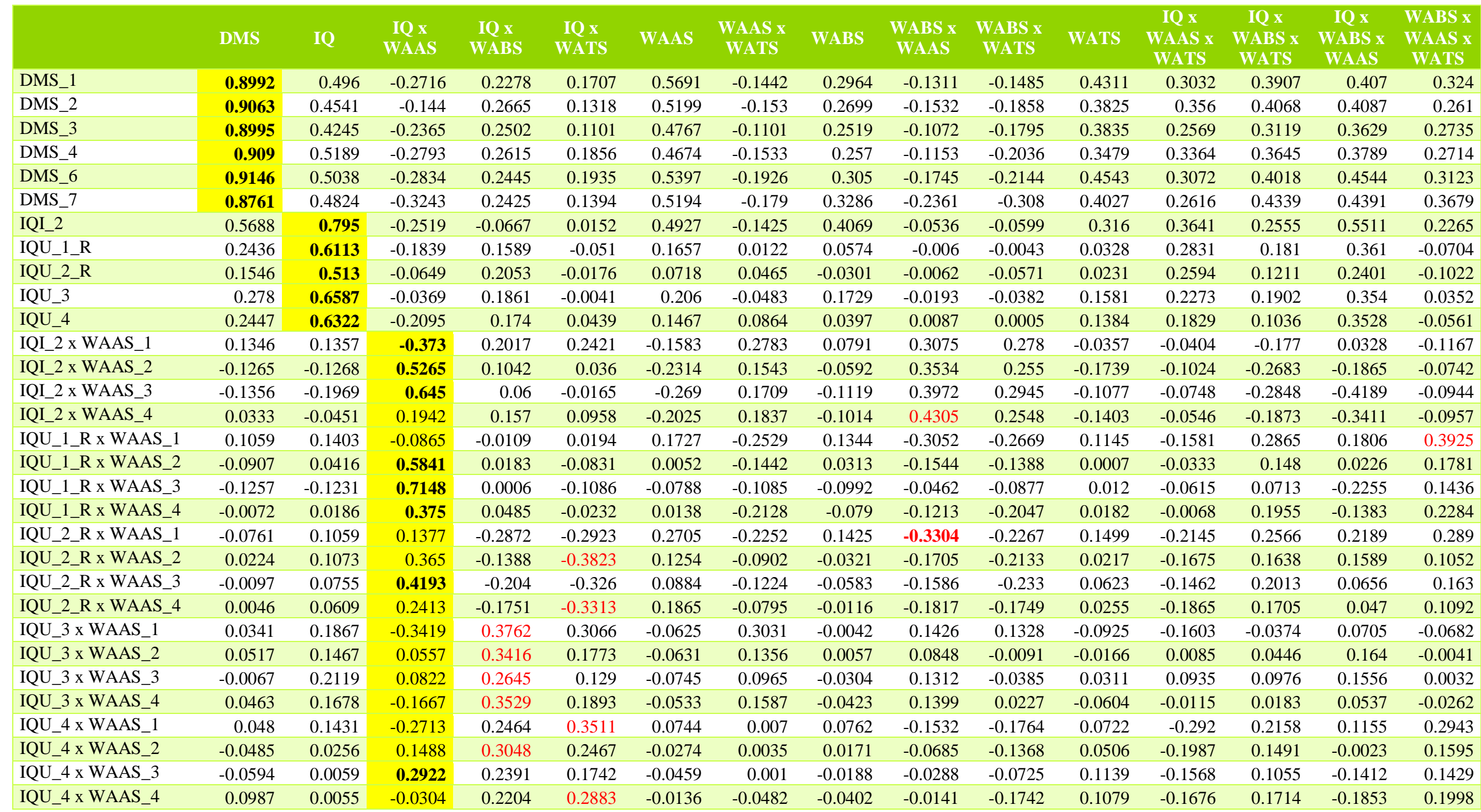

Notes:

- In red: Highest absolute loadings that rank higher on other variables.

- In bold: Highest absolute loadings that rank higher on the own variables. 


\begin{tabular}{|c|c|c|c|c|c|c|c|c|c|c|c|c|c|c|c|}
\hline & DMS & IQ & $\begin{array}{c}\text { IQ } x \\
\text { WAAS }\end{array}$ & $\begin{array}{c}\text { IQ } x \\
\text { WABS }\end{array}$ & $\begin{array}{c}\text { IQ } x \\
\text { WATS }\end{array}$ & WAAS & $\begin{array}{l}\text { WAAS } x \\
\text { WATS }\end{array}$ & WABS & $\begin{array}{l}\text { WABS } x \\
\text { WAAS }\end{array}$ & $\begin{array}{l}\text { WABS } x \\
\text { WATS }\end{array}$ & WATS & $\begin{array}{l}\text { IQ } x \\
\text { WAAS } x \\
\text { WATS }\end{array}$ & $\begin{array}{c}\text { IQ } \mathrm{x} \\
\text { WABS } \mathrm{x} \\
\text { WATS }\end{array}$ & $\begin{array}{c}\text { IQ } \mathrm{x} \\
\text { WABS } \mathrm{x} \\
\text { WAAS }\end{array}$ & $\begin{array}{l}\text { WABS } x \\
\text { WAAS } x \\
\text { WATS }\end{array}$ \\
\hline IQI_2 x WABS_1 & 0.1 & -0.0593 & 0.3177 & 0.5641 & 0.0164 & -0.0712 & 0.2101 & -0.2477 & 0.2115 & 0.0817 & -0.0554 & -0.0129 & 0.1866 & -0.1748 & -0.1737 \\
\hline IQI_2 x WABS_2 & 0.1264 & -0.0291 & 0.3109 & 0.5946 & 0.0115 & -0.0288 & 0.2043 & -0.1748 & 0.2112 & 0.1179 & 0.0023 & -0.0294 & 0.2476 & -0.1662 & -0.1459 \\
\hline IQI_2 x WABS_3 & 0.2169 & 0.1053 & -0.0131 & 0.7567 & 0.1221 & 0.0236 & 0.2095 & -0.121 & 0.1626 & 0.0511 & 0.0207 & 0.0543 & 0.3875 & 0.0244 & -0.175 \\
\hline IQI_2 x WABS_4 & 0.0171 & -0.0259 & 0.2333 & 0.187 & 0.1097 & -0.1382 & 0.1354 & -0.0685 & 0.4209 & 0.3082 & -0.1286 & -0.0795 & -0.2547 & -0.3376 & -0.0696 \\
\hline IQU_1_R x WABS_1 & -0.1605 & -0.0418 & 0.4464 & -0.4784 & -0.2018 & -0.0769 & -0.034 & 0.1581 & 0.2001 & 0.233 & -0.0946 & -0.1837 & -0.2495 & -0.1596 & 0.0776 \\
\hline IQU_1_R x WABS_2 & -0.0109 & -0.0155 & 0.414 & -0.3933 & -0.0873 & -0.0272 & -0.157 & 0.1655 & 0.1609 & 0.1023 & 0.0454 & -0.0805 & -0.1369 & -0.1492 & 0.2544 \\
\hline IQU_1_R x WABS_3 & -0.0046 & 0.1122 & 0.1233 & -0.362 & -0.0008 & 0.0254 & -0.1517 & 0.2766 & 0.1027 & 0.1122 & 0.0335 & -0.0957 & -0.0992 & 0.002 & 0.3022 \\
\hline IQU_1_R x WABS_4 & -0.0295 & 0.0168 & 0.3016 & -0.0723 & 0.124 & 0.0235 & -0.1379 & 0.101 & -0.0251 & -0.011 & 0.0324 & -0.0688 & 0.1037 & -0.0662 & 0.2406 \\
\hline IQU_2_R x WABS_1 & -0.1295 & 0.0111 & 0.2889 & -0.635 & -0.213 & 0.0234 & -0.2283 & 0.1834 & 0.0747 & 0.069 & -0.1072 & -0.1661 & -0.1458 & 0.0154 & 0.2632 \\
\hline IQU_2_R x WABS_2 & -0.0996 & 0.0282 & 0.2888 & -0.612 & -0.2014 & -0.0134 & -0.1312 & 0.1894 & 0.2044 & 0.1669 & -0.0559 & -0.1084 & -0.1658 & -0.0092 & 0.1498 \\
\hline IQU_2_R x WABS_3 & -0.1037 & 0.0953 & 0.112 & -0.6228 & -0.153 & -0.0143 & -0.1361 & 0.186 & 0.195 & 0.1362 & 0.0276 & -0.0852 & -0.1176 & 0.092 & 0.1826 \\
\hline IQU_2_R x WABS_4 & -0.0578 & 0.0712 & 0.1382 & -0.293 & -0.0776 & 0.019 & -0.1096 & 0.0625 & 0.0596 & 0.0107 & -0.0126 & -0.1515 & 0.099 & 0.097 & 0.0904 \\
\hline IQU_3 x WABS_1 & 0.0428 & 0.1765 & -0.0242 & -0.0644 & 0.1709 & 0.02 & 0.0874 & 0.1076 & 0.2836 & 0.2656 & -0.1081 & -0.0315 & -0.2634 & 0.106 & 0.0164 \\
\hline IQU_3 x WABS_2 & 0.1365 & 0.2117 & -0.0508 & -0.0593 & 0.1837 & -0.0298 & -0.0343 & 0.0375 & 0.2698 & 0.1354 & -0.0262 & 0.0482 & -0.1502 & 0.1295 & 0.1242 \\
\hline IQU_3 x WABS_3 & 0.0391 & 0.1896 & -0.1277 & -0.0459 & 0.2795 & -0.0321 & 0.0032 & 0.0676 & 0.2565 & & -0.0472 & -0.0058 & -0.1891 & 0.0629 & 0.128 \\
\hline IQU_3 x WABS_4 & 0.0867 & 0.31 & -0.0912 & 0.3279 & 0.2213 & -0.0281 & 0.0395 & -0.0943 & 0.1829 & 0.0092 & 0.005 & 0.0653 & 0.0828 & 0.1361 & 0.0554 \\
\hline IQU_4 x WABS_1 & -0.0879 & -0.0271 & 0.229 & -0.3794 & 0.1386 & -0.1014 & 0.0111 & 0.0803 & 0.3031 & 0.2662 & -0.1028 & -0.2181 & -0.3774 & -0.2214 & 0.0706 \\
\hline IQU_4 x WABS_2 & -0.0113 & -0.0486 & 0.1995 & -0.2323 & 0.2419 & -0.0198 & -0.14 & 0.213 & 0.1628 & 0.1612 & -0.0115 & -0.1918 & -0.2699 & -0.2247 & 0.2501 \\
\hline IQU_4 x WABS_3 & 0.0085 & 0.0372 & -0.0246 & -0.1975 & 0.3394 & 0.0261 & -0.1402 & 0.2694 & 0.124 & 0.1582 & -0.02 & -0.1579 & -0.2375 & -0.0973 & 0.2838 \\
\hline IQU_4 x WABS_4 & 0.1119 & 0.1055 & 0.1232 & 0.2981 & 0.2011 & 0.101 & -0.0804 & 0.1303 & -0.0376 & -0.0185 & 0.0872 & -0.0693 & 0.2078 & -0.0715 & 0.2318 \\
\hline IQI_2 x WATS_1 & -0.0201 & -0.0592 & 0.0963 & 0.0165 & -0.0272 & -0.0996 & 0.3144 & -0.006 & 0.1693 & 0.2669 & -0.2102 & -0.2129 & -0.2254 & -0.1125 & -0.0161 \\
\hline IQI_2 $x$ WATS_2 & 0.004 & 0.0133 & -0.0927 & 0.0686 & 0.04 & -0.1234 & 0.3182 & -0.0449 & 0.2526 & 0.239 & -0.2256 & -0.1792 & -0.1763 & -0.119 & -0.0193 \\
\hline IQI_2 x WATS_3 & -0.0128 & -0.048 & 0.0875 & 0.0954 & 0.0395 & -0.175 & 0.3826 & -0.1037 & 0.2249 & 0.3082 & -0.2517 & -0.2633 & -0.2604 & -0.2318 & -0.0391 \\
\hline IQU_1_R x WATS_1 & 0.0145 & 0.1465 & 0.1826 & 0.1451 & -0.1501 & 0.0382 & -0.042 & -0.0032 & -0.1316 & -0.113 & 0.0231 & -0.0251 & 0.1796 & -0.0136 & 0.1675 \\
\hline IQU_1_R x WATS_2 & 0.0149 & 0.1762 & 0.0575 & 0.1429 & -0.1302 & 0.0709 & 0.0076 & 0.0681 & -0.1369 & -0.0814 & 0.0109 & 0.0001 & 0.1996 & 0.0595 & 0.1328 \\
\hline IQU_1_R x WATS_3 & -0.0633 & 0.035 & 0.2179 & 0.0963 & -0.1333 & -0.0173 & 0.0032 & -0.0576 & -0.1649 & -0.1327 & -0.0402 & -0.1445 & 0.1189 & -0.102 & 0.1656 \\
\hline IQU_2_R x WATS_1 & -0.0991 & 0.0222 & 0.211 & -0.0244 & -0.4488 & 0.1083 & 0.0441 & -0.0033 & -0.1718 & -0.0463 & -0.1216 & -0.0552 & 0.1491 & 0.0635 & 0.0077 \\
\hline IQU_2_R x WATS_2 & -0.0323 & 0.0361 & 0.0863 & 0.0163 & -0.4201 & 0.0954 & 0.0276 & -0.0347 & -0.1361 & -0.087 & -0.1326 & -0.0217 & 0.1766 & 0.0757 & 0.0186 \\
\hline IQU_2_R x WATS_3 & -0.1189 & -0.0722 & 0.2238 & -0.1213 & -0.4573 & 0.0211 & 0.0353 & -0.1264 & -0.2216 & -0.1391 & -0.1013 & -0.1033 & 0.1063 & -0.0359 & 0.0335 \\
\hline IQU_3 x WATS_1 & 0.0169 & 0.0659 & -0.1733 & 0.2725 & 0.4226 & -0.0078 & 0.0804 & -0.0335 & -0.0317 & 0.0622 & -0.1717 & 0.0444 & 0.0876 & 0.0737 & 0.0278 \\
\hline IQU_3 x WATS_2 & 0.0427 & 0.0947 & -0.1858 & 0.3151 & 0.4678 & -0.0193 & 0.126 & -0.0414 & 0.0272 & 0.1002 & -0.1955 & 0.015 & 0.0659 & 0.0065 & -0.0123 \\
\hline IQU_3 x WATS_3 & 0.0312 & 0.0188 & -0.2663 & 0.2625 & 0.4354 & -0.0656 & 0.1722 & -0.0446 & -0.0257 & 0.0751 & -0.1877 & -0.051 & 0.0342 & -0.035 & -0.0091 \\
\hline IQU_4 x WATS_1 & 0.1181 & -0.0286 & -0.0543 & 0.2224 & 0.7342 & 0.1246 & -0.1039 & 0.0242 & -0.191 & -0.1455 & -0.006 & -0.0107 & 0.2279 & 0.0467 & 0.2473 \\
\hline IQU_4 x WATS_2 & 0.0828 & -0.0015 & -0.1738 & 0.262 & 0.7739 & 0.0704 & -0.0569 & -0.0356 & -0.1183 & -0.0991 & -0.0432 & -0.0357 & 0.209 & 0.0118 & 0.1748 \\
\hline IQU_4 x WATS_3 & 0.1197 & -0.0889 & -0.1016 & 0.2297 & 0.7089 & 0.0811 & -0.0565 & -0.0126 & -0.1763 & -0.1236 & -0.0779 & -0.1093 & 0.1799 & -0.0817 & 0.2131 \\
\hline
\end{tabular}

- In red: Highest absolute loadings that rank higher on other variables.

- In bold: Highest absolute loadings that rank higher on the own variables. 


\begin{tabular}{|c|c|c|c|c|c|c|c|c|c|c|c|c|c|c|c|}
\hline & DMS & IQ & $\begin{array}{c}\text { IQ } \mathrm{x} \\
\text { WAAS }\end{array}$ & $\begin{array}{c}\text { IQ } x \\
\text { WABS }\end{array}$ & $\begin{array}{c}\text { IQ } \mathrm{x} \\
\text { WATS }\end{array}$ & WAAS & $\begin{array}{l}\text { WAAS } x \\
\text { WATS }\end{array}$ & WABS & $\begin{array}{l}\text { WABS } x \\
\text { WAAS }\end{array}$ & $\begin{array}{l}\text { WABS } x \\
\text { WATS }\end{array}$ & WATS & $\begin{array}{c}\text { IQ } \mathrm{x} \\
\text { WAAS } \mathrm{x} \\
\text { WATS }\end{array}$ & $\begin{array}{c}\text { IQ } x \\
\text { WABS } x \\
\text { WATS }\end{array}$ & $\begin{array}{c}\text { IQ } \mathrm{x} \\
\text { WABS } \mathrm{x} \\
\text { WAAS }\end{array}$ & $\begin{array}{l}\text { WABS } x \\
\text { WAAS } x \\
\text { WATS }\end{array}$ \\
\hline WAAS_1 & 0.3911 & 0.1608 & 0.2004 & -0.0297 & -0.0797 & 0.7544 & -0.3441 & 0.4135 & -0.2908 & -0.2704 & 0.3646 & 0.1932 & 0.3892 & 0.3025 & 0.4876 \\
\hline WAAS_2 & 0.5512 & 0.4386 & -0.1927 & 0.0354 & 0.0569 & 0.8916 & -0.2129 & 0.5584 & -0.2906 & -0.1971 & 0.4719 & 0.2899 & 0.4267 & 0.513 & 0.4311 \\
\hline WAAS_3 & 0.5274 & 0.4485 & -0.2614 & 0.0474 & 0.0759 & 0.8864 & -0.1798 & 0.5896 & -0.3418 & -0.1591 & 0.4049 & 0.2618 & 0.4162 & 0.6271 & 0.4166 \\
\hline WAAS_4 & 0.4418 & 0.3075 & -0.0357 & 0.0117 & 0.071 & 0.8341 & -0.2717 & 0.5382 & -0.3712 & -0.2601 & 0.4643 & 0.2211 & 0.4065 & 0.5273 & 0.4811 \\
\hline WAAS_1 x WATS_1 & -0.1131 & 0.0576 & -0.1697 & 0.2073 & 0.0016 & -0.2902 & 0.8164 & -0.1939 & 0.5269 & 0.6009 & -0.1922 & -0.1253 & -0.292 & -0.108 & -0.6153 \\
\hline WAAS_1 x WATS_2 & -0.0687 & 0.016 & -0.1758 & 0.2287 & 0.0806 & -0.2733 & 0.7813 & -0.1429 & 0.4739 & 0.518 & -0.1472 & -0.2025 & -0.2271 & -0.103 & -0.5234 \\
\hline WAAS_1 x WATS_3 & -0.1286 & -0.0128 & -0.2009 & 0.2162 & 0.1079 & -0.2777 & 0.7804 & -0.1682 & 0.4946 & 0.5465 & -0.2014 & -0.2098 & -0.2754 & -0.142 & -0.5594 \\
\hline WAAS_2 x WATS_1 & -0.1356 & -0.1033 & 0.0162 & 0.1435 & -0.1373 & -0.1368 & 0.7494 & -0.0702 & 0.3713 & 0.5358 & -0.1495 & -0.1744 & -0.2619 & -0.0732 & -0.4294 \\
\hline WAAS_2 x WATS_2 & -0.0635 & -0.0292 & -0.1631 & 0.2745 & -0.0559 & -0.21 & 0.7744 & -0.2189 & 0.5083 & 0.5076 & -0.1493 & -0.2309 & -0.2222 & -0.1781 & -0.414 \\
\hline WAAS_2 x WATS_3 & -0.1744 & -0.0841 & -0.0657 & 0.1712 & -0.0598 & -0.2209 & 0.8801 & -0.1759 & 0.4795 & 0.6003 & -0.2007 & -0.2651 & -0.2968 & -0.2167 & -0.4699 \\
\hline WAAS_3 x WATS_1 & -0.0276 & 0.0474 & 0.0338 & 0.2276 & -0.1446 & -0.1238 & 0.7466 & -0.0797 & 0.4599 & 0.5897 & -0.0875 & -0.1445 & -0.2634 & -0.1443 & -0.4576 \\
\hline WAAS_3 x WATS_2 & 0.0105 & -0.0044 & -0.07 & 0.3142 & -0.0762 & -0.2007 & 0.7474 & -0.1353 & 0.4934 & 0.5186 & -0.0664 & -0.1606 & -0.1866 & -0.1172 & -0.4213 \\
\hline WAAS_3 x WATS_3 & -0.1622 & -0.1072 & 0.1099 & 0.2068 & -0.0915 & -0.2304 & 0.8289 & -0.1728 & 0.5186 & 0.5861 & -0.1553 & -0.2432 & -0.3025 & -0.2513 & -0.4758 \\
\hline WAAS_4 x WATS_1 & -0.1382 & 0.0137 & -0.137 & 0.1835 & -0.1444 & -0.2348 & 0.8345 & -0.1784 & 0.5475 & 0.6128 & -0.139 & -0.0696 & -0.2853 & -0.1156 & -0.5788 \\
\hline WAAS_4 x WATS_2 & -0.1405 & -0.0796 & -0.0512 & 0.224 & -0.121 & -0.2737 & 0.8697 & -0.2248 & 0.6039 & 0.6234 & -0.1231 & -0.1546 & -0.296 & -0.1955 & -0.5659 \\
\hline WAAS_4 x WATS_3 & -0.1957 & -0.0947 & -0.085 & 0.1634 & -0.1069 & -0.2544 & 0.8524 & -0.2157 & 0.5512 & 0.61 & -0.1852 & -0.1024 & -0.3236 & -0.2166 & -0.5893 \\
\hline WABS_1 & 0.2518 & 0.3488 & -0.1343 & -0.2801 & 0.0056 & 0.4719 & -0.0949 & 0.8478 & -0.0958 & 0.1083 & 0.2691 & 0.1416 & 0.1521 & 0.4827 & 0.2796 \\
\hline WABS_2 & 0.2699 & 0.2541 & -0.1095 & -0.273 & 0.0447 & 0.5492 & -0.1832 & 0.8889 & -0.1815 & 0.0254 & 0.2699 & 0.1343 & 0.1638 & 0.5002 & 0.4648 \\
\hline WABS_3 & 0.1968 & 0.1449 & 0.0157 & -0.2652 & -0.0311 & 0.4883 & -0.238 & 0.8439 & -0.2086 & 0.0072 & 0.2576 & 0.079 & 0.0985 & 0.3641 & 0.4689 \\
\hline WABS_4 & 0.3407 & 0.2467 & -0.0931 & -0.0447 & 0.0951 & 0.6239 & -0.2206 & 0.8742 & -0.3063 & -0.075 & 0.3009 & 0.1123 & 0.3799 & 0.5273 & 0.4089 \\
\hline WABS_1 x WAAS_1 & 0.0362 & 0.0808 & -0.2523 & 0.2301 & 0.2494 & -0.1904 & 0.3661 & -0.0112 & 0.4707 & 0.326 & -0.0835 & 0.1338 & -0.2123 & -0.0436 & -0.2609 \\
\hline WABS_1 x WAAS_2 & -0.061 & -0.0647 & 0.0567 & 0.1109 & 0.1572 & -0.2012 & 0.2348 & -0.1325 & 0.6146 & 0.3735 & -0.0877 & -0.0067 & -0.3475 & -0.266 & -0.1003 \\
\hline WABS_1 x WAAS_3 & -0.0795 & -0.1445 & 0.2949 & 0.0674 & 0.1158 & -0.2831 & 0.2466 & -0.1784 & 0.638 & 0.4014 & -0.1016 & 0.0193 & -0.3778 & -0.4455 & -0.1541 \\
\hline WABS_1 x WAAS_4 & 0.0067 & -0.0977 & 0.0394 & 0.121 & 0.1512 & -0.217 & 0.249 & -0.0924 & 0.6321 & 0.407 & -0.0613 & 0.0413 & -0.3017 & -0.35 & -0.1404 \\
\hline WABS_2 x WAAS_1 & -0.0992 & 0.1081 & -0.1068 & 0.0622 & -0.0369 & -0.2567 & 0.5915 & -0.1061 & 0.7317 & 0.6329 & -0.2119 & 0.148 & -0.4308 & -0.0646 & -0.6104 \\
\hline WABS_2 x WAAS_2 & -0.1351 & -0.0039 & 0.0844 & -0.0227 & -0.0613 & -0.249 & 0.4402 & -0.1388 & 0.8505 & 0.6179 & -0.1182 & -0.0096 & -0.4625 & -0.2663 & -0.4183 \\
\hline WABS_2 x WAAS_3 & -0.095 & -0.1172 & 0.3076 & -0.0669 & -0.0334 & -0.3094 & 0.3991 & -0.2288 & 0.7876 & 0.5505 & -0.1067 & 0.0122 & -0.4549 & -0.4309 & -0.3545 \\
\hline WABS_2 x WAAS_4 & -0.1294 & -0.0707 & 0.0493 & 0.0467 & -0.0348 & -0.293 & 0.4673 & -0.1299 & 0.8227 & 0.6599 & -0.1523 & -0.0225 & -0.4197 & -0.3533 & -0.4835 \\
\hline WABS_3 x WAAS_1 & -0.1546 & 0.0497 & -0.1067 & 0.0651 & -0.0238 & -0.3378 & 0.6256 & -0.1686 & 0.7737 & 0.6634 & -0.2579 & 0.1293 & -0.4892 & -0.1731 & -0.6856 \\
\hline WABS_3 x WAAS_2 & -0.1265 & -0.0217 & -0.0496 & -0.0185 & -0.0128 & -0.2909 & 0.4676 & -0.1971 & 0.8349 & 0.5729 & -0.1937 & -0.0027 & -0.4311 & -0.2314 & -0.4597 \\
\hline WABS_3 x WAAS_3 & -0.068 & 0.0342 & -0.0633 & -0.0548 & 0.0197 & -0.3184 & 0.4404 & -0.2316 & 0.8257 & 0.5416 & -0.1343 & 0.0552 & -0.4303 & -0.2492 & -0.4186 \\
\hline WABS_3 x WAAS_4 & -0.2107 & -0.0043 & -0.0206 & 0.0083 & -0.0364 & -0.3196 & 0.5629 & -0.1054 & 0.8979 & 0.7703 & -0.2109 & 0.0086 & -0.4727 & -0.263 & -0.6023 \\
\hline WABS_4 x WAAS_1 & -0.0646 & 0.0888 & -0.1989 & 0.1921 & 0.0554 & -0.2573 & 0.5856 & -0.1241 & 0.6433 & 0.547 & -0.1722 & 0.1944 & -0.2473 & -0.0227 & -0.6707 \\
\hline WABS_4 x WAAS_2 & -0.0988 & -0.0001 & 0.0095 & 0.1864 & 0.0257 & -0.2778 & 0.4517 & -0.3146 & 0.7309 & 0.4547 & -0.1724 & 0.0085 & -0.2326 & -0.2263 & -0.4825 \\
\hline WABS_4 x WAAS_3 & -0.0852 & -0.108 & 0.1664 & 0.1338 & 0.0778 & -0.3381 & 0.422 & -0.353 & 0.7233 & 0.4154 & -0.0959 & 0.0223 & -0.2318 & -0.3447 & -0.4399 \\
\hline WABS_4 x WAAS_4 & -0.1866 & -0.1006 & 0.108 & 0.1524 & -0.0255 & -0.348 & 0.5506 & -0.2458 & 0.7954 & 0.6395 & -0.2394 & -0.0131 & -0.3467 & -0.3194 & -0.6093 \\
\hline
\end{tabular}

- In red: Highest absolute loadings that rank higher on other variables.

- In bold: Highest absolute loadings that rank higher on the own variables. 


\begin{tabular}{|c|c|c|c|c|c|c|c|c|c|c|c|c|c|c|c|}
\hline & DMS & IQ & $\begin{array}{c}\text { IQ X } \\
\text { WAAS }\end{array}$ & $\begin{array}{c}\text { IQ x } \\
\text { WABS }\end{array}$ & $\begin{array}{c}\text { IQ } \mathrm{x} \\
\text { WATS }\end{array}$ & WAAS & $\begin{array}{c}\text { WAAS } \\
\mathrm{x} \\
\text { WATS }\end{array}$ & WABS & $\begin{array}{c}\text { WABS } \\
x \\
\text { WAAS }\end{array}$ & $\begin{array}{c}\text { WABS } \\
\mathbf{x} \\
\text { WATS }\end{array}$ & WATS & $\begin{array}{c}\text { IQ } x \\
\text { WAAS } \\
x \\
\text { WATS }\end{array}$ & $\begin{array}{c}\text { IQ } x \\
\text { WABS } \\
x \\
\text { WATS }\end{array}$ & $\begin{array}{c}\text { IQ } x \\
\text { WABS } \\
x \\
\text { WAAS }\end{array}$ & $\begin{array}{c}\text { WABS } \\
\mathbf{x} \\
\text { WAAS } \\
\mathbf{x} \\
\text { WATS }\end{array}$ \\
\hline WABS_1 x WATS_1 & -0.0232 & -0.0846 & 0.0171 & 0.0444 & 0.093 & -0.0397 & 0.2953 & 0.1357 & 0.2983 & 0.483 & -0.1674 & -0.0123 & -0.3689 & -0.1597 & -0.0546 \\
\hline WABS_1 x WATS_2 & 0.0007 & -0.1103 & -0.0913 & 0.0733 & 0.1219 & -0.1256 & 0.2645 & 0.0172 & 0.3733 & 0.4235 & -0.1852 & 0.009 & -0.3467 & -0.1608 & -0.0553 \\
\hline WABS_1 x WATS_3 & -0.1721 & -0.1877 & 0.0355 & -0.0607 & 0.1415 & -0.1483 & 0.343 & 0.0738 & 0.3931 & 0.5397 & -0.2188 & -0.0859 & -0.4019 & -0.2396 & -0.0775 \\
\hline WABS_2 x WATS_1 & -0.1688 & 0.0054 & 0.0932 & -0.0451 & -0.1524 & -0.166 & 0.5696 & 0.0068 & 0.5945 & 0.8387 & -0.198 & -0.0355 & -0.518 & -0.1962 & -0.4802 \\
\hline WABS_2 $\mathrm{x}$ WATS_2 & -0.0567 & 0.0393 & -0.0215 & 0.0272 & -0.0583 & -0.1573 & 0.5017 & 0.0486 & 0.6415 & 0.7761 & -0.1016 & 0.0395 & -0.4119 & -0.1549 & -0.4085 \\
\hline WABS_2 x WATS_3 & -0.2207 & -0.0655 & 0.087 & -0.1117 & -0.0442 & -0.1952 & 0.5799 & 0.0513 & 0.6846 & 0.8533 & -0.1161 & -0.0225 & -0.4306 & -0.2377 & -0.4444 \\
\hline WABS_3 $x$ WATS_1 & -0.1617 & -0.0198 & 0.1076 & -0.0672 & -0.0499 & -0.196 & 0.5267 & 0.0485 & 0.5683 & 0.8031 & -0.15 & 0.0118 & -0.4885 & -0.1359 & -0.5097 \\
\hline WABS_3 x WATS_2 & -0.0959 & 0.0242 & 0.0404 & -0.0339 & 0.0377 & -0.2657 & 0.4733 & -0.0202 & 0.6543 & 0.779 & -0.1177 & -0.0174 & -0.4504 & -0.214 & -0.4525 \\
\hline WABS_3 x WATS_3 & -0.2253 & 0.0186 & -0.0311 & -0.1522 & 0.0383 & -0.2294 & 0.5179 & 0.0344 & 0.6947 & 0.8413 & -0.1662 & 0.0081 & -0.4157 & -0.1514 & -0.4911 \\
\hline WABS_4 x WATS_1 & -0.1249 & 0.0459 & -0.0155 & 0.1303 & -0.0958 & -0.1512 & 0.681 & -0.0415 & 0.5183 & 0.7866 & -0.1129 & -0.0018 & -0.3005 & -0.0768 & -0.5858 \\
\hline WABS_4 x WATS_2 & -0.09 & -0.059 & 0.0378 & 0.1859 & -0.058 & -0.2321 & 0.5872 & -0.1272 & 0.5254 & 0.6692 & -0.1226 & -0.0753 & -0.2961 & -0.1632 & -0.489 \\
\hline WABS_4 x WATS_3 & -0.2426 & -0.0951 & 0.0683 & 0.016 & -0.04 & -0.2224 & 0.6433 & -0.0612 & 0.5563 & 0.7531 & -0.1812 & -0.0703 & -0.3354 & -0.1708 & -0.5143 \\
\hline WATS_1 & 0.4249 & 0.2445 & -0.0854 & 0.047 & 0.0535 & 0.4345 & -0.1839 & 0.2505 & -0.1752 & -0.2045 & 0.9213 & 0.3237 & 0.4682 & 0.2709 & 0.4248 \\
\hline WATS_2 & 0.4228 & 0.2435 & -0.008 & 0.0322 & 0.009 & 0.4569 & -0.1455 & 0.3173 & -0.2191 & -0.1592 & 0.9359 & 0.3371 & 0.4513 & 0.329 & 0.4 \\
\hline WATS_3 & 0.3751 & 0.2391 & -0.0671 & 0.0707 & -0.0157 & 0.5073 & -0.2306 & 0.3169 & -0.2253 & -0.2013 & 0.893 & 0.3898 & 0.4862 & 0.2964 & 0.4256 \\
\hline IQI_2xWAAS_1xWATS_1 & 0.1097 & 0.1798 & 0.0952 & -0.3252 & -0.2373 & 0.3245 & -0.3128 & 0.2723 & -0.1438 & -0.1045 & 0.3322 & 0.2782 & 0.1643 & 0.2451 & 0.3182 \\
\hline IQI_2xWAAS_1xWATS_2 & 0.1207 & 0.2198 & 0.0926 & -0.294 & -0.2682 & 0.3392 & -0.3422 & 0.2637 & -0.1476 & -0.0916 & 0.3058 & 0.3231 & 0.1388 & 0.2333 & 0.3199 \\
\hline IQI_2xWAAS_1xWATS_3 & 0.13 & 0.1834 & 0.1677 & -0.2735 & -0.2921 & 0.3125 & -0.3568 & 0.2027 & -0.1658 & -0.1016 & 0.2932 & 0.3168 & 0.1596 & 0.196 & 0.3174 \\
\hline IQI_2xWAAS_2xWATS_1 & 0.1141 & 0.3233 & -0.0452 & -0.1394 & -0.0752 & 0.2181 & -0.1466 & 0.1939 & -0.0045 & -0.0292 & 0.3757 & 0.3909 & 0.2271 & 0.2479 & 0.189 \\
\hline IQI_2xWAAS_2xWATS_2 & 0.0715 & 0.2243 & 0.2561 & -0.2784 & -0.1732 & 0.326 & -0.2024 & 0.3712 & -0.1486 & -0.0242 & 0.4522 & 0.4414 & 0.21 & 0.3705 & 0.2613 \\
\hline IQI_2xWAAS_2xWATS_3 & 0.1988 & 0.278 & 0.0492 & -0.181 & -0.1575 & 0.3137 & -0.2494 & 0.2895 & -0.1157 & -0.0741 & 0.4676 & 0.5355 & 0.3155 & 0.399 & 0.2697 \\
\hline IQI_2xWAAS_3xWATS_1 & 0.0802 & 0.1971 & -0.0619 & -0.1809 & -0.0757 & 0.2933 & -0.1776 & 0.3181 & -0.1158 & -0.0688 & 0.3578 & 0.3654 & 0.2476 & 0.3845 & 0.253 \\
\hline IQI_2 x WAAS_3 x WATS_2 & 0.0594 & 0.2331 & 0.1815 & -0.2957 & -0.1724 & 0.3742 & -0.1878 & 0.3792 & -0.1436 & 0.0032 & 0.411 & 0.3426 & 0.1674 & 0.3241 & 0.2981 \\
\hline IQI_2 x WAAS_3 x WATS_3 & 0.2253 & 0.3192 & -0.1855 & -0.1663 & -0.0943 & 0.3526 & -0.2313 & 0.3149 & -0.1392 & -0.0729 & 0.3923 & 0.4576 & 0.2944 & 0.4504 & 0.2782 \\
\hline IQI_2 x WAAS_4 x WATS_1 & 0.1038 & 0.2586 & 0.1786 & -0.281 & -0.1079 & 0.2708 & -0.1579 & 0.2908 & -0.0935 & -0.0587 & 0.3348 & 0.345 & 0.1688 & 0.3377 & 0.2466 \\
\hline IQI_2 x WAAS_4 x WATS_2 & 0.1841 & 0.4158 & 0.0163 & -0.2646 & -0.0972 & 0.3572 & -0.2101 & 0.3526 & -0.1583 & -0.0795 & 0.3779 & 0.4307 & 0.2342 & 0.447 & 0.308 \\
\hline IQI_2 x WAAS_4 x WATS_3 & 0.1917 & 0.3692 & 0.0536 & -0.2943 & -0.1317 & 0.3441 & -0.2121 & 0.3368 & -0.2016 & -0.0862 & 0.3526 & 0.3755 & 0.257 & 0.4189 & 0.3156 \\
\hline IQU_1_R x WAAS_1 x WATS_1 & -0.0244 & 0.2047 & -0.1044 & 0.1368 & -0.2534 & -0.1924 & 0.3331 & -0.1676 & 0.4679 & 0.3625 & -0.0263 & 0.4354 & -0.1678 & 0.0171 & -0.5479 \\
\hline IQU_1_R x WAAS_1 x WATS_2 & 0.0329 & 0.2178 & -0.0496 & 0.1308 & -0.2765 & -0.0996 & 0.2467 & -0.0953 & 0.3817 & 0.3008 & 0.0284 & 0.4872 & -0.1223 & 0.0572 & -0.4475 \\
\hline IQU_1_R x WAAS_1 x WATS_3 & -0.0006 & 0.1459 & -0.0015 & 0.1609 & -0.2626 & -0.1598 & 0.2598 & -0.1762 & 0.4458 & 0.3337 & -0.0096 & 0.472 & -0.1946 & -0.0334 & -0.5142 \\
\hline IQU_1_R x WAAS_2 x WATS_1 & -0.0357 & 0.2353 & -0.0125 & 0.095 & -0.2993 & -0.085 & 0.2328 & -0.0571 & 0.2272 & 0.1915 & 0.0313 & 0.4415 & 0.0728 & 0.2183 & -0.3538 \\
\hline IQU_1_R x WAAS_2 x WATS_2 & -0.0097 & 0.1676 & 0.1584 & 0.1322 & -0.3324 & -0.0953 & 0.1458 & -0.133 & 0.2437 & 0.1217 & 0.0541 & 0.4271 & 0.0708 & 0.1203 & -0.287 \\
\hline IQU_1_R x WAAS_2 x WATS_3 & 0.0623 & 0.2485 & -0.0516 & 0.1318 & -0.2928 & -0.0381 & 0.1589 & -0.051 & 0.2234 & 0.1623 & 0.0902 & 0.5287 & 0.094 & 0.2329 & -0.3613 \\
\hline
\end{tabular}

- In red: Highest absolute loadings that rank higher on other variables.

- In bold: Highest absolute loadings that rank higher on the own variables. 


\begin{tabular}{|c|c|c|c|c|c|c|c|c|c|c|c|c|c|c|c|}
\hline & DMS & IQ & $\begin{array}{c}\text { IQ } \mathrm{x} \\
\text { WAAS }\end{array}$ & $\begin{array}{l}\text { IQ } x \\
\text { WABS }\end{array}$ & $\begin{array}{c}\text { IQ } \mathrm{x} \\
\text { WATS }\end{array}$ & WAAS & $\begin{array}{c}\text { WAAS } \\
x \\
\text { WATS }\end{array}$ & WABS & $\begin{array}{c}\text { WABS } \\
x \\
\text { WAAS }\end{array}$ & $\begin{array}{c}\text { WABS } \\
x \\
\text { WATS }\end{array}$ & WATS & $\begin{array}{c}\text { IQ } x \\
\text { WAAS } \\
x \\
\text { WATS }\end{array}$ & $\begin{array}{c}\text { IQ } x \\
\text { WABS } \\
x \\
\text { WATS }\end{array}$ & $\begin{array}{c}\text { IQ } x \\
\text { WABS } \\
x \\
\text { WAAS }\end{array}$ & $\begin{array}{c}\text { WABS } \\
x \\
\text { WAAS } \\
x \\
\text { WATS }\end{array}$ \\
\hline IQU_1_R x WAAS_3 x WATS_1 & 0.0225 & 0.2417 & -0.1538 & 0.101 & -0.1753 & 0.0096 & 0.1635 & 0.0163 & 0.1632 & 0.0973 & 0.1235 & 0.4669 & 0.1443 & 0.2841 & -0.2512 \\
\hline IQU_1_R x WAAS_3 x WATS_2 & -0.0098 & 0.182 & 0.1124 & 0.099 & -0.2657 & -0.0334 & 0.1699 & -0.0646 & 0.2072 & 0.1219 & 0.1333 & 0.4353 & 0.0738 & 0.1577 & -0.2605 \\
\hline IQU_1_R x WAAS_3 x WATS_3 & 0.1234 & 0.2721 & -0.2375 & 0.1674 & -0.1633 & 0.0059 & 0.1503 & -0.0086 & 0.1787 & 0.1197 & 0.1282 & 0.5464 & 0.1266 & 0.3047 & -0.3004 \\
\hline IQU_1_R x WAAS_4 x WATS_1 & -0.108 & 0.2145 & -0.0053 & 0.1186 & -0.3075 & -0.2234 & 0.4432 & -0.1646 & 0.371 & 0.339 & -0.1712 & 0.246 & -0.1271 & 0.1009 & -0.5712 \\
\hline IQU_1_R x WAAS_4 x WATS_2 & 0.0293 & 0.2964 & -0.0898 & 0.1576 & -0.2751 & -0.1265 & 0.3246 & -0.1027 & 0.2945 & 0.2176 & -0.0756 & 0.347 & 0.0117 & 0.1962 & -0.4529 \\
\hline IQU_1_R x WAAS_4 x WATS_3 & -0.012 & 0.2549 & -0.0689 & 0.1539 & -0.2624 & -0.147 & 0.3664 & -0.1219 & 0.325 & 0.2779 & -0.0731 & 0.317 & -0.0766 & 0.1409 & -0.5441 \\
\hline IQU_2_R x WAAS_1 x WATS_1 & 0.1917 & 0.0475 & -0.2137 & 0.4204 & 0.2103 & -0.1877 & 0.2091 & -0.1458 & 0.2792 & 0.1255 & -0.0796 & 0.356 & -0.0842 & -0.0735 & -0.2471 \\
\hline IQU_2_R x WAAS_1 x WATS_2 & 0.1807 & 0.0601 & -0.232 & 0.421 & 0.1749 & -0.182 & 0.2345 & -0.1714 & 0.3054 & 0.1576 & -0.1039 & 0.3586 & -0.1222 & -0.0806 & -0.2939 \\
\hline IQU_2_R x WAAS_1 x WATS_3 & 0.1457 & -0.0039 & -0.2181 & 0.4042 & 0.1962 & -0.1898 & 0.2575 & -0.1895 & 0.317 & 0.1781 & -0.1063 & 0.321 & -0.167 & -0.1293 & -0.3183 \\
\hline IQU_2_R x WAAS_2 $x$ WATS_1 & 0.1677 & 0.1383 & -0.1457 & 0.36 & 0.1355 & -0.0579 & 0.0241 & -0.1517 & 0.1203 & -0.0448 & 0.1267 & 0.5317 & 0.2028 & 0.0456 & -0.0831 \\
\hline IQU_2_R x WAAS_2 x WATS_2 & 0.0886 & 0.0637 & 0.0429 & 0.3266 & 0.0865 & -0.0145 & 0.043 & -0.0824 & 0.0751 & -0.018 & 0.1259 & 0.5303 & 0.1649 & 0.0656 & -0.1269 \\
\hline IQU_2_R x WAAS_2 x WATS_3 & 0.1443 & 0.0411 & -0.1057 & 0.4048 & 0.1381 & -0.0493 & 0.0723 & -0.1638 & 0.121 & -0.0062 & 0.1313 & 0.5363 & 0.15 & 0.0022 & -0.1694 \\
\hline IQU_2_R x WAAS_3 x WATS_1 & 0.1951 & 0.1086 & -0.1576 & 0.3683 & 0.115 & -0.0746 & 0.0605 & -0.1627 & 0.1707 & -0.0275 & 0.0863 & 0.5517 & 0.1571 & 0.088 & -0.1535 \\
\hline IQU_2_R x WAAS_3 x WATS_2 & 0.1048 & 0.0754 & 0.021 & 0.345 & 0.0634 & -0.063 & 0.1077 & -0.1608 & 0.1827 & 0.0359 & 0.068 & 0.5026 & 0.077 & 0.0036 & -0.2033 \\
\hline IQU_2_R x WAAS_3 x WATS_3 & 0.1591 & 0.1029 & -0.2097 & 0.4063 & 0.1309 & -0.0637 & 0.1227 & -0.1604 & 0.1761 & 0.041 & 0.0678 & 0.5345 & 0.0816 & 0.0373 & -0.2319 \\
\hline IQU_2_R x WAAS_4 x WATS_1 & 0.1644 & 0.1009 & -0.1049 & 0.4035 & 0.1597 & -0.0963 & 0.0566 & -0.1288 & 0.1173 & -0.0429 & 0.029 & 0.4607 & 0.1077 & 0.025 & -0.1129 \\
\hline IQU_2_R x WAAS_4 x WATS_2 & 0.1705 & 0.1508 & -0.1336 & 0.4171 & 0.139 & -0.0536 & 0.0607 & -0.1056 & 0.1245 & -0.0323 & 0.0475 & 0.5222 & 0.1329 & 0.064 & -0.1573 \\
\hline IQU_2_R x WAAS_4 x WATS_3 & 0.1498 & 0.0836 & -0.1074 & 0.4477 & 0.159 & -0.0767 & 0.1294 & -0.1619 & 0.1491 & -0.0023 & 0.0373 & 0.4369 & 0.05 & -0.0323 & -0.2024 \\
\hline IQU_3 x WAAS_1 x WATS_1 & 0.1786 & 0.2437 & 0.1784 & -0.0358 & -0.0875 & 0.2554 & -0.2741 & 0.1176 & -0.039 & -0.0417 & 0.1405 & 0.5084 & 0.2152 & 0.2304 & 0.0332 \\
\hline IQU_3 x WAAS_1 x WATS_2 & 0.1817 & 0.2755 & 0.1464 & -0.0142 & -0.103 & 0.2663 & -0.3299 & 0.0891 & -0.0433 & -0.0801 & 0.1732 & 0.5429 & 0.2371 & 0.2228 & 0.083 \\
\hline IQU_3 x WAAS_1 x WATS_3 & 0.1614 & 0.2164 & 0.1512 & -0.0817 & -0.1504 & 0.2431 & -0.3287 & 0.1023 & -0.0763 & -0.0932 & 0.2046 & 0.5255 & 0.2342 & 0.2061 & 0.0881 \\
\hline IQU_3 x WAAS_2 x WATS_1 & 0.0675 & 0.214 & 0.1675 & 0.0409 & 0.1265 & 0.1488 & -0.1408 & 0.0213 & 0.0369 & 0.0366 & 0.1462 & 0.4474 & 0.1949 & 0.1276 & -0.018 \\
\hline IQU_3 x WAAS_2 x WATS_2 & 0.0652 & 0.1513 & 0.2835 & 0.0217 & 0.1376 & 0.2405 & -0.2561 & 0.1284 & -0.0784 & -0.0362 & 0.207 & 0.6062 & 0.2876 & 0.3039 & 0.0499 \\
\hline IQU_3 x WAAS_2 $x$ WATS_3 & 0.1143 & 0.0934 & 0.3059 & 0.006 & 0.0597 & 0.1843 & -0.2496 & 0.0586 & -0.0665 & -0.0251 & 0.2493 & 0.6005 & 0.2875 & 0.2089 & 0.0359 \\
\hline
\end{tabular}

- In red: Highest absolute loadings that rank higher on other variables.

- In bold: Highest absolute loadings that rank higher on the own variables. 


\begin{tabular}{|c|c|c|c|c|c|c|c|c|c|c|c|c|c|c|c|}
\hline & DMS & IQ & $\begin{array}{c}\text { IQ } \mathrm{x} \\
\text { WAAS }\end{array}$ & $\begin{array}{l}\text { IQ x } \\
\text { WABS }\end{array}$ & $\begin{array}{l}\text { IQ x } \\
\text { WATS }\end{array}$ & WAAS & $\begin{array}{c}\text { WAAS } \\
x \\
\text { WATS }\end{array}$ & WABS & $\begin{array}{c}\text { WABS } \\
\text { X } \\
\text { WAAS }\end{array}$ & $\begin{array}{c}\text { WABS } \\
x \\
\text { WATS }\end{array}$ & WATS & $\begin{array}{c}\text { IQ } x \\
\text { WAAS } \\
x \\
\text { WATS }\end{array}$ & $\begin{array}{c}\text { IQ } x \\
\text { WABS } \\
x \\
\text { WATS }\end{array}$ & $\begin{array}{c}\text { IQ } x \\
\text { WABS } \\
x \\
\text { WAAS }\end{array}$ & $\begin{array}{c}\text { WABS } \\
x \\
\text { WAAS } \\
x \\
\text { WATS }\end{array}$ \\
\hline IQU_3 x WAAS_3 x WATS_1 & 0.0039 & 0.04 & 0.409 & 0.0116 & 0.1452 & 0.0964 & -0.1756 & 0.0001 & 0.0034 & 0.0057 & 0.0763 & 0.4451 & 0.1718 & 0.156 & -0.005 \\
\hline IQU_3 x WAAS_3 x WATS_2 & 0.0806 & 0.1803 & 0.2456 & 0.0235 & 0.1767 & 0.192 & -0.2492 & 0.0472 & -0.0452 & -0.0517 & 0.1486 & 0.5652 & 0.2728 & 0.2627 & 0.0588 \\
\hline IQU_3 x WAAS_3 x WATS_3 & 0.0134 & 0.1257 & 0.3167 & -0.0287 & 0.0698 & 0.1853 & -0.2531 & 0.043 & -0.0825 & -0.0285 & 0.1521 & 0.5159 & 0.23 & 0.1833 & 0.042 \\
\hline IQU_3 x WAAS_4 x WATS_1 & 0.1474 & 0.1854 & 0.1377 & -0.0255 & 0.1453 & 0.2177 & -0.1491 & 0.1014 & -0.0306 & -0.0044 & 0.0853 & 0.4536 & 0.2106 & 0.2586 & -0.042 \\
\hline IQU_3 x WAAS_4 x WATS_2 & 0.1934 & 0.304 & 0.0487 & 0.0271 & 0.2064 & 0.2775 & -0.191 & 0.131 & -0.0628 & -0.0159 & 0.0974 & 0.5365 & 0.2803 & 0.3228 & 0.006 \\
\hline IQU_3 x WAAS_4 x WATS_3 & 0.1647 & 0.3427 & 0.0783 & 0.0418 & 0.1174 & 0.2331 & -0.1683 & 0.0648 & -0.0569 & -0.0112 & 0.1594 & 0.4647 & 0.2562 & 0.2665 & 0.0025 \\
\hline IQU_4 x WAAS_1 x WATS_1 & -0.0037 & 0.1869 & 0.0821 & 0.0808 & -0.0089 & -0.0387 & 0.1781 & -0.1425 & 0.3518 & 0.3221 & -0.0716 & 0.4634 & -0.0986 & 0.08 & -0.4754 \\
\hline IQU_4 x WAAS_1 x WATS_2 & 0.0916 & 0.2269 & 0.0694 & 0.1163 & 0.0034 & 0.065 & 0.0507 & -0.0813 & 0.2853 & 0.2151 & -0.0001 & 0.5485 & 0.0016 & 0.1213 & -0.3361 \\
\hline IQU_4 x WAAS_1 x WATS_3 & 0.0641 & 0.1776 & 0.0537 & 0.0621 & -0.0664 & 0.0091 & 0.0677 & -0.0762 & 0.2909 & 0.2369 & 0.0094 & 0.5554 & -0.0296 & 0.0896 & -0.3778 \\
\hline IQU_4 x WAAS_2 x WATS_1 & -0.0089 & 0.205 & 0.0423 & 0.1251 & 0.1824 & 0.0176 & 0.1149 & -0.0874 & 0.2219 & 0.254 & -0.0035 & 0.4342 & 0.0342 & 0.1218 & -0.3335 \\
\hline IQU_4 x WAAS_2 x WATS_2 & 0.0022 & 0.1171 & 0.2279 & 0.1006 & 0.1791 & 0.1049 & 0.0189 & 0.0086 & 0.0956 & 0.1769 & 0.04 & 0.5135 & 0.083 & 0.2141 & -0.239 \\
\hline IQU_4 x WAAS_2 x WATS_3 & 0.0228 & 0.1392 & 0.0836 & 0.0958 & 0.1301 & 0.0625 & 0.0507 & -0.029 & 0.1524 & 0.1963 & 0.0535 & 0.5761 & 0.093 & 0.2202 & -0.3092 \\
\hline IQU_4 x WAAS_3 x WATS_1 & -0.0314 & 0.1023 & 0.0999 & 0.1724 & 0.2965 & 0.025 & 0.1008 & -0.0272 & 0.1804 & 0.2705 & -0.0463 & 0.4398 & 0.0182 & 0.1692 & -0.3441 \\
\hline IQU_4 x WAAS_3 x WATS_2 & -0.0117 & 0.1112 & 0.2163 & 0.1686 & 0.3117 & 0.0857 & 0.0503 & 0.0076 & 0.1246 & 0.2446 & -0.0082 & 0.4505 & 0.0329 & 0.1408 & -0.2726 \\
\hline IQU_4 x WAAS_3 x WATS_3 & 0.0702 & 0.1832 & -0.0569 & 0.1616 & 0.287 & 0.0875 & 0.0547 & 0.0044 & 0.1378 & 0.2037 & 0.0356 & 0.5585 & 0.1077 & 0.2563 & -0.2987 \\
\hline IQU_4 x WAAS_4 x WATS_1 & -0.0479 & 0.1355 & 0.0301 & 0.0622 & 0.1753 & -0.0364 & 0.2748 & -0.1011 & 0.2761 & 0.357 & -0.1197 & 0.3264 & -0.1175 & 0.142 & -0.4798 \\
\hline IQU_4 x WAAS_4 x WATS_2 & 0.0517 & 0.232 & -0.0387 & 0.0723 & 0.2296 & 0.0773 & 0.1372 & -0.0345 & 0.148 & 0.225 & -0.0385 & 0.4383 & 0.0051 & 0.246 & -0.3256 \\
\hline IQU_4 x WAAS_4 x WATS_3 & -0.0172 & 0.2557 & -0.0168 & 0.1033 & 0.1466 & -0.0003 & 0.2406 & -0.0903 & 0.2311 & 0.3297 & -0.0734 & 0.3917 & -0.0699 & 0.1895 & -0.4402 \\
\hline IQI_2 x WABS_1 x WATS_1 & 0.238 & 0.2552 & -0.1179 & 0.2752 & 0.0474 & 0.3561 & -0.1578 & 0.1852 & -0.2847 & -0.3146 & 0.4546 & 0.3184 & 0.8051 & 0.4711 & 0.2227 \\
\hline IQI_2 x WABS_1 x WATS_2 & 0.2068 & 0.2408 & 0.0525 & 0.1993 & 0.0005 & 0.3707 & -0.1031 & 0.2309 & -0.2942 & -0.2362 & 0.4526 & 0.2509 & 0.7397 & 0.4098 & 0.1971 \\
\hline IQI_2 x WABS_1 x WATS_3 & 0.3413 & 0.3123 & -0.1836 & 0.2819 & 0.0421 & 0.3588 & -0.1684 & 0.1738 & -0.2948 & -0.2851 & 0.4663 & 0.3391 & 0.802 & 0.5099 & 0.2301 \\
\hline IQI_2 x WABS_2 x WATS_1 & 0.211 & 0.2649 & -0.0998 & 0.2387 & 0.0009 & 0.3576 & -0.0763 & 0.2131 & -0.2502 & -0.2316 & 0.319 & 0.368 & 0.6852 & 0.4954 & 0.1223 \\
\hline IQI_2 x WABS_2 x WATS_2 & 0.1506 & 0.2308 & 0.1168 & 0.207 & -0.078 & 0.3832 & -0.0149 & 0.2334 & -0.2979 & -0.1621 & 0.2703 & 0.2775 & 0.6197 & 0.4381 & 0.123 \\
\hline IQI_2 x WABS_2 x WATS_3 & 0.3066 & 0.2884 & -0.1318 & 0.2684 & -0.0176 & 0.3471 & -0.045 & 0.1548 & -0.2774 & -0.1876 & 0.2924 & 0.3594 & 0.6658 & 0.5342 & 0.1363 \\
\hline IQI_2 x WABS_3 x WATS_1 & 0.1758 & 0.2925 & -0.0874 & 0.2638 & -0.0396 & 0.297 & -0.0112 & 0.1127 & -0.2364 & -0.1677 & 0.1842 & 0.1961 & 0.5684 & 0.3459 & 0.0822 \\
\hline IQI_2 x WABS_3 x WATS_2 & 0.2133 & 0.2844 & -0.039 & 0.2313 & -0.0753 & 0.3822 & -0.0325 & 0.2102 & -0.3487 & -0.1802 & 0.1599 & 0.2272 & 0.5829 & 0.4783 & 0.1171 \\
\hline IQI_2 x WABS_3 x WATS_3 & 0.2677 & 0.2489 & 0.0432 & 0.2837 & -0.1274 & 0.3136 & -0.0425 & 0.0641 & -0.3054 & -0.1766 & 0.1503 & 0.2035 & 0.5856 & 0.4143 & 0.1124 \\
\hline IQI_2 x WABS_4 x WATS_1 & -0.0004 & 0.2038 & 0.0411 & -0.2401 & -0.0894 & 0.2223 & -0.0991 & 0.3814 & -0.0332 & 0.0332 & 0.2212 & 0.2394 & 0.1413 & 0.3002 & 0.1966 \\
\hline IQI_2 x WABS_4 x WATS_2 & 0.0793 & 0.3318 & -0.0455 & -0.2524 & -0.0577 & 0.3399 & -0.1213 & 0.4842 & -0.1263 & 0.0302 & 0.2519 & 0.2621 & 0.1946 & 0.3729 & 0.2279 \\
\hline IQI_2 x WABS_4 x WATS_3 & 0.2076 & 0.3405 & -0.1613 & -0.1508 & -0.0275 & 0.2696 & -0.1364 & 0.3284 & -0.0965 & -0.0186 & 0.2882 & 0.2768 & 0.2766 & 0.3911 & 0.2477 \\
\hline IQU_1_R x WABS_1 x WATS_1 & 0.1104 & 0.142 & -0.11 & -0.1988 & 0.003 & 0.0209 & -0.0552 & 0.2443 & 0.1167 & 0.0953 & 0.0856 & 0.2814 & -0.0165 & 0.2331 & 0.1019 \\
\hline IQU_1_R x WABS_1 x WATS_2 & 0.0547 & 0.0581 & 0.0694 & -0.1938 & -0.0362 & -0.0653 & -0.07 & 0.1075 & 0.2186 & 0.1148 & 0.0728 & 0.2276 & -0.0752 & 0.0811 & 0.0719 \\
\hline IQU_1_R x WABS_1 x WATS_3 & 0.16 & 0.1515 & -0.2062 & -0.1501 & 0.0352 & -0.0014 & -0.0803 & 0.2551 & 0.1619 & 0.1011 & 0.0864 & 0.3485 & 0.0397 & 0.2689 & 0.0627 \\
\hline
\end{tabular}

- In red: Highest absolute loadings that rank higher on other variables.

- In bold: Highest absolute loadings that rank higher on the own variables. 


\begin{tabular}{|c|c|c|c|c|c|c|c|c|c|c|c|c|c|c|c|}
\hline & DMS & IQ & $\begin{array}{c}\text { IQ } x \\
\text { WAAS }\end{array}$ & $\begin{array}{c}\text { IQ x } \\
\text { WABS }\end{array}$ & $\begin{array}{c}\text { IQ x } \\
\text { WATS }\end{array}$ & WAAS & $\begin{array}{l}\text { WAAS } \\
\quad x \\
\text { WATS }\end{array}$ & WABS & $\begin{array}{l}\text { WABS } \\
\quad x \\
\text { WAAS }\end{array}$ & $\begin{array}{l}\text { WABS } \\
x \\
\text { WATS }\end{array}$ & WATS & $\begin{array}{c}\text { IQ } x \\
\text { WAAS } \\
x \\
\text { WATS }\end{array}$ & $\begin{array}{c}\text { IQ } x \\
\text { WABS } \\
x \\
\text { WATS }\end{array}$ & $\begin{array}{c}\text { IQ } x \\
\text { WABS } \\
x \\
\text { WAAS }\end{array}$ & $\begin{array}{c}\text { WABS } \\
x \\
\text { WAAS } \\
x \\
\text { WATS }\end{array}$ \\
\hline $\begin{array}{l}\text { IQU_1_R x WABS_2 x } \\
\text { WATS_1 }\end{array}$ & -0.0652 & 0.1897 & -0.107 & -0.3535 & -0.1868 & -0.1061 & 0.2472 & 0.079 & 0.3599 & 0.3588 & -0.0825 & 0.254 & -0.2436 & 0.1986 & -0.2697 \\
\hline $\begin{array}{l}\text { IQU_1_R x WABS_2 x } \\
\text { WATS_2 }\end{array}$ & -0.1082 & 0.0957 & 0.1243 & -0.4071 & -0.244 & -0.1534 & 0.2144 & 0.0127 & 0.4019 & 0.3717 & -0.1113 & 0.1869 & -0.3643 & 0.0543 & -0.2219 \\
\hline $\begin{array}{l}\text { IQU_1_R x WABS_2 x } \\
\text { WATS_3 }\end{array}$ & -0.0657 & 0.1414 & -0.1128 & -0.3337 & -0.2093 & -0.1244 & 0.2395 & 0.1207 & 0.376 & 0.4154 & -0.157 & 0.2503 & -0.3057 & 0.1931 & -0.2943 \\
\hline $\begin{array}{l}\text { IQU_1_R x WABS_3 x } \\
\text { WATS_1 } \\
\text { IOU } 1 \mathrm{R} \times \text { WABS } 3 \times\end{array}$ & -0.1258 & 0.205 & -0.037 & -0.3879 & -0.1995 & -0.1061 & 0.2372 & 0.0883 & 0.3993 & 0.4019 & -0.1536 & 0.21 & -0.3551 & 0.0651 & -0.3172 \\
\hline WATS_2 & -0.044 & 0.234 & -0.0668 & -0.3994 & -0.1932 & -0.1034 & 0.1442 & 0.0494 & 0.4164 & 0.3408 & -0.1613 & 0.2364 & -0.3712 & 0.0744 & -0.2375 \\
\hline $\begin{array}{l}\text { IQU_1_R x WABS_3 x } \\
\text { WATS_3 } \\
\text { IOU } 1 \text { R x WABS } 4 \text { x }\end{array}$ & -0.0992 & 0.1544 & 0.0062 & -0.4088 & -0.2243 & -0.1697 & 0.2714 & 0.0976 & 0.4798 & 0.5078 & -0.2081 & 0.186 & -0.4675 & 0.0316 & -0.3655 \\
\hline $\begin{array}{l}\text { IQU_1_R x WABS_4 x } \\
\text { WATS_1 } \\
\text { IQU_1_R x WABS_4 x }\end{array}$ & -0.1043 & 0.2345 & -0.1172 & 0.0529 & -0.1196 & -0.1476 & 0.394 & -0.0277 & 0.3716 & 0.3287 & -0.0432 & 0.294 & -0.0084 & 0.1934 & -0.4947 \\
\hline WATSS_2 & 0.0385 & 0.2466 & -0.148 & 0.1215 & -0.036 & -0.0897 & 0.2195 & -0.0382 & 0.3188 & 0.1714 & 0.0616 & 0.2962 & 0.1107 & 0.1615 & -0.3248 \\
\hline $\begin{array}{l}\text { IQU_1_R x WABS_4 x } \\
\text { WATS_3 } \\
\text { IQU_2_R x WABS_1 x }\end{array}$ & 0.0352 & 0.2446 & -0.2078 & 0.0666 & -0.0366 & -0.0665 & 0.2514 & 0.1048 & 0.3028 & 0.2657 & 0.038 & 0.2936 & 0.0876 & 0.234 & -0.3668 \\
\hline WATS_1 & 0.022 & 0.0782 & -0.1229 & -0.1128 & -0.0074 & -0.2488 & 0.2292 & -0.0099 & 0.4746 & 0.3487 & 0.0321 & 0.2819 & -0.2516 & -0.009 & -0.2176 \\
\hline $\begin{array}{l}\text { WATS_2 } \\
\text { IQU_2_R x WABS_1 x }\end{array}$ & -0.0391 & 0.0543 & -0.0013 & -0.124 & -0.0145 & -0.2192 & 0.2397 & 0.0617 & 0.4294 & 0.3633 & 0.0522 & 0.236 & -0.25 & -0.0416 & -0.2087 \\
\hline $\begin{array}{l}\text { WATS_3 } \\
\text { IQU_2_R x }\end{array}$ & -0.0397 & 0.0218 & -0.1521 & -0.0547 & 0.0464 & -0.2462 & 0.2346 & 0.0782 & 0.467 & 0.3672 & -0.0149 & 0.2817 & -0.2012 & -0.0169 & -0.247 \\
\hline WATS_1 & 0.0806 & 0.0682 & -0.122 & -0.1849 & 0.0062 & -0.1335 & -0.0135 & 0.0993 & 0.2438 & 0.0869 & 0.0455 & 0.2739 & -0.159 & 0.0528 & 0.1224 \\
\hline $\begin{array}{l}\text { IQU_2_R x WABS_2 x } \\
\text { WATS_2 }\end{array}$ & -0.0024 & 0.0291 & 0.025 & -0.267 & -0.0677 & -0.1479 & 0.044 & 0.0972 & 0.2634 & 0.1646 & -0.0037 & 0.204 & -0.2722 & -0.0082 & 0.0671 \\
\hline $\begin{array}{l}\text { IQU_2_R x WABS_2 x } \\
\text { WATS_3 }\end{array}$ & 0.0032 & -0.0289 & -0.1232 & -0.1819 & 0.0005 & -0.1699 & 0.0513 & 0.1364 & 0.2748 & 0.2108 & -0.0635 & 0.2267 & -0.217 & 0.0163 & 0.027 \\
\hline $\begin{array}{l}\text { IQU_2_R x WABS_3 x } \\
\text { WATS_1 }\end{array}$ & 0.0629 & 0.0636 & -0.1309 & -0.2034 & 0.0281 & -0.1676 & -0.0321 & 0.0119 & 0.2684 & 0.0961 & -0.1305 & 0.1572 & -0.2466 & -0.0455 & 0.098 \\
\hline $\begin{array}{l}\text { IQU_2_R x WABS_3 x } \\
\text { WATS_2 }\end{array}$ & 0.0302 & 0.079 & -0.0854 & -0.2496 & -0.0175 & -0.1237 & -0.0093 & 0.0918 & 0.2379 & 0.1388 & -0.1915 & 0.1402 & -0.3141 & 0.0016 & 0.0561 \\
\hline $\begin{array}{l}\text { IQU_2_R x WABS_3 x } \\
\text { WATS_3 }\end{array}$ & -0.0343 & -0.0463 & -0.0553 & -0.1854 & 0.0427 & -0.1871 & 0.0439 & 0.1159 & 0.2961 & 0.2461 & -0.2047 & 0.1085 & -0.3251 & -0.076 & 0.0094 \\
\hline $\begin{array}{l}\text { IQU_2_R x WABS_4 x } \\
\text { WATS_1 }\end{array}$ & 0.1174 & 0.0216 & -0.2056 & 0.3139 & 0.3149 & -0.1261 & -0.0089 & -0.0649 & 0.1088 & -0.1106 & 0.0412 & 0.3098 & 0.2334 & 0.0899 & 0.0352 \\
\hline $\begin{array}{l}\text { IQU_2_R x WABS_4 x } \\
\text { WATS_2 }\end{array}$ & 0.0738 & 0.0834 & -0.166 & 0.2705 & 0.2908 & -0.0626 & 0.0053 & 0.0182 & 0.0886 & -0.0708 & 0.0621 & 0.3027 & 0.2361 & 0.1232 & -0.0134 \\
\hline
\end{tabular}




\begin{tabular}{|c|c|c|c|c|c|c|c|c|c|c|c|c|c|c|c|}
\hline & DMS & IQ & $\begin{array}{c}\text { IQ x } \\
\text { WAAS }\end{array}$ & $\begin{array}{c}\text { IQ x } \\
\text { WABS }\end{array}$ & $\begin{array}{c}\text { IQ x } \\
\text { WATS }\end{array}$ & WAAS & $\begin{array}{c}\text { WAAS } \\
\text { X } \\
\text { WATS }\end{array}$ & WABS & $\begin{array}{c}\text { WABS } \\
x \\
\text { WAAS }\end{array}$ & $\begin{array}{c}\text { WABS } \\
\text { X } \\
\text { WATS }\end{array}$ & WATS & $\begin{array}{c}\text { IQ } x \\
\text { WAAS } \\
x \\
\text { WATS }\end{array}$ & $\begin{array}{c}\text { IQ } x \\
\text { WABS } \\
x \\
\text { WATS }\end{array}$ & $\begin{array}{c}\text { IQ } x \\
\text { WABS } \\
x \\
\text { WAAS }\end{array}$ & $\begin{array}{c}\text { WABS } \\
x \\
\text { WAAS } \\
x \\
\text { WATS }\end{array}$ \\
\hline IQU_2_R x WABS_4 x WATS_3 & 0.0111 & -0.0241 & -0.1728 & 0.2607 & 0.3016 & -0.1251 & 0.036 & 0.0598 & 0.1547 & 0.039 & 0.0101 & 0.2523 & 0.1834 & 0.0598 & -0.043 \\
\hline IQU_3 x WABS_1 x WATS_1 & 0.1109 & 0.1299 & 0.1773 & -0.3144 & -0.0793 & 0.1711 & -0.0804 & 0.3167 & 0.057 & 0.0773 & 0.3279 & 0.1806 & 0.0213 & 0.1905 & 0.2528 \\
\hline IQU_3 x WABS_1 x WATS_2 & 0.1313 & 0.2026 & 0.0787 & -0.3238 & -0.0657 & 0.2087 & -0.1185 & 0.3348 & 0.0414 & 0.0663 & 0.3912 & 0.2591 & 0.0897 & 0.2785 & 0.2643 \\
\hline IQU_3 x WABS_1 x WATS_3 & 0.124 & 0.1423 & 0.1247 & -0.3198 & -0.1246 & 0.1926 & -0.1737 & 0.2964 & 0.0049 & 0.0337 & 0.3652 & 0.2322 & 0.1091 & 0.2084 & 0.2853 \\
\hline IQU_3 x WABS_2 $x$ WATS_1 & -0.0483 & 0.1232 & 0.1498 & -0.4089 & -0.0848 & 0.0133 & 0.0251 & 0.1615 & 0.2173 & 0.1522 & 0.1076 & 0.1652 & -0.1674 & 0.1392 & 0.0148 \\
\hline IQU_3 x WABS_2 x WATS_2 & -0.0519 & 0.1945 & 0.053 & -0.4593 & -0.0744 & 0.0394 & -0.0015 & 0.1996 & 0.1943 & 0.1545 & 0.1322 & 0.1842 & -0.176 & 0.2177 & 0.0797 \\
\hline IQU_3 x WABS_2 x WATS_3 & -0.0023 & 0.0785 & 0.1242 & -0.4135 & -0.1286 & -0.0288 & 0.0118 & 0.1562 & 0.165 & 0.2034 & 0.1034 & 0.17 & -0.1698 & 0.1176 & 0.0459 \\
\hline IQU_3 x WABS_3 x WATS_1 & 0.0553 & 0.3093 & -0.0559 & -0.3366 & -0.1473 & 0.0165 & 0.0544 & 0.1107 & 0.2652 & 0.1809 & 0.0211 & 0.119 & -0.1881 & 0.0989 & -0.0068 \\
\hline IQU_3 x WABS_3 $x$ WATS_2 & 0.0532 & 0.2941 & -0.0033 & -0.4186 & -0.1602 & 0.0528 & -0.0136 & 0.1596 & 0.1788 & 0.1409 & 0.0045 & 0.1181 & -0.2062 & 0.1896 & 0.0639 \\
\hline IQU_3 x WABS_3 $x$ WATS_3 & 0.0438 & 0.2155 & -0.0114 & -0.4281 & -0.2055 & 0.051 & -0.0244 & 0.2007 & 0.151 & 0.1832 & 0.0049 & 0.1357 & -0.1761 & 0.1638 & 0.0398 \\
\hline IQU_3 x WABS_4 $\mathrm{x}$ WATS_1 & 0.0433 & 0.207 & 0.0884 & -0.001 & 0.0364 & 0.0802 & 0.0146 & 0.0255 & 0.1016 & 0.0249 & 0.0838 & 0.362 & 0.2206 & 0.25 & -0.0618 \\
\hline IQU_3 x WABS_4 x WATS_2 & 0.1155 & 0.3642 & -0.0523 & 0.0043 & 0.1056 & 0.1755 & -0.0554 & 0.0997 & 0.0259 & -0.0252 & 0.1601 & 0.4356 & 0.3219 & 0.3542 & 0.0151 \\
\hline IQU_3 x WABS_4 x WATS_3 & 0.0799 & 0.2455 & -0.0549 & -0.0083 & 0.0191 & 0.1313 & -0.0586 & 0.1312 & 0.0125 & 0.0412 & 0.1392 & 0.3895 & 0.2979 & 0.2793 & -0.0162 \\
\hline IQU_4 x WABS_1 x WATS_1 & 0.0277 & 0.0693 & -0.0738 & -0.257 & 0.142 & -0.0045 & -0.07 & 0.1872 & 0.1705 & 0.1523 & 0.1319 & 0.1719 & -0.2272 & 0.1302 & 0.1809 \\
\hline IQU_4 x WABS_1 x WATS_2 & 0.0355 & 0.0697 & 0.0392 & -0.3122 & 0.0981 & 0.0355 & -0.0578 & 0.2768 & 0.1536 & 0.188 & 0.1646 & 0.1683 & -0.2415 & 0.1112 & 0.1682 \\
\hline IQU_4 x WABS_1 x WATS_3 & 0.1309 & 0.1209 & -0.1639 & -0.2599 & 0.1279 & 0.069 & -0.0996 & 0.301 & 0.1429 & 0.1335 & 0.1831 & 0.2749 & -0.117 & 0.2111 & 0.1899 \\
\hline IQU_4 x WABS_2 x WATS_1 & -0.2198 & 0.0881 & -0.0097 & -0.2954 & -0.0739 & -0.1566 & 0.3098 & 0.081 & 0.4355 & 0.5556 & -0.1394 & 0.0931 & -0.5153 & 0.0415 & -0.3815 \\
\hline IQU_4 x WABS_2 x WATS_2 & -0.1804 & 0.0917 & 0.0761 & -0.3586 & -0.0608 & -0.0965 & 0.2352 & 0.1913 & 0.3516 & 0.5144 & -0.0921 & 0.0944 & -0.5173 & 0.053 & -0.2679 \\
\hline IQU_4 x WABS_2 x WATS_3 & -0.1411 & 0.1283 & -0.1146 & -0.3611 & -0.0486 & -0.1181 & 0.2838 & 0.1516 & 0.4088 & 0.5162 & -0.1007 & 0.1583 & -0.4474 & 0.1238 & -0.3272 \\
\hline IQU_4 x WABS_3 x WATS_1 & -0.1782 & 0.2017 & -0.0052 & -0.314 & -0.191 & -0.1656 & 0.3368 & 0.0506 & 0.4742 & 0.5712 & -0.1426 & 0.0396 & -0.5732 & -0.0354 & -0.3963 \\
\hline IQU_4 x WABS_3 $x$ WATS_2 & -0.1142 & 0.2077 & 0.0115 & -0.353 & -0.1719 & -0.0774 & 0.2303 & 0.1923 & 0.3446 & 0.4938 & -0.1106 & 0.0788 & -0.5364 & 0.0692 & -0.2667 \\
\hline IQU_4 x WABS_3 $x$ WATS_3 & -0.1255 & 0.162 & -0.0211 & -0.4067 & -0.2062 & -0.1329 & 0.2808 & 0.1293 & 0.4351 & 0.5264 & -0.1329 & 0.0999 & -0.5319 & 0.0356 & -0.3436 \\
\hline IQU_4 x WABS_4 x WATS_1 & -0.1264 & 0.182 & 0.0744 & 0.1072 & -0.1595 & -0.062 & 0.4042 & -0.0394 & 0.3448 & 0.491 & -0.0884 & 0.3219 & -0.1153 & 0.1447 & -0.5664 \\
\hline IQU_4 x WABS_4 x WATS_2 & -0.0388 & 0.278 & 0.037 & 0.1336 & -0.1107 & 0.044 & 0.322 & 0.1006 & 0.2425 & 0.4371 & -0.0095 & 0.4012 & -0.0154 & 0.2294 & -0.465 \\
\hline IQU_4 x WABS_4 $\mathrm{x}$ WATS_3 & -0.016 & 0.2287 & -0.0782 & 0.0434 & -0.1411 & -0.0231 & 0.3614 & 0.0415 & 0.3319 & 0.4412 & -0.0119 & 0.4113 & -0.0112 & 0.2172 & -0.5139 \\
\hline WAAS_1 x IQI_2 x WABS_1 & 0.1595 & 0.0565 & 0.2111 & 0.0143 & -0.1606 & 0.4136 & -0.2937 & 0.174 & -0.3973 & -0.2942 & 0.2616 & -0.0031 & 0.4522 & 0.2343 & 0.3793 \\
\hline WAAS_1 x IQI_2 x WABS_2 & 0.2016 & 0.1382 & 0.1399 & 0.058 & -0.1231 & 0.4046 & -0.1681 & 0.1977 & -0.3088 & -0.2302 & 0.3055 & 0.0642 & 0.4817 & 0.2791 & 0.2605 \\
\hline WAAS_1 x IQI_2 x WABS_3 & 0.1912 & 0.2261 & 0.0289 & 0.0541 & -0.1562 & 0.4247 & -0.2204 & 0.2161 & -0.4132 & -0.2912 & 0.2924 & 0.0519 & 0.5401 & 0.4162 & 0.2861 \\
\hline WAAS_1 x IQI_2 x WABS_4 & 0.0406 & 0.1266 & 0.2518 & -0.327 & -0.1744 & 0.2918 & -0.251 & 0.2194 & -0.1974 & -0.0947 & 0.1469 & -0.0626 & 0.0776 & 0.1396 & 0.3346 \\
\hline WAAS_2 x IQI_2 x WABS_1 & 0.3784 & 0.4015 & -0.1755 & 0.1893 & -0.0161 & 0.5232 & -0.1339 & 0.3567 & -0.4262 & -0.2969 & 0.3166 & 0.2329 & 0.6945 & 0.6999 & 0.2601 \\
\hline WAAS_2 x IQI_2 x WABS_2 & 0.3689 & 0.4065 & -0.1577 & 0.1898 & -0.0275 & 0.4848 & -0.0809 & 0.3023 & -0.363 & -0.2715 & 0.2813 & 0.3038 & 0.625 & 0.7061 & 0.1997 \\
\hline WAAS_2 x IQI_2 x WABS_3 & 0.216 & 0.3037 & 0.0555 & 0.1273 & -0.0881 & 0.3873 & -0.0923 & 0.2149 & -0.3692 & -0.2498 & 0.257 & 0.2414 & 0.5558 & 0.5541 & 0.1813 \\
\hline WAAS_2 x IQI_2 x WABS_4 & 0.2111 & 0.3292 & -0.0382 & -0.3284 & -0.0319 & 0.4126 & -0.1792 & 0.4821 & -0.2565 & -0.0883 & 0.1997 & 0.1984 & 0.1585 & 0.5781 & 0.2922 \\
\hline WAAS_3 x IQI_2 x WABS_1 & 0.3233 & 0.447 & -0.4306 & 0.1587 & 0.0099 & 0.4814 & -0.1173 & 0.351 & -0.4115 & -0.2701 & 0.2622 & 0.1983 & 0.5921 & 0.8065 & 0.2391 \\
\hline WAAS_3 x IQI_2 x WABS_2 & 0.2904 & 0.4422 & -0.4264 & 0.1502 & 0.0248 & 0.4316 & -0.0708 & 0.2908 & -0.3384 & -0.2571 & 0.253 & 0.2445 & 0.5566 & 0.7883 & 0.1962 \\
\hline WAAS_3 x IQI_2 x WABS_3 & 0.1866 & 0.2211 & 0.023 & 0.1108 & -0.0603 & 0.399 & -0.113 & 0.2068 & -0.3991 & -0.3134 & 0.295 & 0.189 & 0.6045 & 0.5975 & 0.2326 \\
\hline
\end{tabular}

- In red: Highest absolute loadings that rank higher on other variables.

- In bold: Highest absolute loadings that rank higher on the own variables. 


\begin{tabular}{|c|c|c|c|c|c|c|c|c|c|c|c|c|c|c|c|}
\hline & DMS & IQ & $\begin{array}{c}\text { IQ } x \\
\text { WAAS }\end{array}$ & $\begin{array}{c}\text { IQ } x \\
\text { WABS }\end{array}$ & $\begin{array}{l}\text { IQ } x \\
\text { WATS }\end{array}$ & WAAS & $\begin{array}{c}\text { WAAS } \\
\text { X } \\
\text { WATS }\end{array}$ & WABS & $\begin{array}{c}\text { WABS } \\
x \\
\text { WAAS }\end{array}$ & $\begin{array}{c}\text { WABS } \\
x \\
\text { WATS }\end{array}$ & WATS & $\begin{array}{c}\text { IQ } x \\
\text { WAAS } \\
x \\
\text { WATS }\end{array}$ & $\begin{array}{c}\text { IQ } x \\
\text { WABS } \\
x \\
\text { WATS }\end{array}$ & $\begin{array}{c}\text { IQ } x \\
\text { WABS } \\
x \\
\text { WAAS }\end{array}$ & $\begin{array}{c}\text { WABS } \\
x \\
\text { WAAS } \\
x \\
\text { WATS }\end{array}$ \\
\hline WAAS_3 x IQI_2 x WABS_4 & 0.2081 & 0.4263 & -0.3081 & -0.2611 & -0.0108 & 0.4121 & -0.1645 & 0.4243 & -0.2759 & -0.1297 & 0.186 & 0.1745 & 0.2045 & 0.7115 & 0.2949 \\
\hline WAAS_4 x IQI_2 x WABS_1 & 0.2036 & 0.3782 & -0.1496 & 0.1017 & -0.0581 & 0.4385 & -0.1516 & 0.3171 & -0.4297 & -0.2569 & 0.2348 & 0.136 & 0.5064 & 0.7412 & 0.253 \\
\hline WAAS_4 x IQI_2 x WABS_2 & 0.1795 & 0.3916 & -0.1218 & 0.0921 & -0.0947 & 0.3943 & -0.0941 & 0.2928 & -0.3582 & -0.1969 & 0.197 & 0.2078 & 0.4274 & 0.7318 & 0.163 \\
\hline WAAS_4 x IQI_2 x WABS_3 & 0.2336 & 0.3329 & -0.0107 & 0.1251 & -0.1487 & 0.4261 & -0.1373 & 0.2716 & -0.4316 & -0.2683 & 0.2136 & 0.228 & 0.5595 & 0.6724 & 0.2142 \\
\hline WAAS_4 x IQI_2 x WABS_4 & 0.156 & 0.4586 & -0.2295 & -0.2244 & -0.0483 & 0.3904 & -0.1828 & 0.4434 & -0.2802 & -0.0912 & 0.1812 & 0.1724 & 0.1883 & 0.705 & 0.2542 \\
\hline IQU_1_R x WABS_1 x WAAS_1 & 0.0859 & 0.0032 & 0.0037 & 0.0241 & 0.01 & -0.1329 & 0.1913 & 0.005 & 0.3845 & 0.2641 & -0.0505 & 0.2721 & -0.3029 & -0.1165 & -0.2046 \\
\hline IQU_1_R x WABS_1 x WAAS_2 & 0.2026 & 0.2287 & -0.2285 & -0.083 & -0.0296 & 0.0112 & -0.0416 & 0.0946 & 0.2618 & 0.0611 & -0.0297 & 0.255 & -0.0778 & 0.2199 & 0.0227 \\
\hline IQU_1_R x WABS_1 x WAAS_3 & 0.1954 & 0.3522 & -0.47 & -0.0881 & 0.019 & 0.1204 & 0.0182 & 0.2546 & 0.0852 & 0.0671 & 0.0292 & 0.2716 & -0.009 & 0.5122 & 0.0198 \\
\hline IQU_1_R x WABS_1 x WAAS_4 & 0.1038 & 0.2901 & -0.2365 & -0.0945 & -0.0235 & 0.0539 & 0.0459 & 0.2604 & 0.1145 & 0.1271 & -0.0174 & 0.2026 & -0.0726 & 0.4422 & -0.0098 \\
\hline IQU_1_R x WABS_2 x WAAS_1 & -0.0615 & 0.0961 & 0.0085 & -0.1289 & -0.1506 & -0.2071 & 0.4432 & -0.0434 & 0.5839 & 0.5193 & -0.1355 & 0.2682 & -0.4401 & -0.1057 & -0.52 \\
\hline IQU_1_R x WABS_2 x WAAS_2 & 0.0607 & 0.2847 & -0.1436 & -0.2058 & -0.1945 & -0.0333 & 0.2086 & 0.1006 & 0.3901 & 0.3315 & -0.1158 & 0.2724 & -0.2622 & 0.2278 & -0.233 \\
\hline IQU_1_R x WABS_2 x WAAS_3 & 0.0723 & 0.377 & -0.3894 & -0.142 & -0.0971 & 0.101 & 0.141 & 0.2705 & 0.1442 & 0.2187 & -0.0163 & 0.2733 & -0.1051 & 0.5007 & -0.1278 \\
\hline IQU_1_R x WABS_2 x WAAS_4 & -0.0742 & 0.2976 & -0.1587 & -0.2137 & -0.1827 & -0.0427 & 0.2493 & 0.1638 & 0.2549 & 0.3393 & -0.1384 & 0.1911 & -0.2554 & 0.4068 & -0.2698 \\
\hline IQU_1_R x WABS_3 x WAAS_1 & -0.0412 & 0.1785 & -0.119 & -0.1129 & -0.1226 & -0.2184 & 0.4562 & -0.0316 & 0.5815 & 0.5343 & -0.139 & 0.2985 & -0.4721 & -0.0198 & -0.5651 \\
\hline IQU_1_R x WABS_3 $x$ WAAS_2 & -0.0773 & 0.1579 & 0.0893 & -0.2805 & -0.2205 & -0.1427 & 0.1964 & 0.0453 & 0.4457 & 0.3718 & -0.0914 & 0.25 & -0.3745 & 0.0839 & -0.2805 \\
\hline IQU_1_R x WABS_3 x WAAS_3 & -0.0761 & 0.1709 & 0.0116 & -0.2804 & -0.1745 & -0.0721 & 0.2045 & 0.168 & 0.3354 & 0.374 & -0.0465 & 0.243 & -0.3347 & 0.1861 & -0.2401 \\
\hline IQU_1_R x WABS_3 $x$ WAAS_4 & -0.0595 & 0.2629 & -0.0863 & -0.3057 & -0.2018 & -0.1621 & 0.3266 & 0.1132 & 0.4883 & 0.482 & -0.162 & 0.2764 & -0.4047 & 0.2218 & -0.4029 \\
\hline IQU_1_R x WABS_4 x WAAS_1 & -0.0861 & 0.1113 & 0.0564 & 0.1382 & -0.0517 & -0.2412 & 0.522 & -0.1641 & 0.5255 & 0.4843 & -0.2035 & 0.2831 & -0.3201 & -0.092 & -0.645 \\
\hline IQU_1_R x WABS_4 x WAAS_2 & 0.1141 & 0.2749 & -0.1483 & 0.1836 & -0.0178 & -0.0459 & 0.2372 & -0.0303 & 0.3376 & 0.2294 & -0.0511 & 0.3016 & 0.0071 & 0.2052 & -0.3598 \\
\hline IQU_1_R x WABS_4 x WAAS_3 & 0.1197 & 0.3883 & -0.3409 & 0.1517 & 0.0016 & 0.0757 & 0.2289 & 0.1802 & 0.1313 & 0.216 & -0.0275 & 0.3085 & 0.0456 & 0.4937 & -0.2906 \\
\hline IQU_1_R x WABS_4 x WAAS_4 & 0.0373 & 0.3738 & -0.2994 & 0.0735 & -0.0041 & -0.0195 & 0.2877 & 0.1266 & 0.2497 & 0.2888 & -0.0631 & 0.2889 & -0.0057 & 0.451 & -0.3844 \\
\hline IQU_2_R x WABS_1 x WAAS_1 & 0.0523 & 0 & -0.1339 & 0.2248 & 0.1059 & -0.289 & 0.3661 & -0.1576 & 0.5174 & 0.3492 & -0.1698 & 0.2791 & -0.3683 & -0.164 & -0.4439 \\
\hline IQU_2_R x WABS_1 x WAAS_2 & 0.0415 & 0.1442 & -0.112 & -0.0445 & 0.0163 & -0.1715 & 0.2303 & 0.1024 & 0.4251 & 0.3351 & -0.1567 & 0.2765 & -0.328 & 0.0781 & -0.2895 \\
\hline IQU_2_R x WABS_1 x WAAS_3 & 0.0522 & 0.2238 & -0.2585 & 0.0324 & 0.0574 & -0.1292 & 0.2438 & 0.1178 & 0.3715 & 0.3168 & -0.1421 & 0.2973 & -0.2874 & 0.2036 & -0.288 \\
\hline
\end{tabular}

- In red: Highest absolute loadings that rank higher on other variables.

- In bold: Highest absolute loadings that rank higher on the own variables. 


\begin{tabular}{|c|c|c|c|c|c|c|c|c|c|c|c|c|c|c|c|}
\hline & DMS & IQ & $\begin{array}{l}\text { IQ } x \\
\text { WAAS }\end{array}$ & $\begin{array}{l}\text { IQ } x \\
\text { WABS }\end{array}$ & $\begin{array}{l}\text { IQ } x \\
\text { WATS }\end{array}$ & WAAS & $\begin{array}{l}\text { WAAS } \\
\mathrm{x} \text { WATS }\end{array}$ & WABS & $\begin{array}{c}\text { WABS } \\
\mathrm{X} \\
\text { WAAS }\end{array}$ & $\begin{array}{c}\text { WABS } \\
x \\
\text { WATS }\end{array}$ & WATS & $\begin{array}{c}\text { IQ } \mathrm{x} \\
\text { WAAS } \\
\mathrm{x} \text { WATS }\end{array}$ & $\begin{array}{c}\text { IQ } x \\
\text { WABS } \\
x \\
\text { WATS }\end{array}$ & $\begin{array}{c}\text { IQ } x \\
\text { WABS } \\
x \\
\text { WAAS }\end{array}$ & $\begin{array}{c}\text { WABS } \\
x \\
\text { WAAS } \\
x \text { WATS }\end{array}$ \\
\hline $\begin{array}{l}\text { IQU_2_R x WABS_1 x } \\
\text { WAAS_4 }\end{array}$ & -0.0125 & 0.1596 & -0.1636 & 0.0339 & 0.0528 & -0.182 & 0.2474 & 0.0738 & 0.4302 & 0.3592 & -0.1424 & 0.2728 & -0.2911 & 0.146 & -0.3073 \\
\hline $\begin{array}{l}\text { IQU_2_R x WABS_2 x } \\
\text { WAAS_1 }\end{array}$ & 0.1108 & 0.0194 & -0.13 & 0.1967 & 0.1468 & -0.2375 & 0.2303 & -0.0824 & 0.4054 & 0.2225 & -0.097 & 0.2959 & -0.2817 & -0.1358 & -0.2555 \\
\hline $\begin{array}{l}\text { IQU_2_R x WABS_2 x } \\
\text { WAAS_2 }\end{array}$ & 0.0957 & 0.161 & -0.0965 & -0.1021 & 0.0087 & -0.0788 & 0.0743 & 0.1994 & 0.2687 & 0.2205 & -0.1083 & 0.2635 & -0.2767 & 0.145 & -0.0476 \\
\hline $\begin{array}{l}\text { IQU_2_R x WABS_2 x } \\
\text { WAAS_3 }\end{array}$ & 0.0902 & 0.2404 & -0.259 & 0.0063 & 0.0261 & -0.046 & 0.1151 & 0.223 & 0.2276 & 0.2436 & -0.1022 & 0.2778 & -0.2276 & 0.2719 & -0.112 \\
\hline $\begin{array}{l}\text { IQU_2_R x WABS_2 x } \\
\text { WAAS_4 }\end{array}$ & 0.0369 & 0.1676 & -0.1701 & -0.0408 & 0.0607 & -0.1151 & 0.0737 & 0.1312 & 0.2536 & 0.1931 & -0.0959 & 0.2455 & -0.2086 & 0.2297 & -0.0488 \\
\hline $\begin{array}{l}\text { IQU_2_R x WABS_3 x } \\
\text { WAAS_1 }\end{array}$ & 0.1297 & 0.0416 & -0.1876 & 0.2291 & 0.1843 & -0.2282 & 0.2553 & -0.0848 & 0.4069 & 0.2405 & -0.1053 & 0.2854 & -0.2917 & -0.1083 & -0.2708 \\
\hline $\begin{array}{l}\text { IQU_2_R x WABS_3 x } \\
\text { WAAS_2 }\end{array}$ & 0.0409 & 0.0722 & 0.0245 & -0.0834 & 0.0481 & -0.1235 & 0.1054 & 0.1897 & 0.2871 & 0.2766 & -0.1077 & 0.228 & -0.3418 & 0.0265 & -0.0785 \\
\hline $\begin{array}{l}\text { IQU_2_R x WABS_3 x } \\
\text { WAAS_3 }\end{array}$ & -0.0065 & 0.0487 & 0.027 & 0.0116 & 0.0228 & -0.1282 & 0.1735 & 0.1787 & 0.3275 & 0.3476 & -0.1286 & 0.2254 & -0.3711 & 0.004 & -0.171 \\
\hline $\begin{array}{l}\text { IQU_2_R x WABS_3 x } \\
\text { WAAS_4 }\end{array}$ & 0.0556 & 0.0736 & -0.1161 & -0.0245 & 0.1181 & -0.169 & 0.122 & 0.1128 & 0.3483 & 0.2554 & -0.1156 & 0.2528 & -0.2679 & 0.0641 & -0.0787 \\
\hline $\begin{array}{l}\text { IQU_2_R x WABS_4 x } \\
\text { WAAS_1 }\end{array}$ & 0.146 & 0.0382 & -0.1871 & 0.4155 & 0.2336 & -0.2145 & 0.2849 & -0.1652 & 0.3453 & 0.1629 & -0.118 & 0.2749 & -0.1586 & -0.0963 & -0.3166 \\
\hline $\begin{array}{l}\text { IQU_2_R x WABS_4 x } \\
\text { WAAS_2 }\end{array}$ & 0.1155 & 0.1387 & -0.0842 & 0.3447 & 0.2423 & -0.0456 & 0.1263 & 0.1301 & 0.1247 & 0.089 & -0.0489 & 0.2541 & 0.0288 & 0.1913 & -0.1522 \\
\hline $\begin{array}{l}\text { IQU_2_R x WABS_4 x } \\
\text { WAAS_3 }\end{array}$ & 0.0655 & 0.2033 & -0.1833 & 0.3913 & 0.179 & -0.0189 & 0.195 & 0.1366 & 0.1359 & 0.1644 & -0.0833 & 0.2591 & -0.016 & 0.2561 & -0.2206 \\
\hline $\begin{array}{l}\text { IQU_2_R x WABS_4 x } \\
\text { WAAS_4 }\end{array}$ & 0.0908 & 0.183 & -0.2449 & 0.3077 & 0.2642 & -0.089 & 0.1134 & 0.0704 & 0.2047 & 0.0999 & -0.0272 & 0.279 & 0.0464 & 0.2454 & -0.1306 \\
\hline WAAS_1 x IQU_3 x WABS_1 & 0.1352 & 0.1591 & 0.2334 & -0.2943 & -0.1789 & 0.2929 & -0.3669 & 0.2279 & -0.0942 & -0.1449 & 0.2376 & 0.1537 & 0.1072 & 0.267 & 0.3866 \\
\hline WAAS_1 x IQU_3 x WABS_2 & 0.0523 & 0.1977 & 0.168 & -0.3023 & -0.1314 & 0.125 & -0.153 & 0.1334 & 0.1243 & 0.058 & 0.1066 & 0.1111 & -0.0804 & 0.2062 & 0.109 \\
\hline WAAS_1 x IQU_3 x WABS_3 & 0.0898 & 0.3109 & 0.1555 & -0.3336 & -0.1786 & 0.2274 & -0.1432 & 0.2269 & 0.0814 & 0.0908 & 0.1045 & 0.1415 & -0.0834 & 0.2532 & 0.1027 \\
\hline WAAS_1 x IQU_3 x WABS_4 & 0.0664 & 0.3662 & 0.1577 & 0.001 & -0.2305 & 0.2364 & -0.0633 & 0.0894 & -0.012 & -0.0174 & 0.125 & 0.174 & 0.1588 & 0.3023 & 0.0384 \\
\hline WAAS_2 x IQU_3 x WABS_1 & 0.2351 & 0.2786 & 0.1066 & -0.3472 & -0.0231 & 0.27 & -0.1954 & 0.3593 & -0.0102 & 0.0096 & 0.1642 & 0.1199 & 0.0097 & 0.4021 & 0.3011 \\
\hline WAAS_2 x IQU_3 x WABS_2 & 0.0352 & 0.2629 & 0.1446 & -0.3263 & -0.0563 & 0.1713 & -0.0603 & 0.3392 & 0.1303 & 0.1969 & -0.0222 & 0.0927 & -0.2056 & 0.3334 & 0.0776 \\
\hline WAAS_2 x IQU_3 x WABS_3 & 0.0486 & 0.2661 & 0.2232 & -0.3327 & -0.0786 & 0.1523 & -0.0696 & 0.3175 & 0.116 & 0.2266 & 0.0495 & 0.2026 & -0.169 & 0.2759 & 0.0569 \\
\hline WAAS_2 x IQU_3 x WABS_4 & 0.1294 & 0.3508 & 0.1369 & 0.0665 & -0.0811 & 0.2642 & 0 & 0.3254 & -0.0699 & 0.0686 & 0.11 & 0.2444 & 0.179 & 0.4863 & -0.0016 \\
\hline WAAS_3 x IQU_3 x WABS_1 & 0.1563 & 0.3401 & 0.0595 & -0.3732 & -0.03 & 0.319 & -0.1776 & 0.4072 & -0.0479 & 0.0417 & 0.1074 & 0.0465 & -0.0551 & 0.4551 & 0.2971 \\
\hline WAAS_3 x IQU_3 x WABS_2 & 0.0307 & 0.2786 & 0.0963 & -0.2494 & -0.0776 & 0.1655 & -0.0062 & 0.3631 & 0.0697 & 0.252 & -0.0586 & 0.0518 & -0.2154 & 0.3255 & 0.0444 \\
\hline WAAS_3 x IQU_3 x WABS_3 & -0.0731 & 0.1505 & 0.3079 & -0.3029 & -0.1209 & 0.1549 & -0.0779 & 0.3667 & 0.0489 & 0.2465 & -0.007 & 0.1363 & -0.2195 & 0.2497 & 0.0448 \\
\hline WAAS_3 x IQU_3 x WABS_4 & 0.0498 & 0.4057 & 0.0542 & 0.0989 & -0.1145 & 0.298 & -0.0044 & 0.3553 & -0.1209 & 0.0894 & 0.0668 & 0.1976 & 0.147 & 0.4744 & -0.0013 \\
\hline WAAS_4 x IQU_3 x WABS_1 & 0.1684 & 0.2945 & -0.0209 & -0.406 & 0.0165 & 0.3524 & -0.222 & 0.47 & -0.113 & -0.0281 & 0.1597 & 0.1155 & 0.0637 & 0.5325 & 0.3538 \\
\hline WAAS_4 x IQU_3 x WABS_2 & 0.0962 & 0.2599 & 0.0337 & -0.4011 & -0.0326 & 0.2056 & -0.0657 & 0.3461 & 0.0668 & 0.1127 & 0.0478 & 0.1939 & -0.0706 & 0.4364 & 0.088 \\
\hline WAAS_4 x IQU_3 x WABS_3 & 0.0539 & 0.2348 & 0.0781 & -0.5067 & -0.0817 & 0.1855 & -0.0849 & 0.3281 & 0.0919 & 0.1466 & 0.0157 & 0.1707 & -0.1532 & 0.3643 & 0.0882 \\
\hline WAAS_4 x IQU_3 x WABS_4 & 0.1253 & 0.3889 & -0.0881 & -0.0928 & -0.0605 & 0.2781 & -0.0161 & 0.3138 & -0.0497 & 0.0133 & 0.1276 & 0.2499 & 0.223 & 0.5279 & 0.0106 \\
\hline
\end{tabular}




\begin{tabular}{|c|c|c|c|c|c|c|c|c|c|c|c|c|c|c|c|}
\hline & DMS & IQ & $\begin{array}{l}\text { IQ } x \\
\text { WAAS }\end{array}$ & $\begin{array}{l}\text { IQ } x \\
\text { WABS }\end{array}$ & $\begin{array}{l}\text { IQ } x \\
\text { WATS }\end{array}$ & WAAS & $\begin{array}{l}\text { WAAS } \\
\mathrm{x} \text { WATS }\end{array}$ & WABS & $\begin{array}{c}\text { WABS } \\
x \\
\text { WAAS }\end{array}$ & $\begin{array}{c}\text { WABS } \\
x \\
\text { WATS }\end{array}$ & WATS & $\begin{array}{c}\text { IQ } x \\
\text { WAAS } \\
x \text { WATS }\end{array}$ & $\begin{array}{c}\text { IQ } x \\
\text { WABS } \\
x \\
\text { WATS }\end{array}$ & $\begin{array}{c}\text { IQ } x \\
\text { WABS } \\
x \\
\text { WAAS }\end{array}$ & $\begin{array}{c}\text { WABS } \\
x \\
\text { WAAS } \\
x \text { WATS }\end{array}$ \\
\hline WAAS_1 x IQU_4 x WABS_1 & 0.1231 & 0.0477 & 0.0925 & -0.1004 & 0.1168 & -0.0244 & -0.0074 & -0.0041 & 0.3113 & 0.1605 & 0.0178 & 0.2845 & -0.2767 & -0.0901 & 0.0193 \\
\hline WAAS_1 x IQU_4 x WABS_2 & -0.118 & 0.1048 & 0.0982 & -0.2375 & -0.0703 & -0.1706 & 0.355 & -0.094 & 0.576 & 0.5115 & -0.167 & 0.1734 & -0.506 & -0.114 & -0.4743 \\
\hline WAAS_1 x IQU_4 x WABS_3 & -0.0996 & 0.1977 & 0.0265 & -0.2454 & -0.1015 & -0.1496 & 0.3455 & -0.0748 & 0.5528 & 0.5187 & -0.1713 & 0.2404 & -0.5035 & -0.0147 & -0.4924 \\
\hline WAAS_1 x IQU_4 x WABS_4 & -0.0609 & 0.2264 & 0.0812 & 0.1062 & -0.2256 & -0.1329 & 0.4779 & -0.2278 & 0.5198 & 0.4344 & -0.1131 & 0.3136 & -0.2046 & -0.0129 & -0.6236 \\
\hline WAAS_2 x IQU_4 x WABS_1 & 0.2197 & 0.2511 & -0.1461 & -0.3038 & 0.2039 & 0.1523 & -0.0805 & 0.3297 & 0.1285 & 0.1428 & 0.0417 & 0.2078 & -0.238 & 0.2923 & 0.181 \\
\hline WAAS_2 x IQU_4 x WABS_2 & 0.0134 & 0.253 & -0.0866 & -0.3798 & 0.0149 & -0.0037 & 0.1614 & 0.1454 & 0.3346 & 0.343 & -0.1035 & 0.1992 & -0.39 & 0.2365 & -0.1909 \\
\hline WAAS_2 x IQU_4 x WABS_3 & -0.0753 & 0.1954 & 0.0966 & -0.4131 & -0.0516 & -0.0533 & 0.1427 & 0.1071 & 0.3415 & 0.3688 & -0.0832 & 0.2389 & -0.416 & 0.1317 & -0.2085 \\
\hline WAAS_2 $x$ IQU_4 $\mathrm{x}$ WABS_4 & 0.0422 & 0.3453 & 0.0174 & 0.0415 & -0.1891 & 0.0558 & 0.3205 & 0.0374 & 0.258 & 0.254 & 0.0035 & 0.3915 & 0.0189 & 0.385 & -0.3954 \\
\hline WAAS_3 x IQU_4 x WABS_1 & 0.1645 & 0.3477 & -0.3297 & -0.1914 & 0.1622 & 0.1527 & -0.0239 & 0.3078 & 0.0508 & 0.109 & 0.0187 & 0.1789 & -0.1469 & 0.4796 & 0.1025 \\
\hline WAAS_3 $x$ IQU_4 $x$ WABS_2 & 0.0407 & 0.3329 & -0.3011 & -0.2809 & 0.0852 & 0.0357 & 0.1203 & 0.1661 & 0.2123 & 0.2265 & -0.0429 & 0.1748 & -0.2598 & 0.4242 & -0.1186 \\
\hline WAAS_3 $x$ IQU_4 $x$ WABS_3 & -0.084 & 0.1187 & 0.1066 & -0.4207 & 0.042 & -0.0967 & 0.1459 & 0.0655 & 0.3749 & 0.3533 & -0.0728 & 0.1904 & -0.453 & 0.1267 & -0.1929 \\
\hline WAAS_3 x IQU_4 $x$ WABS_4 & 0.0774 & 0.4111 & -0.2225 & 0.0581 & -0.0414 & 0.0898 & 0.2495 & 0.0493 & 0.1457 & 0.1462 & 0.0578 & 0.3288 & 0.072 & 0.5269 & -0.263 \\
\hline WAAS_4 x IQU_4 x WABS_1 & 0.0766 & 0.263 & -0.233 & -0.2081 & 0.1261 & 0.1359 & -0.0428 & 0.3146 & -0.0076 & 0.0901 & 0.0161 & 0.1651 & -0.1349 & 0.473 & 0.1281 \\
\hline WAAS_4 x IQU_4 x WABS_2 & -0.0808 & 0.2804 & -0.1567 & -0.2743 & -0.0572 & 0.0359 & 0.1794 & 0.2094 & 0.1861 & 0.3297 & -0.0919 & 0.1685 & -0.3061 & 0.4088 & -0.2206 \\
\hline WAAS_4 x IQU_4 x WABS_3 & -0.0775 & 0.1879 & -0.036 & -0.3639 & -0.0773 & -0.025 & 0.201 & 0.1731 & 0.3072 & 0.4202 & -0.1274 & 0.234 & -0.3997 & 0.2279 & -0.2885 \\
\hline WAAS_4 x IQU_4 x WABS_4 & -0.0105 & 0.3586 & -0.2004 & 0.0086 & -0.1543 & 0.0727 & 0.2998 & 0.1437 & 0.1724 & 0.2983 & -0.0283 & 0.3022 & -0.0339 & 0.4857 & -0.3857 \\
\hline $\begin{array}{l}\text { WABS_1 x WAAS_1 x } \\
\text { WATS_1 }\end{array}$ & 0.0172 & 0.115 & 0.2363 & -0.4144 & -0.2813 & 0.3306 & -0.3774 & 0.2521 & -0.272 & -0.1825 & 0.2289 & 0.0544 & 0.2094 & 0.2304 & 0.4121 \\
\hline $\begin{array}{l}\text { WABS_1 x WAAS_1 x } \\
\text { WATS_2 }\end{array}$ & 0.0399 & 0.1118 & 0.2678 & -0.3708 & -0.3102 & 0.3287 & -0.3959 & 0.1963 & -0.2573 & -0.192 & 0.2024 & 0.0935 & 0.1891 & 0.2113 & 0.4165 \\
\hline $\begin{array}{l}\text { WABS_1 x WAAS_1 x } \\
\text { WATS_3 }\end{array}$ & -0.0132 & 0.0776 & 0.2977 & -0.4178 & -0.313 & 0.3473 & -0.4036 & 0.2479 & -0.31 & -0.1937 & 0.2115 & 0.0549 & 0.1962 & 0.1973 & 0.4171 \\
\hline $\begin{array}{l}\text { WABS_1 x WAAS_2 x } \\
\text { WATS_1 }\end{array}$ & 0.061 & 0.1494 & -0.0018 & -0.3776 & -0.1031 & 0.3105 & -0.2524 & 0.3058 & -0.0823 & -0.0846 & 0.3531 & 0.2006 & 0.2012 & 0.305 & 0.3804 \\
\hline $\begin{array}{l}\text { WABS_1 x WAAS_2 x } \\
\text { WATS_2 }\end{array}$ & 0.0667 & 0.2037 & 0.0958 & -0.4217 & -0.1152 & 0.3864 & -0.1855 & 0.4643 & -0.2104 & -0.0172 & 0.3483 & 0.1662 & 0.1749 & 0.3533 & 0.3574 \\
\hline $\begin{array}{l}\text { WABS_1 } x \text { WAAS_2 x } \\
\text { WATS_3 }\end{array}$ & 0.1313 & 0.2049 & -0.0258 & -0.3577 & -0.1178 & 0.3905 & -0.289 & 0.4125 & -0.1531 & -0.0842 & 0.4022 & 0.2201 & 0.2883 & 0.3273 & 0.4176 \\
\hline $\begin{array}{l}\text { WABS_1 x WAAS_3 x } \\
\text { WATS_1 }\end{array}$ & 0.0929 & 0.2252 & -0.1109 & -0.3982 & -0.1013 & 0.3462 & -0.2761 & 0.3426 & -0.1688 & -0.1412 & 0.2984 & 0.1688 & 0.2635 & 0.3888 & 0.4202 \\
\hline $\begin{array}{l}\text { WABS_1 x WAAS_3 x } \\
\text { WATS_2 }\end{array}$ & 0.0633 & 0.1797 & 0.1654 & -0.5062 & -0.1816 & 0.4076 & -0.2584 & 0.4592 & -0.2553 & -0.0808 & 0.3084 & 0.0908 & 0.187 & 0.3663 & 0.4611 \\
\hline $\begin{array}{l}\text { WABS_1 x WAAS_3 x } \\
\text { WATS_3 }\end{array}$ & 0.1045 & 0.2175 & -0.0877 & -0.3906 & -0.1375 & 0.4097 & -0.3091 & 0.4445 & -0.2496 & -0.1384 & 0.3012 & 0.1524 & 0.2893 & 0.4312 & 0.444 \\
\hline $\begin{array}{l}\text { WABS_1 x WAAS_4 x } \\
\text { WATS_1 }\end{array}$ & 0.0172 & 0.1662 & 0.1249 & -0.5099 & -0.1751 & 0.3406 & -0.2343 & 0.364 & -0.1836 & -0.0536 & 0.2489 & 0.0596 & 0.1339 & 0.3054 & 0.3922 \\
\hline
\end{tabular}

- In red: Highest absolute loadings that rank higher on other variables.

- In bold: Highest absolute loadings that rank higher on the own variables. 


\begin{tabular}{|c|c|c|c|c|c|c|c|c|c|c|c|c|c|c|c|}
\hline & DMS & IQ & $\begin{array}{l}\text { IQ x } \\
\text { WAAS }\end{array}$ & $\begin{array}{l}\text { IQ x } \\
\text { WABS }\end{array}$ & $\begin{array}{l}\text { IQ } x \\
\text { WATS }\end{array}$ & WAAS & $\begin{array}{l}\text { WAAS } \\
\mathrm{x} \text { WATS }\end{array}$ & WABS & $\begin{array}{l}\text { WABS } \\
\quad x \\
\text { WAAS }\end{array}$ & $\begin{array}{l}\text { WABS } \\
x \\
\text { WATS }\end{array}$ & WATS & $\begin{array}{l}\text { IQ } x \\
\text { WAAS } \\
\text { x WATS }\end{array}$ & $\begin{array}{c}\text { IQ } x \\
\text { WABS } \\
x \\
\text { WATS }\end{array}$ & $\begin{array}{c}\text { IQ } x \\
\text { WABS } \\
x \\
\text { WAAS }\end{array}$ & $\begin{array}{l}\text { WABS } \\
x \\
\text { WAAS } \\
x \text { WATS }\end{array}$ \\
\hline $\begin{array}{l}\text { WABS_1 x WAAS_4 x } \\
\text { WATS_2 }\end{array}$ & 0.0801 & 0.2002 & 0.081 & -0.4633 & -0.1461 & 0.4135 & -0.2713 & 0.463 & -0.2483 & -0.0791 & 0.2925 & 0.1206 & 0.198 & 0.3954 & 0.4359 \\
\hline $\begin{array}{l}\text { WABS_1 x WAAS_4 x } \\
\text { WATS_3 }\end{array}$ & 0.0222 & 0.1529 & 0.0932 & -0.4639 & -0.1475 & 0.3745 & -0.2669 & 0.452 & -0.2502 & -0.074 & 0.2588 & 0.0329 & 0.2104 & 0.348 & 0.4205 \\
\hline $\begin{array}{l}\text { WABS_2 } x \text { WAAS_1 } x \\
\text { WATS_1 }\end{array}$ & 0.2846 & 0.0552 & 0.0714 & -0.1366 & 0.1237 & 0.4498 & -0.6567 & 0.3734 & -0.6044 & -0.5985 & 0.3966 & -0.0173 & 0.476 & 0.2372 & 0.9405 \\
\hline $\begin{array}{l}\text { WABS_2 x WAAS_1 x } \\
\text { WATS_2 } \\
\text { WABS_2 } x \text { WAAS_1 }\end{array}$ & 0.277 & 0.0886 & 0.1092 & -0.1639 & 0.0601 & 0.468 & -0.6539 & 0.3522 & -0.5785 & -0.5725 & 0.3916 & 0.0013 & 0.471 & 0.2558 & 0.9356 \\
\hline $\begin{array}{l}\text { WATS_3 } \\
\text { WABS } 2 \times \text { WAAS } 2 \times\end{array}$ & 0.2512 & 0.0333 & 0.1386 & -0.1919 & 0.0795 & 0.4618 & -0.6589 & 0.3833 & -0.6275 & -0.5729 & 0.3936 & -0.03 & 0.479 & 0.2198 & 0.938 \\
\hline $\begin{array}{l}\text { WABS_2 x } \\
\text { WATS_1 } \\
\text { WABS_2 x }\end{array}$ & 0.3227 & 0.0518 & -0.0651 & -0.1444 & 0.1959 & 0.4226 & -0.5582 & 0.3848 & -0.4746 & -0.5096 & 0.4335 & 0.1204 & 0.4182 & 0.3034 & 0.8951 \\
\hline $\begin{array}{l}\text { WATS_2 } \\
\text { WABS_2 x WAAS_2 x }\end{array}$ & 0.2792 & 0.1058 & 0.0402 & -0.2826 & 0.1035 & 0.4654 & -0.4613 & 0.4746 & -0.5052 & -0.3804 & 0.4039 & 0.0982 & 0.3177 & 0.3529 & 0.8422 \\
\hline WATS_3 & 0.3147 & 0.07 & -0.0643 & -0.1845 & 0.1516 & 0.4517 & -0.5431 & 0.448 & -0.5043 & -0.4443 & 0.4063 & 0.1102 & 0.4075 & 0.3057 & 0.9126 \\
\hline $\begin{array}{l}\text { WABS_2 } x \text { WAAS_3 } x \\
\text { WATS_1 } \\
\text { WABS } 2 \times \text { WAAS } 3 \times\end{array}$ & 0.3134 & 0.152 & -0.1926 & -0.1949 & 0.1937 & 0.4445 & -0.5025 & 0.3974 & -0.4495 & -0.4854 & 0.4176 & 0.1121 & 0.4382 & 0.3804 & 0.8402 \\
\hline $\begin{array}{l}\text { WABS_2 } \\
\text { WATS_2 } \\
\text { WABS 2 }\end{array}$ & 0.2592 & 0.1079 & 0.0466 & -0.3343 & 0.1043 & 0.4599 & -0.4638 & 0.4349 & -0.4695 & -0.4085 & 0.4041 & 0.0437 & 0.3338 & 0.3561 & 0.8585 \\
\hline $\begin{array}{l}\text { WABS_2 x WAAS_3 x } \\
\text { WATS_3 }\end{array}$ & 0.3247 & 0.1232 & -0.1484 & -0.2107 & 0.1395 & 0.482 & -0.5191 & 0.4851 & & -0.4359 & 0.3978 & 0.0952 & 0.4332 & 0.4154 & 0.8753 \\
\hline $\begin{array}{l}\text { WABS_2 x WAAS_4 x } \\
\text { WATS_1 }\end{array}$ & 0.3023 & 0.0487 & 0.0264 & -0.1361 & 0.19 & 0.4371 & -0.5949 & 0.4218 & -0.5614 & -0.5196 & 0.3766 & 0.0475 & 0.3985 & 0.2637 & 0.9098 \\
\hline $\begin{array}{l}\text { WABS_2 } x \text { WAAS_4 } x \\
\text { WATS_2 }\end{array}$ & 0.2954 & 0.0773 & 0.0258 & -0.2053 & 0.1254 & 0.4908 & -0.571 & 0.492 & -0.5827 & -0.4625 & 0.3685 & 0.066 & 0.3552 & 0.3516 & 0.9198 \\
\hline $\begin{array}{l}\text { WABS_2 XWAAS_4 X } \\
\text { WATS_3 }\end{array}$ & 0.2737 & 0.0244 & 0.0328 & -0.2016 & 0.1474 & 0.4254 & -0.5618 & 0.4527 & -0.5746 & -0.4646 & 0.3376 & 0.0218 & 0.3778 & 0.2988 & 0.9051 \\
\hline $\begin{array}{l}\text { WABS_3 x WAAS_1 x } \\
\text { WATS_1 }\end{array}$ & 0.2505 & 0.0088 & 0.1093 & -0.1491 & 0.1143 & 0.4381 & -0.6777 & 0.3751 & -0.6402 & -0.6001 & 0.3876 & -0.0278 & 0.4688 & 0.2305 & 0.941 \\
\hline $\begin{array}{l}\text { WABS_3 x WAAS_1 x } \\
\text { WATS_2 } \\
\text { WABS_3 x WAAS_1 x }\end{array}$ & 0.2652 & 0.0789 & 0.1288 & -0.1845 & 0.0507 & 0.4702 & -0.6863 & 0.3556 & -0.6105 & -0.5789 & 0.4091 & 0.0134 & 0.4747 & 0.2513 & 0.9302 \\
\hline $\begin{array}{l}\text { WABS_3 x WAAS_1 x } \\
\text { WATS_3 } \\
\text { WABS_3 x WAAS_2 x }\end{array}$ & 0.2238 & 0.0463 & 0.1518 & -0.2001 & 0.0471 & 0.471 & -0.7014 & 0.3814 & -0.6487 & -0.5875 & 0.3878 & -0.018 & 0.4748 & 0.2284 & 0.9299 \\
\hline WATS_1 & 0.3027 & 0.1087 & -0.0983 & -0.1418 & 0.1862 & 0.3827 & -0.5186 & 0.2973 & -0.435 & -0.4587 & 0.3338 & 0.0272 & 0.346 & 0.2059 & 0.8337 \\
\hline $\begin{array}{l}\text { WABS_3 x WAAS_2 } x \\
\text { WATS_2 } \\
\text { WABS_3 x WAAS_2 } x\end{array}$ & 0.2934 & 0.1038 & -0.006 & -0.282 & 0.1101 & 0.4889 & -0.494 & 0.4799 & -0.5544 & -0.4084 & 0.3271 & 0.0696 & 0.3054 & 0.3867 & 0.8322 \\
\hline WATS_3 & 0.299 & 0.0151 & 0.047 & -0.1997 & 0.116 & 0.4579 & -0.5911 & 0.4318 & -0.5432 & -0.4706 & 0.325 & 0.0196 & 0.3425 & 0.2541 & 0.9235 \\
\hline
\end{tabular}




\begin{tabular}{|c|c|c|c|c|c|c|c|c|c|c|c|c|c|c|c|}
\hline & DMS & IQ & $\begin{array}{l}\text { IQ } x \\
\text { WAAS }\end{array}$ & $\begin{array}{l}\text { IQ } x \\
\text { WABS }\end{array}$ & $\begin{array}{l}\text { IQ } x \\
\text { WATS }\end{array}$ & WAAS & $\begin{array}{l}\text { WAAS } \\
\mathrm{x} \text { WATS }\end{array}$ & WABS & $\begin{array}{c}\text { WABS } \\
x \\
\text { WAAS }\end{array}$ & $\begin{array}{c}\text { WABS } \\
x \\
\text { WATS }\end{array}$ & WATS & $\begin{array}{c}\text { IQ } x \\
\text { WAAS } \\
\text { x WATS }\end{array}$ & $\begin{array}{c}\text { IQ } x \\
\text { WABS } \\
x \\
\text { WATS }\end{array}$ & $\begin{array}{c}\text { IQ } x \\
\text { WABS } \\
x \\
\text { WAAS }\end{array}$ & $\begin{array}{c}\text { WABS } \\
\mathbf{x} \\
\text { WAAS } \\
\mathbf{x} \\
\text { WATS }\end{array}$ \\
\hline $\begin{array}{l}\text { WABS_3 x WAAS_3 x } \\
\text { WATS_1 }\end{array}$ & 0.2623 & 0.0557 & -0.0673 & -0.2473 & 0.1928 & 0.3771 & -0.5199 & 0.3138 & -0.4606 & -0.4882 & 0.3451 & 0.0032 & 0.3604 & 0.2713 & 0.8378 \\
\hline $\begin{array}{l}\text { WABS_3 x WAAS_3 x } \\
\text { WATS_2 }\end{array}$ & 0.328 & 0.1683 & -0.1043 & -0.3247 & 0.1634 & 0.485 & -0.5137 & 0.423 & -0.5046 & -0.4502 & 0.3693 & 0.042 & 0.3524 & 0.3748 & 0.8655 \\
\hline $\begin{array}{l}\text { WABS_3 x WAAS_3 x } \\
\text { WATS_3 }\end{array}$ & 0.2786 & 0.0787 & 0.0088 & -0.2761 & 0.1341 & 0.4925 & -0.597 & 0.4587 & -0.5531 & -0.4701 & 0.3423 & -0.0405 & 0.3556 & 0.2741 & 0.9449 \\
\hline $\begin{array}{l}\text { WABS_3 x WAAS_4 x } \\
\text { WATS_1 }\end{array}$ & 0.287 & -0.013 & 0.0455 & -0.1309 & 0.2024 & 0.4164 & -0.6034 & 0.3992 & -0.5997 & -0.5292 & 0.3414 & -0.0289 & 0.3792 & 0.2461 & 0.9309 \\
\hline $\begin{array}{l}\text { WABS_3 x WAAS_4 x } \\
\text { WATS_2 }\end{array}$ & 0.2995 & 0.0622 & 0.0364 & -0.2031 & 0.1441 & 0.4752 & -0.578 & 0.4742 & -0.6104 & -0.4708 & 0.3428 & 0.0055 & 0.3432 & 0.3214 & 0.9222 \\
\hline $\begin{array}{l}\text { WABS_3 x WAAS_4 x } \\
\text { WATS_3 }\end{array}$ & 0.2772 & 0.0115 & 0.0231 & -0.1969 & 0.1589 & 0.4506 & -0.6112 & 0.4706 & -0.6078 & -0.501 & 0.3172 & -0.0327 & 0.3749 & 0.2752 & 0.9374 \\
\hline $\begin{array}{l}\text { WABS_4 x WAAS_1 x } \\
\text { WATS_1 }\end{array}$ & 0.2817 & 0.0065 & 0.0789 & -0.0316 & 0.1094 & 0.4429 & -0.6297 & 0.3276 & -0.6618 & -0.6257 & 0.3902 & -0.0809 & 0.5245 & 0.2173 & 0.9178 \\
\hline $\begin{array}{l}\text { WABS_4 x WAAS_1 x } \\
\text { WATS_2 }\end{array}$ & 0.2469 & 0.003 & 0.1386 & -0.0624 & 0.0161 & 0.4453 & -0.6105 & 0.2706 & -0.6297 & -0.5935 & 0.3599 & -0.0648 & 0.486 & 0.2259 & 0.8774 \\
\hline $\begin{array}{l}\text { WABS_- } 4 \text { x WAAS_1 x } \\
\text { WATS_3 }\end{array}$ & 0.199 & -0.0223 & 0.1634 & -0.1237 & 0.0261 & 0.4519 & -0.6174 & 0.3243 & -0.6692 & -0.5835 & 0.3498 & -0.0902 & 0.4711 & 0.2072 & 0.8858 \\
\hline $\begin{array}{l}\text { WABS_4 x WAAS_2 x } \\
\text { WATS_1 }\end{array}$ & 0.3144 & -0.024 & 0.0075 & 0.0589 & 0.18 & 0.3913 & -0.5202 & 0.2797 & -0.533 & -0.5707 & 0.4104 & 0.0148 & 0.5304 & 0.266 & 0.837 \\
\hline $\begin{array}{l}\text { WABS_4 x WAAS_2 x } \\
\text { WATS_2 }\end{array}$ & 0.3278 & 0.16 & -0.0694 & -0.0492 & 0.1354 & 0.5017 & -0.4271 & 0.4303 & -0.5764 & -0.4518 & 0.4265 & 0.09 & 0.5221 & 0.417 & 0.7392 \\
\hline $\begin{array}{l}\text { WABS_4 x WAAS_2 x } \\
\text { WATS_3 }\end{array}$ & 0.379 & 0.1006 & -0.0958 & 0.0398 & 0.172 & 0.4886 & -0.5468 & 0.3856 & -0.5676 & -0.5424 & 0.4624 & 0.0725 & 0.612 & 0.3247 & 0.8662 \\
\hline $\begin{array}{l}\text { WABS_4 x WAAS_3 x } \\
\text { WATS_1 }\end{array}$ & 0.3559 & 0.086 & -0.1138 & -0.0178 & 0.2035 & 0.4215 & -0.5216 & 0.2835 & -0.5555 & -0.6155 & 0.4525 & -0.0099 & 0.5934 & 0.327 & 0.8874 \\
\hline $\begin{array}{l}\text { WABS_4 x WAAS_3 x } \\
\text { WATS_2 }\end{array}$ & 0.3398 & 0.1209 & -0.0781 & -0.0949 & 0.1287 & 0.5057 & -0.451 & 0.366 & -0.5762 & -0.5126 & 0.4359 & 0.049 & 0.5332 & 0.4308 & 0.7823 \\
\hline $\begin{array}{l}\text { WABS_4 x WAAS_3 x } \\
\text { WATS_3 }\end{array}$ & 0.3347 & 0.0934 & -0.1151 & -0.0536 & 0.1355 & 0.5362 & -0.5333 & 0.4303 & -0.6236 & -0.5522 & 0.4344 & 0.0158 & 0.5889 & 0.4186 & 0.8674 \\
\hline $\begin{array}{l}\text { WABS_4 x WAAS_4 x } \\
\text { WATS_1 }\end{array}$ & 0.3357 & 0.0443 & -0.0116 & 0.0498 & 0.2358 & 0.4428 & -0.5989 & 0.3579 & -0.6241 & -0.59 & 0.4321 & -0.0229 & 0.5477 & 0.2676 & 0.9074 \\
\hline $\begin{array}{l}\text { WABS_4 x WAAS_4 x } \\
\text { WATS_2 }\end{array}$ & 0.358 & 0.1048 & -0.0358 & 0.0168 & 0.2064 & 0.5171 & -0.583 & 0.4547 & -0.6486 & -0.5592 & 0.4796 & 0.048 & 0.5939 & 0.3898 & 0.8787 \\
\hline $\begin{array}{l}\text { WABS_4 x WAAS_4 x } \\
\text { WATS_3 }\end{array}$ & 0.3294 & 0.0639 & -0.0542 & -0.013 & 0.2156 & 0.4781 & -0.5995 & 0.447 & -0.6201 & -0.547 & 0.4458 & 0.0096 & 0.5865 & 0.3442 & 0.8765 \\
\hline
\end{tabular}

- In red: Highest absolute loadings that rank higher on other variables.

- In bold: Highest absolute loadings that rank higher on the own variables. 